\title{
Schrift am Grabmal. Zur Materialität der Inschriften an archaischen Grabmälern aus Athen und Attika
}

\author{
von Corinna Reinhardt
}

Grabmonumente setzten ein dauerhaftes Mal für den Verstorbenen. Eine Inschrift fixierte dabei den Namen und ermöglichte dadurch eine Zuordnung des Grabmals an die verstorbene Person sowie eine Erinnerung an diese. Hierzu trat an den meisten archaischen Grabmonumenten des 6. Jhs. v. Chr. eine Figur, die den Verstorbenen im Bild repräsentierte und gleichzeitig der Einheit von Text und Grabmal eine weitere Komponente hinzufügte. ${ }^{69}$ Aus dieser Konstellation ergibt sich nicht nur die Frage, wie am Grabmal der Text ,materialisiert' wurde und welcher Bezug darüber zwischen der Inschrift und dem Grabmal entstand, sondern auch die Frage, in welchem Zusammenhang Bild und Text am Grabmal standen und inwiefern die formale Gestaltung der Schrift hierbei von Bedeutung war.

Während der ästhetische Zusammenhang zwischen Inschriften und Monumenten gegenüber Untersuchungen des Textinhaltes bislang kaum im Fokus der Forschung steht, sind gerade Analysen von Bild-Text-Bezügen nicht nur für den funerären Bereich seit längerem etabliert. ${ }^{70}$ Aber auch hier bleibt die ästhetische Präsentation der Inschriften (ihre Position, Gestaltung und ihr direktes Umfeld) bei der Vernetzung von Textinhalt und Bild häufig unberücksichtigt - im Gegensatz zu ästhetischen Aspekten des Bildes. Verschiedene Untersuchungen von Schrift in anderen Kontexten - etwa der archaischen Vasenmalerei - haben jedoch bereits gezeigt, dass die

69 Figürliche Darstellungen erscheinen erst in einem zweiten Schritt auf Grabmälern (nach Jeffery 1962, 149 um 570 v. Chr.). Die älteren steinernen Male, die meist noch in das 7. Jh. v. Chr. datiert werden, sind z. T. undekoriert (sofern dies aus dem Erhaltenen zu erschließen ist) oder tragen allein eine Inschrift: Athen, Kerameikos Inv. unbekannt, um 650 v. Chr. (?): Jeffery 1962, 123 Nr. 1 mit Abb. 7; Kissas 2000, 37 A 1 Abb. 3 (keine Inschrift erhalten); Athen, Kerameikos, um 600 v. Chr. (?): Jeffery 1962, 123f. Nr. 2 mit Abb. 8; Kissas 2000, 38 A 2 Abb.4-5) (keine Inschrift erhalten); Athen, Epigraphisches Museum Inv. 10646, Mitte/zweite Hälfte 7. Jh. v. Chr.: Jeffery 1962, 129 Nr. 22 Taf. 36c (mit Inschrift: IG I3 1194; vgl. die Diskussion um ein mögliches Relief bei Jeffery); Aufbewahrungsort unsicher (Athen, Epigraphisches Museum?), 7. Jh. v. Chr.?: Jeffery 1962, 135f. Nr. 39 Abb. 12 (mit Inschrift: IG I 1247). Vgl. auch eine frühe Stele aus dem ersten oder zweiten Viertel des 6. Jhs. v. Chr. mit Ornamentverzierung und ohne Inschrift auf dem Stelenschaft: Athen, Kerameikos Museum Inv. unbekannt, 1./2. Viertel des 6. Jhs. v. Chr.: Richter 1961, 12f. Nr. 7 Abb. 29, 30.

70 Vgl. etwa: Clairmont 1970; Martini 2006; Martini 2008; Lorenz 2010. Eine Tagung zum Thema IkonoTexte - Duale Mediensituationen in den Altertumswissenschaften fand 2006 in Gießen statt.

Die angeführten Übersetzungen der Inschriften in IG $I^{3}$ folgen in diesem Kapitel, wenn nicht anders angegeben, K. Hallof in der Online-Edition (http://telota.bbaw.de/ig/). 
Gestaltung der Schrift nicht nur Aussagen über die materielle Schriftkultur zulässt, sondern auch eine inhaltliche Bedeutung für das jeweilige Monument oder das Bild haben konnte. ${ }^{71}$ Die Möglichkeiten beschränken sich so keineswegs nur auf einen Zusammenhang zum Textinhalt oder zum Lesen des Textes, etwa der Frage danach, ob die materielle Fixierung des Textes durch ein bestimmtes Layout das Verständnis des Textinhaltes fördern könnte. ${ }^{72}$ Komplexer wird dies noch, wenn der Bezug zum Bild oder zum Monument einbezogen wird: Gestaltungsphänomene der Schrift können den Betrachter/Leser etwa dazu verleitet haben, Teile des Textes präzise einer Figur im Bild zuzuschreiben, wie etwa bei Namensbeischriften, oder konnten etwa durch den Buchstabenverlauf - wie es Beispiele in der attischen Vasenmalerei gibt - gesprochene Rede oder Gesang anzeigen, um nur wenige Beispiele zu nennen. ${ }^{73}$ Ebenso wurde vorgeschlagen, dass gerade die spezifische Gestaltung der Schrift beim Betrachter Interesse für das schrifttragende Monument ${ }^{74}$ weckte, was unter anderem im Kontext der konkurrierenden Votivkultur in den Heiligtümern überzeugt. Nicht nur Interesse, sondern auch die Blickführung des Betrachters stehen im Fokus, wenn etwa durch die Position und Gestaltung der Schrift einem Bereich des Monuments besondere Bedeutung zugemessen wurde. ${ }^{75}$

Vor diesem Hintergrund wird nun im Folgenden anhand archaischer Grabmäler ${ }^{76}$ aus Athen und Attika die Frage untersucht, wie mit der frühen Verschriftlichung von

71 Vgl. u. a. Lissarrague 1990, 126-128; Gerleigner 2015.

72 Die Auswirkung der Verschriftlichung von Text für das Verstehen des Textinhaltes stand bereits in verschiedenen Forschungsfeldern im Fokus. Vgl. zur „semiotischen Interferenz“ Assmann 1988b, 147, 150; zur Auswirkung der Materialität der Zeichen auf den Betrachtungs- und Leseprozess s. Assmann 1988a, 240-242. Zu formalen Gestaltungselementen als Hilfen für das Verstehen des Textes: Krämer 2003, 160. Die Verschriftlichung als Problem klingt bisweilen in den Untersuchungen zu ästhetischen Parametern in Inschriften als Unterstützung des Lesevorgangs an, vgl. Day 2010, 48-59 mit Tabelle 2 auf S. 80-84. Auf die Möglichkeit, dass das ,Layout‘ der Inschrift dem Leser geholfen haben könnte, den Weihenden und den Bildhauer in der Inschrift zu finden, wies Keesling 2003, 32 hin. Unter anderem stellte sie hier die häufige Position des Namens des Weihenden am Anfang der ersten Zeile heraus, oder die Absetzung der Bildhauerinschrift von der Weihinschrift: Keesling 2003, 32-34.

73 Vgl. die Beispiele in Gerleigner 2015. Ein Zusammenhang zum Textinhalt muss nicht bestehen. Hiervon zeugen eindrücklich die sogenannten nonsense-inscriptions in der attischen Vasenmalerei: diese ergeben keinen sinnvollen Text, können aber durch ihre Position und Orientierung eine Funktion im Bild übernehmen, in dem sie etwa gesprochene Rede oder Gesang einer Figur implizieren, ohne dass diese Rede mit konkretem Inhalt gefüllt ist - vgl. Lissarrague 1990, 126-128; Gerleigner 2015, 223. Vgl. zur gesprochenen Rede/Gesang in den Vasenbildern auch Lissarrague 1990, 123-139; Lissarrague 1992, 200-202.

74 Day sprach in seiner Untersuchung der archaischen Weihepigramme von der Athener Akropolis u. a. von gestalterischen Strategien der Inschrift, um die Aufmerksamkeit und das Interesse des Betrachters für das Monument zu erregen: Day 2010, 48-53 mit Tabelle 1 auf S.76-79.

75 Zur Bedeutung der Position der Inschriften auf Kouroi siehe Lorenz 2010. Hierzu auch weiter unten in diesem Kapitel, S. 66.

76 Als Materialgrundlage schrifttragender Grabmäler wird für die erhaltenen Basen Kissas 2000 herangezogen. Für schrifttragende attische Grabstelen/Platten s. den Anhang. 
Text im archaischen Griechenland die Potentiale der visuellen Präsenz von Texten genutzt wurden und welche Phänomene der materiellen Schriftkultur sich hier fassen lassen. Die Untersuchung zielt zudem darauf, die Rolle von Inschriften in der ästhetischen Konzeption von archaischen Grabmälern herauszuarbeiten.

Im Folgenden werden zunächst anhand formaler Phänomene (I) mögliche Zusammenhänge zwischen den Inschriften und dem Bild untersucht, indem danach gefragt wird, in welchem Bereich die Inschriften angebracht waren und ob sie durch ihre Gestaltung besondere Bezüge zur Figur erkennen lassen, die über den allgemeinen und offensichtlichen Bezug der Anbringung an demselben Monument hinausgehen. Anschließend (II) werden dieselben Fragen in Hinblick auf einen formalen Zusammenhang zum Monument gestellt und weitere Phänomene der materiellen Schriftgestaltung erarbeitet. Diese Grundlage ermöglicht es einerseits, Inschriften als Teil der ästhetischen Gestaltung des Grabmals zu verstehen, und andererseits abschließend (III) auf die möglichen Wechselwirkungen zwischen Bild und Text zurückzukommen, die maßgeblich von deren materieller Fixierung am Grabmal sowie ihren Rezeptionsmöglichkeiten abhängen.

\section{Die Figur im Zentrum? Position und Gestaltung der Inschriften am Grabmonument}

\section{Position der Inschriften}

Außerhalb Attikas waren in archaischer Zeit Inschriften häufig direkt auf den Statuen angebracht, wie unter anderem Koren und Kouroi aus dem Heraion von Samos bezeugen; dabei stehen die Inschriften in den Gewändern der Koren oder auf dem unbekleideten Körper der Kouroi. ${ }^{77}$ In Attika sind jedoch mit Ausnahme zweier Votivstatuen aus Sounion ${ }^{78}$ keine Inschriften auf Statuen bezeugt. Hier dienten am

77 Vgl. die Beispiele: Kore, Samos, Heraion Magazin Inv. III P 12: Freyer-Schauenburg 1974, 14-16 Nr.2B Taf. 2 (= IG XII 6, 2, 557); Kore, sog. Hera des Cheramyes, Paris, Louvre Inv. MA 686: FreyerSchauenburg 1974, 21-27 Nr. 6 Taf. 5, 6 (= IG XII 6, 2, 558A); Kore, Berlin, Antikensammlung Inv. 1750: Freyer-Schauenburg 1974, 27-31 Nr. 7 Taf. 7, 8 (= IG XII 6, 2, 558C); Kouros, Samos, Vathy Museum Inv. 69: Freyer-Schauenburg 1974, 69-73 Nr. 35 Taf. 20-22 (= IG XII 6, 2, 586); Beinfragmente eines Kouros, Samos, Heraion Magazin Inv. II S 223 und unbekannt: Freyer-Schauenburg 1974, 95f. Nr. 49 A/B Taf. 35 (= IG XII 6, 2, 558D). Auf der sog. Geneleos-Gruppe (Freyer-Schauenburg 1974, 106-130 Nr.58-63 Taf.44-53) sind die Inschriften (IG XII 6, 2, 559A-F) an verschiedenen Stellen angebracht: auf dem Gewand, auf den Stuhlbeinen oder auf der Plinthe. Zum Beschriften von Statuen vgl. Keesling 2003, 11; Hurwit 2015, 114; Dietrich 2017a, 302-309. Vgl. auch Kapitel III, bes. S. 177-179.

78 Vgl. Hurwit 2015, 114 Anm. 37. Athen, Nationalmuseum Inv. 3449 (Aliki Moustaka, in: Despinis/ Kaltsas 2014, 197f. Abb. 648; IG I $\mathrm{I}^{3}$ 1024B) und Athen, Nationalmuseum Inv. 3450 (Aliki Moustaka, in: Despinis/Kaltsas 2014, 198f. Abb. 649; IG I³ 1024A). 
häufigsten ${ }^{79}$ die block- und stufenförmigen Unterbauten der Stelen und Statuen als Inschriftenträger (Abb. 1.1).

Archaische Grabmonumente bestehen offenbar deutlich seltener als die gleichzeitigen Votivmonumente aus Pfeilern und Säulen mit darauf aufgestellten Statuen. ${ }^{80}$ Von den wenigen erhaltenen Beispielen sind einige Bestandteile mit Inschriften überliefert: Zwei Deckblöcke jeweils eines Grabmonumentes mit einem Pfeilerunterbau präsentieren Inschriften auf ihrer Vorderseite und bringen damit die Inschrift in die Nähe des ehemals auf dem Pfeiler aufgestellten Kouros. ${ }^{81}$ Während aber im ersten Fall die Grabinschrift horizontal über die Blockseite eingemeißelt ist, wie es auch bei den Stufen- oder Quaderunterbauten üblich ist, kombinierte man im Fall des Grabmonumentes des Neilonides (Abb. 1.2) auf einer Seite des Pfeilerdeckblocks zwei Inschriften in unterschiedlicher Ausrichtung mit dem gemalten Bild einer sitzenden Figur. ${ }^{82}$ Links der Figur steht in einem hochrechteckigen Bereich eine vertikal orientierte Inschrift. Sie lautet übersetzt: „Endoios fertigte auch dieses (Werk)“ “83 Rechts der Figur findet sich im oberen Bereich der Fläche eine horizontal orientierte, fünfzeilige Inschrift, die das sêma dem Neilonides zuweist, für den sein Vater Neilon dies als mnêma aufstellen ließ. ${ }^{84}$ Der Name des Toten steht, wie auch sonst üblich, ${ }^{85}$ im Genetiv - und ist damit dem sêma zugeordnet.

Vergleichbare Deckblöcke anderer Pfeilermonumenten zeigen keine Inschriften, sondern sind mit Reliefbildern ausgestaltet. ${ }^{86}$ Bei ihnen müssen die Handwerker die Inschriften weiter unten am Monument - auf dem Pfeilerschaft oder auf der Basis des

79 Ob man Clairmont 1970, 7 zustimmen kann, dass die meisten archaischen attischen Inschriften auf den Basen angebracht waren, ist fraglich. Es finden sich zwar viele Inschriften auf den Basen, aber das Beschriften der Stelen selbst darf nicht unterschätzt werden, zumal die Gegenprüfung (Stelenbasen ohne Inschriften) nicht möglich ist.

80 Vgl. die Materialgrundlagen Kissas 2000 und $D A A$.

81 Kissas 2000, 70 f. A 41 Abb. 48, 49 (IG I⿳3 1344); Kissas 2000, 71-73 A 42 Abb. 50, 51 (IG I 1214; CEG I 42; DNO I 368).

82 Athen, Epigraphisches Museum Inv. 12870, Anfang 4. Viertel des 6. Jhs. v. Chr.: Viviers 1992, 67-77; Keesling 1999; Kissas 2000, 71-73 A 42 Abb. 50, 51. Zu den Inschriften: IG I3 1214; CEG I 42; DNO I 368. Wohl im Zuge einer Zweitverwendung des Blocks sind die Inschriften und das gemalte Bild durch Werkzeugschläge beschädigt worden.

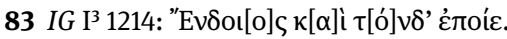

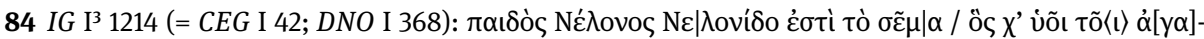

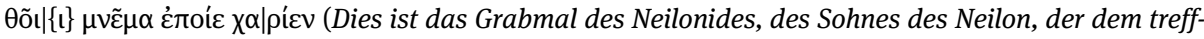
lichen Sohn auch das liebreiche Grabmal errichtete. Übs. nach DNO I 368); vgl. Keesling 1999, $509 \mathrm{f}$.

85 Hiervon gibt es unter den attischen Beispielen nur wenige Ausnahmen, die vor allem damit zusammenhängen, dass der Name ohne Zusammenhang zu dem sêma in die Grabinschrift eingebunden ist: siehe Kat. 1.9, 1.11, 1.18. Zwei Beispiele nennen den Namen ohne eine solche Einbindung im Nominativ: Kat. 1.15, 1.17. Ähnlich ist dies bei den böotischen archaischen Grabinschriften, unter denen nur im Falle der Grabstele des Dermys und des Kitylos (siehe Anm.118) die Namen im Nominativ vermerkt sind. Schild-Xenidou geht dagegen davon aus, das die Nominativform des Namens die übliche Form auch auf archaischen Grabreliefs war: Schild-Xenidou 2008, 152-157.

86 Kissas 2000, 74f. A 43 Abb. 52-54, 75 A 44, 75f. A 45 Abb. 55. 


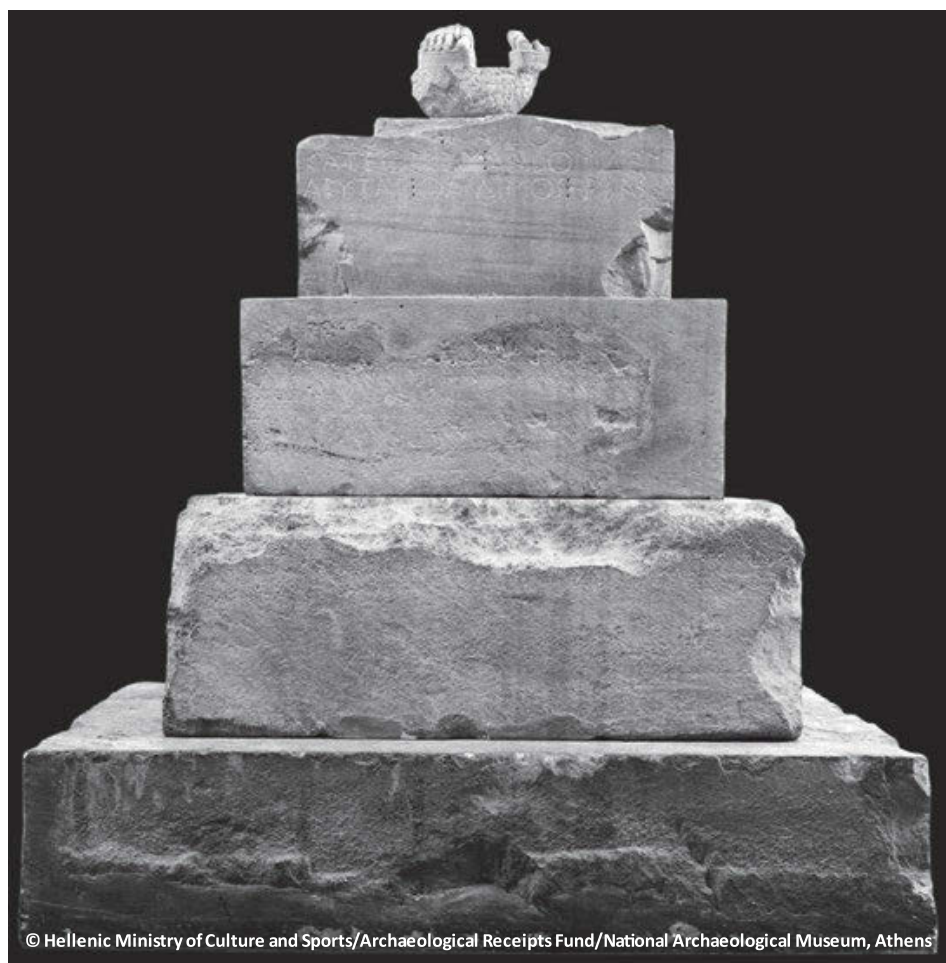

Abb.1.1: Stufenunterbau des Grabmonumentes für eine Kore um 550/540 v. Chr. (Athen, Nationalmuseum 81).
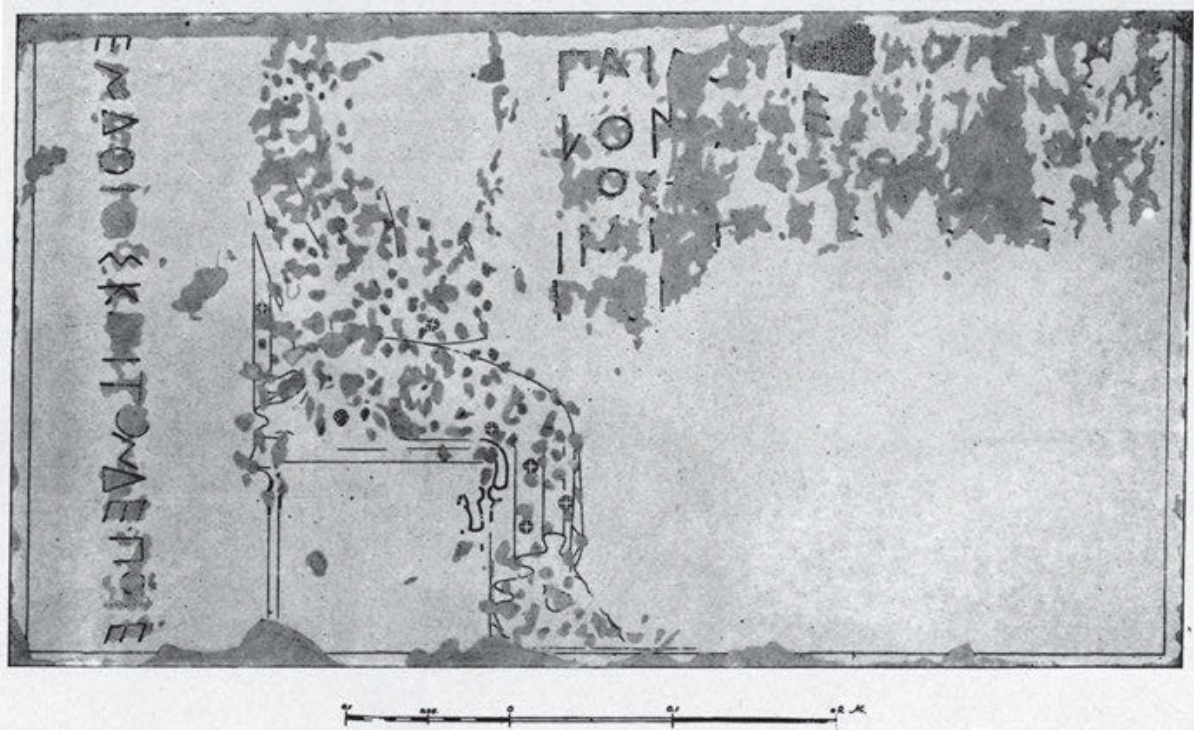

Abb.1.2: Zeichnung (M. Y. Fomine 1922) einer Seite des Pfeilerdeckblockes vom Grabmonument des Neilonides, Anfang 4. Viertel des 6. Jahrhunderts v. Chr. (Athen, Epigraphisches Museum 12870). 
Pfeilers - angebracht haben, weil diese Monumente Statuen trugen, wie die Einlassspuren in ihren Oberseiten nachweisen. Bereits aus diesem Befund lässt sich schließen, dass sich die Inschriften an Pfeilermonumenten nicht immer in der direkten Nähe der aufgestellten Statue befanden.

Säulen präsentierten ebenfalls Grabstatuen, auch wenn sie sich nur erschwert als solche zu erkennen geben. Kissas listet in seinem Katalog zwei Säulen auf, die aufgrund ihrer Inschrift von Grabmonumenten stammen müssen. ${ }^{87}$ Hier verlaufen die Inschriften, wie es auch bei den zeitgleichen Weihgeschenken üblich ist, ${ }^{88}$ innerhalb der Kanneluren. Inschriften auf den Kapitellen solcher Säulen, die als Standfläche für die Statuen fungierten, sind im Gegensatz zu Beispielen aus dem Votivbereich ${ }^{89}$ nicht erhalten.

Auf den bereits genannten Stufenbasen der Grabmonumente, die entweder eine Stele oder eine Statue trugen, brachten die Handwerker die Inschriften in den meisten, aber bezeichnenderweise nicht in allen Fällen auf der Vorderseite der obersten Stufe an: Von den insgesamt 30 beschrifteten Exemplaren von archaischen Stufenbasen aus Athen und Attika ${ }^{90}$ zeigen nämlich nach der Untersuchung von Konstantinos Kissas nur 19 die Inschrift auf dem obersten Block ${ }^{91}$, fünf auf einem mittleren Block ${ }^{92}$ und vier auf dem untersten oder einem unteren Block ${ }^{93}$. Bei zweien ist die Position unklar - sie stammen entweder von dem obersten oder dem mittleren Block. ${ }^{94}$ Es fällt auf, dass bei den Stufenbasen mit Inschrift auf dem mittleren Block diese Stufe auch aus Marmor besteht, wie auch sonst in der Regel die obersten Blöcke der Stufenbasen und die einfachen Quaderbasen. Die vier Beispiele von untersten oder unteren Blöcken von Stufenbasen mit Inschriften bestehen dagegen aus Kalkstein. Eine Ähnlichkeit zu Marmor erreichte man dabei durch das Aufbringen von hellem Stuck,

87 Kissas 2000, 79 A 47 (IG I3 1269; CEG I 36; DNO I 350), 79f. A 48 Abb. 61 (IG I 1264).

88 Vgl. zu den Säulen von Votivmonumenten: $D A A, 3-60$.

89 Vgl. die Beispiele $D A A, 50-59$ Nr.48-57 (einige bereits aus den ersten beiden Jahrzehnten des 5. Jhs. v. Chr.).

90 Nach der Materialgrundlage bei Kissas 2000.

91 Davon Stelenbasen: Kissas 2000, 42f. A 8 Abb.11 (?) (IG I3 1195), 44f. A 11 Abb.13 (IG I3 1194bis; CEG I 13), 57-59 A 23 Abb. 33-36 (IG I3 1266; CEG I 32), 59 A 24 Abb. 37 (IG I3 1204; CEG I 28), 59f. A 25 Abb. 38 (IG I3 1243; CEG I 40), 60 A 26 (IG I3 1349), 65f. A 35 (IG I3 1276), 66 A 36 Abb. 43 (IG I3 1380; CEG I 66; DNO I 367). Basen für eine Stele und Säulen (?): Kissas 2000, 48-50 A 16 Abb.18-21 (IG I 1213; CEG I 43), 67f. A 38 Abb. 44, 45 (IG I3 1231; CEG I 70). Basen für Statuen: Kissas 2000, 46f. A 13 Abb.16, 17 (IG I3 1251; CEG I 18; DNO I 359), 47 A 14 (IG I3 1261; CEG I 24; DNO I 348), 47f. A 15 (?) (IG I 1199; CEG I 17), 51-54 A 19 Abb. 27 (IG I I211; CEG I 41; DNO I 349), 55f. A 21 Abb. 31, 32 (IG I 1218; CEG I 50; DNO I 376), 61 A 27 Abb. 39 (IG I ${ }^{3} 1366$ ), 63f. A 30 Abb. 41 (IG I ${ }^{3}$ 1232), 68f. A 39 Abb. 46, 47 (IG I ${ }^{3}$ 1244). Basis für eine Säule: Kissas 2000, 51 A 18 Abb. 23 (IG I³ 1208; CEG I 34; DNO I 347).

92 Kissas 2000, 46 A 12 Abb. 14, 15 (IG I3 1242, CEG I 31), 50 A 17 Abb. 22 (IG I3 1234; CEG I 69), 54f. A 20 Abb. 28-30 (IG I3 1240; CEG I 27), 61f. A 28 (IG I3 1365; CEG I 52; DNO I 378), 66f. A 37 (IG I3 1367).

93 Kissas 2000, 56f. A 22 (IG I $\mathrm{I}^{3}$ 1205; CEG I 38), 64 A 31 (IG I $\mathrm{I}^{3}$ 1226; CEG I 61), 64f. A 32 Abb. 42 (IG I ${ }^{3}$ 1227; CEG I 60), 65 A 33 (IG I ${ }^{3}$ 1236; CEG I 73) (alle aus Kalkstein, bei dreien Stuckierung überliefert). 94 Kissas 2000, 43 A 9 (IG I3 1196; CEG I 14; DNO I 358) (Kalkstein), 62f. A 29 Abb. 40 (IG I3 1357; CEG I 58) (Marmor). 
welcher das eigentliche Material verschleierte. ${ }^{95}$ Dieses Vorgehen war offenbar auch bei den wenigen Ausnahmen von Quaderbasen ${ }^{96}$ und oberen Stufen einer Stufenbasis $^{97}$ üblich, die nicht aus Marmor bestanden. Damit scheint zwar ein Zusammenhang zwischen der Anbringung der Inschrift und dem Material des beschrifteten Bereichs zu bestehen, nicht aber zwingend zur obersten Stufe - mithin derjenigen, die die Inschrift in die unmittelbarste Nähe zur Statue oder Stele gerückt hätte.

Diejenigen Grabmonumente, die nicht nur eine einzelne Stele oder Statue auf dem Unterbau trugen, wie es in den meisten Fällen üblich ist, bestätigen zudem den Eindruck, dass in formaler Hinsicht Inschriften und Figuren nicht eng aufeinander bezogen sind: Auf dem Basisblock des Grabmals des Philoitios und des Ktesias ${ }^{98}$ und dem Basisblock, der einem Olympioniken mit heute unbekanntem Namen ${ }^{99}$ galt, lassen sich jeweils mittig eine zentrale Stele und zwei flankierende Säulen rekonstruieren. ${ }^{100}$ Die Grabinschrift nimmt nicht auf einen der drei aufgestellten Teile Bezug, sondern erstreckt sich über die gesamte Breite des Blockes. Ein vergleichbarer Fall findet sich bei mehreren archaischen Votivmonumenten von der Athener Akropolis, bei denen ein gemeinsamer Unterbau mehrere Statuen oder Statuetten trug. Hier sind die Inschriften nicht auf einen bestimmten Teil der Aufstellung ausgerichtet, auch wenn aus dem Text hervorgeht, dass es sich um eine Weihung zweier Protagonisten handelt: Das Votiv des Lysias und Euarchis an Athena überliefert die Inschrift auf dem Kapitell der Pfeilerbasis, das auf der Oberseite zwei Bettungen aufweist. ${ }^{101}$ Nach

95 Siehe Anm. 93. Auch Stelen aus Kalkstein waren üblicherweise mit Stuck überzogen: vgl. eine Stele aus Athen (Athen, Kerameikos Museum Inv. unbekannt): Richter 1961, 21f. Kat. 23 Abb. 86.

96 Kissas 2000, 39f. A 4 Abb. 7, 8 (IG I³ 1200; CEG I 19), 40f. A 5 Abb. 9 (IG I 1206; CEG I 35). Bei Kissas 2000, 38f. A 3 Abb. 6 (IG I 1209) keine Stuckierung überliefert.

97 Kissas 2000, 42f. A 8 Abb. 11 (IG I 1195) (Kalkstein, gelblicher Stuck, vgl. Jeffery 1962, 116 Nr.1); Kissas 2000, 250 C 7 (IG I³ 1203; CEG I 22) stammt entweder von einer Quaderbasis, oder vom obersten Block einer Stufenbasis und besteht aus stuckiertem Kalkstein. Bei Kissas 2000, 43 A 9 (IG I³ 1196; CEG I 14; DNO I 358) ist offenbar keine Stuckierung überliefert.

98 Athen, Epigraphisches Museum Inv. 13290, um 500 v. Chr.: Kissas 2000, 67f. A 38 Abb. 44, 45 (IG I³ 1231; CEG I 70).

99 Athen, Kerameikos Museum Inv. I 332, drittes Viertel des 6. Jhs. v. Chr.: Kissas 2000, 48-50 A 16 Abb.18-21 (IG I3 1213; CEG I 43); aus zwei Blöcken bestehend; erhalten ist nur der linke Teil.

100 Hierzu: Kissas 2000, 49, 68. Vgl. auch Knigge 2006, bes. 142-151 mit Abb. 4. Weitgehend ungeklärt ist, was die Säulen trugen. Die Vorschläge beinhalten etwa Sphingen, Dreifüßen, Kesseln oder Kouroi: vgl. die Verweise bei Kissas 2000, 49 mit Anm. 231, 68 mit Anm.254. Kissas hält es für möglich, dass die Säulen kein Element trugen: Kissas 2000, 50, 68 (mit Verweis auf das Kapitell einer Grabsäule aus Korfu: McGowan 1995, bes. 618 Abb. 1). Vgl. auch den Rekonstruktionsvorschlag von Knigge zu Kissas 2000, 48-50 A 16 mit bekrönenden Kesseln als Hinweis auf Siegespreise: Knigge 2006, bes. 142-151.

101 Athen, Epigraphisches Museum Inv. 6348, Ende 6. Jh. v. Chr.: DAA Nr. 292 mit Abb.; Kissas 2000, 144-146 B 81 Abb. 164-166; IG I³ 644. Es kann sich nicht um eine spätere Hinzufügung handeln, da die beiden Einlassungen jeweils nicht mittig sind und zudem auch die Inschriftenhand dieselbe zu sein scheint. Vgl. ebenso die Weihung des Kynarbos von der Athener Akropolis (Athen, Epigraphisches Museum Inv. 6301, um 500 v. Chr.: DAA Nr. 79 mit Abb.; Kissas 2000, 99f. B 22 Abb. 89; Kaczko 2016, 197-200 Nr. 48 mit Abb.; IG I³ 745; CEG I 228; vgl. Keesling 2003, 114f. zur Frage nach den Aufstellungen 
der Dedikationsinschrift des Eucharis schließt unmittelbar die des Lysias an. Für den Betrachter wird beim Lesen der Inschrift weder durch ihren Inhalt, noch durch ihre Gestaltung ersichtlich, welche der Statuen mit wessen Stiftung in Verbindung steht. Dies wollte man offenbar nicht in dieser Weise differenzieren.

Die Grabmäler präsentieren Inschriften aber nicht nur auf den Unterbauten der Statuen oder Stelen, sondern bisweilen auch direkt auf den Grabstelen selbst in verschiedenen Bereichen. Archaische Grabstelenmonumente bestehen ab dem 6.Jh. v. Chr. aus einem Unterbau, einem Stelenschaft und einem oberen Abschluss, den anfangs ein Kapitell und eine bekrönende Sphinx (Abb.1.3), später eine Palmette bildete. ${ }^{102}$ Die meisten der Grabstelen dieses Typs zeigen eine oder zwei großformatige Figuren in Relief, Malerei oder Einritzung, oberhalb und unterhalb derer oftmals ein Zwischenraum bis zum oberen Abschluss beziehungsweise bis zur Basis bleibt. Die verschiedenen Bereiche auf der Stele können zudem durch Leisten getrennt sein.

Einige Grabstelen, nicht nur früher Entstehungszeit, verzichten jedoch auf eine großformatige Figur. ${ }^{103}$ Die Grabinschrift erscheint in diesen Fällen an unterschiedlichen Stellen auf dem Stelenschaft: Sie verläuft entweder wie ein Ornamentband ${ }^{104}$

im Zusammenhang zur Inschrift) und die Weihung der Psakythe (Athen, Epigraphisches Museum Inv. 6250: DAA Nr. 81; Kissas 2000, 100f. B 23 Abb. 90, 91; IG I ${ }^{3}$ 656). Eine Ausnahme stellt möglicherweise die Weihung des -chares und Tychandros von der Athener Akropolis dar (Athen, Epigraphisches Museum Inv. 6320ß, 6392, 6501, 6376, Anfang 5. Jh. v. Chr.: DAA Nr. 210; Kissas 2000, 114f. B 42 Abb.108, 109; Kaczko 2016, 230-233 Nr. 59 mit Abb.59a, b; IG I3 695; CEG I 239): Das Kapitell eines (möglicherweise) zwei-Pfeiler-Monumentes zeigt sowohl an der Langseite, als auch an der Schmalseite eine Inschrift. Auf der Oberseite gibt es zwei Einlassungen. Eine größere rechteckige, die sich über das abgebrochene Ende des Blocks erstreckte, und eine kleinere, die aufgrund des Anschlusses sekundär zur ersten sein muss und sehr viel kleiner ist. Die Inschriften sollen von der selben Hand geschrieben sein (Keesling 2005, 403); insofern handelt es sich vielleicht um Arbeitsschritte und keine separate Zufügung. Raubitschek, Kissas und Keesling gehen davon aus, dass die Inschrift auf der Schmalseite mit der kleineren Statue in Verbindung steht, die Inschrift auf der Langseite dagegen auf der mit der größeren Einlassung. Keesling erschloss aus dem Beginn der Weihinschrift des Tychandros auf der

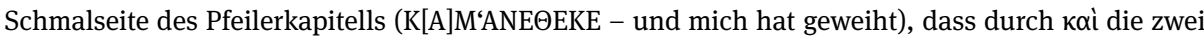
Phasen der Weihung deutlich wären. Keesling rekonstruierte zwei Pferdestatuen (Keesling 2005, $403-$ 406 mit Abb. 8).

102 Hierzu und zum Folgenden Richter 1961, 2f. Zur Entwicklung der archaischen Stelenmonumente auch: Schmaltz 1983, bes. 149-165.

$103 \mathrm{Zu}$ Stelen ohne Bild des Verstorbenen mit dem wichtigen Hinweis auf den Charakter der Stele als Mal: Schmaltz 1983, 160. Einige weitere Stelen müssen für die Frage nach dem Zusammenhang von Figur und Inschrift aufgrund ihres fragmentierten Erhaltungszustandes ausgeschlossen werden. So ist in Einzelfällen nicht einmal sicher zu unterscheiden, ob es sich tatsächlich um eine aufgestellte Stele nach den bekannten Grabstelentypen handelt, oder vielmehr um eine Platte, die an der Umfassungsmauer eines Tumulus oder an der Wand eines Grabgebäudes angebracht war, wie Jeffery zwei Fragmente aus einem Tumulus in Velanideza deutete (Kat. 1.9, 1.10): Beide überliefern vielleicht den oberen Abschluss einer Platte/Stele und in diesem oberen Bereich eine Grabinschrift. Da der untere Teil jeweils fehlt, ist unklar, ob und, wenn ja, wie sie mit Bildern ausgestaltet waren.

104 Vgl. hierzu Schmaltz 1979, 35 Anm. 96. Vgl. etwa die rahmenden, breiten Ornamentbänder auf einer weiteren Poros-Grabstele aus dem Kerameikos (Athen, Kerameikos Museum Inv. P 1133), die nach 


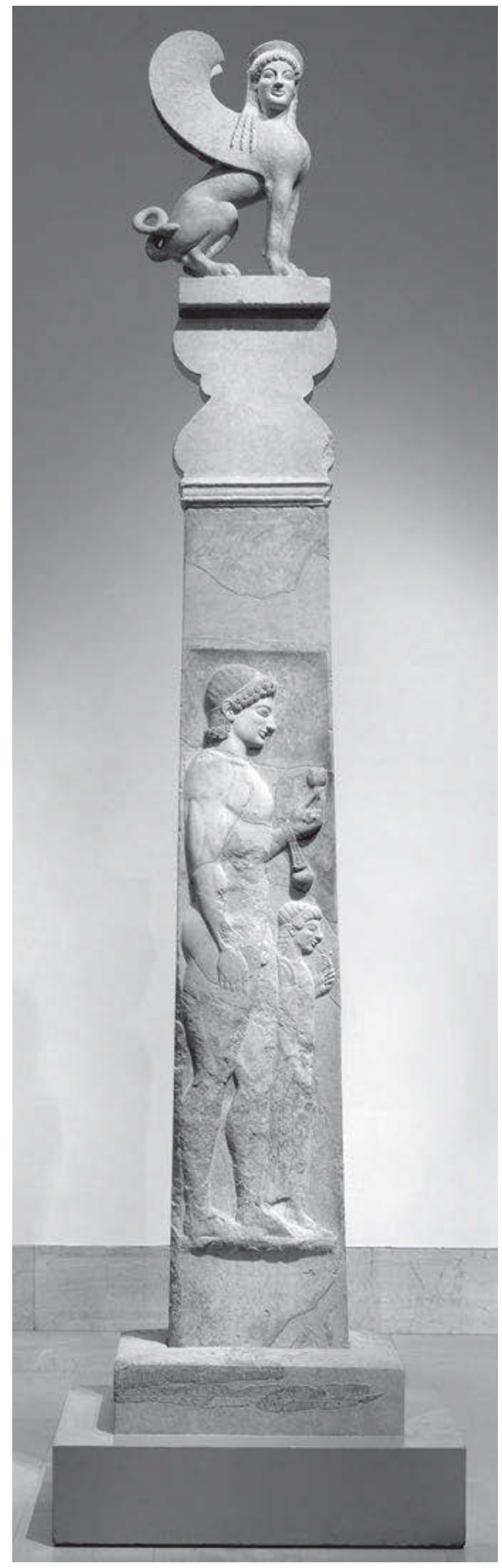

Abb.1.3: Sogenannte Geschwisterstele New York/Athen/Berlin um 530 v. Chr. (New York, Metropolitan Museum of Art 11.185a-c, f, g + Berlin, Antikensammlung, Staatliche Museen zu Berlin, SPK Sk 1531 + Athen, Nationalmuseum 4518). 
vertikal am Rand oder in der Mitte der Stele ${ }^{105}$ oder ist horizontal im unteren Drittel (Abb. 1.4) ${ }^{106}$ oder - wie im Falle der Grabstele des Antiphanes (Kat.1.3) (Abb.1.5) - auf mittlerer Höhe eingemeißelt. Bei dieser war über der Inschrift noch ein Hahn aufgemalt, der das Fehlen einer figürlichen Repräsentation des Verstorbenen bezeugt.

Stelen mit Inschrift und Figurdarstellung präsentieren die Inschriften ebenfalls in unterschiedlichen Bereichen, ohne dass es ausschließlich für Inschriften vorgesehene Felder gibt. Bis auf eine frühe Grabstele (Kat. 1.14) aus der Zeit um 580 v. Chr., auf der die Abschlussleiste des Kapitells als Schreibgrund verwendet wurde, ${ }^{107}$ beschränken sich die Inschriften aber stets auf den unteren Bereich der Stele. Entweder stehen sie auf der plastisch hervorgehobenen Leiste, die die Figur von dem Predellabereich oder der Basis trennt, oder direkt auf der Predella. Auf den Leisten sind nur die kürzeren Bildhauerinschriften sicher $\mathrm{zu}$ fassen, wie dies auf der Stele des Aristion im Athener Nationalmuseum der Fall ist (Abb.1.6a-b). ${ }^{108}$ Im Predellabereich erscheinen Inschriften entweder alleine, ${ }^{109}$ oder zusammen mit einer bildlichen Darstellung, wie es die Grabstele des Kalliades verdeutlicht (Abb.1.7). ${ }^{110}$ Unter dem rechten Knie der dort gezeigten Gorgo ist ein Feld leicht abgesetzt, in dem in drei Zeilen die kurze Grabinschrift eingeschrieben ist.

Es wird deutlich, dass man an archaischen attischen Grabdenkmälern weder auf die rundplastische Grabstatue, noch auf oder in das direkte Umfeld der Figur auf der Grabstele schrieb. Auf dem mittleren Teil des Stelenschafts gibt es Inschriften nur in den Fällen, bei denen der Verstorbene nicht durch eine Figur repräsentiert wurde. Der Bereich im direkten Umfeld der Figur auf der Grabstele scheint also von Inschriften

Willemsen in das zweite oder dritte Jahrzehnt des 6. Jhs. v. Chr. datiert: Willemsen 1970, 23-27 Taf. 9; Richter 1961, 12f. Abb. 29, 30. Vgl. hierzu Schmaltz 1979, 35 Anm. 96.

105 Auf der Porosstele für Semiades (Kat. 1.4) verläuft die Grabinschrift vertikal am rechten Rand der Stele. Die Grabstele des -kleides (Kat. 1.13) überliefert nach der Beschreibung von Schmaltz eine Grabinschrift, die mittig auf der Stele von unten nach oben verläuft.

106 Grabstele von der Athener Agora (Kat. 1.1). Hier ist nur das retrograd geschriebene Ende des Namens des Verstorbenen auf dem Stelenschaft im unteren Drittel erhalten. Ob oder was darüber gemalt war, ist aufgrund fehlender Reste unbekannt. Harrison (Harrison 1956, 27, 37f.) und Richter (Richter 1961, 44) nahmen an, dass es sich hierbei um die verschollene Stele des Theron handelt, die Fauvel in Glyphada entdeckte und nach Athen brachte. Das Fragment wurde in einem zerstörten modernen Haus an der Athener Agora aufgefunden. Guarducci (in Richter 1961,169) bezweifelte wegen bezeichnender Unstimmigkeiten zwischen den überlieferten Zeichnungen und dem Stück die Identifizierung. 107 Vgl. auch eine bereits frühklassische Grabstele des Pollis (Abb.1.24) angeblich aus der Region um Megara (Malibu, J. Paul Getty Museum Inv. 90.AA.129, 480/470 v. Chr.): Grossman 2001, 98-100 Nr.36 mit Abb. Dort steht die Grabinschrift auf dem Stelenschaft über der Figur. Zur Inschrift SEG 40, 404; SEG 45, 421; Corcella 1995; Ebert 1996a; Ebert 1996b, $19-25$.

108 s. Kat. 1.2; vgl. Kat. 1.6; 1.16. Ob die sehr fragmentierte Inschrift auf einer Grabstele (Kat. 1.5) tatsächlich der Reste einer Bildhauerinschrift trägt, ist nicht gesichert.

109 Inschrift im Predellabereich: Kat. 1.12.

110 Kat. 1.15. Vgl. für eine mögliche Rekonstruktion der Stele die Grabstele im Athener Nationalmuseum Inv. 2687: Richter 1961, 22 Nr. 27 Abb. 83. 


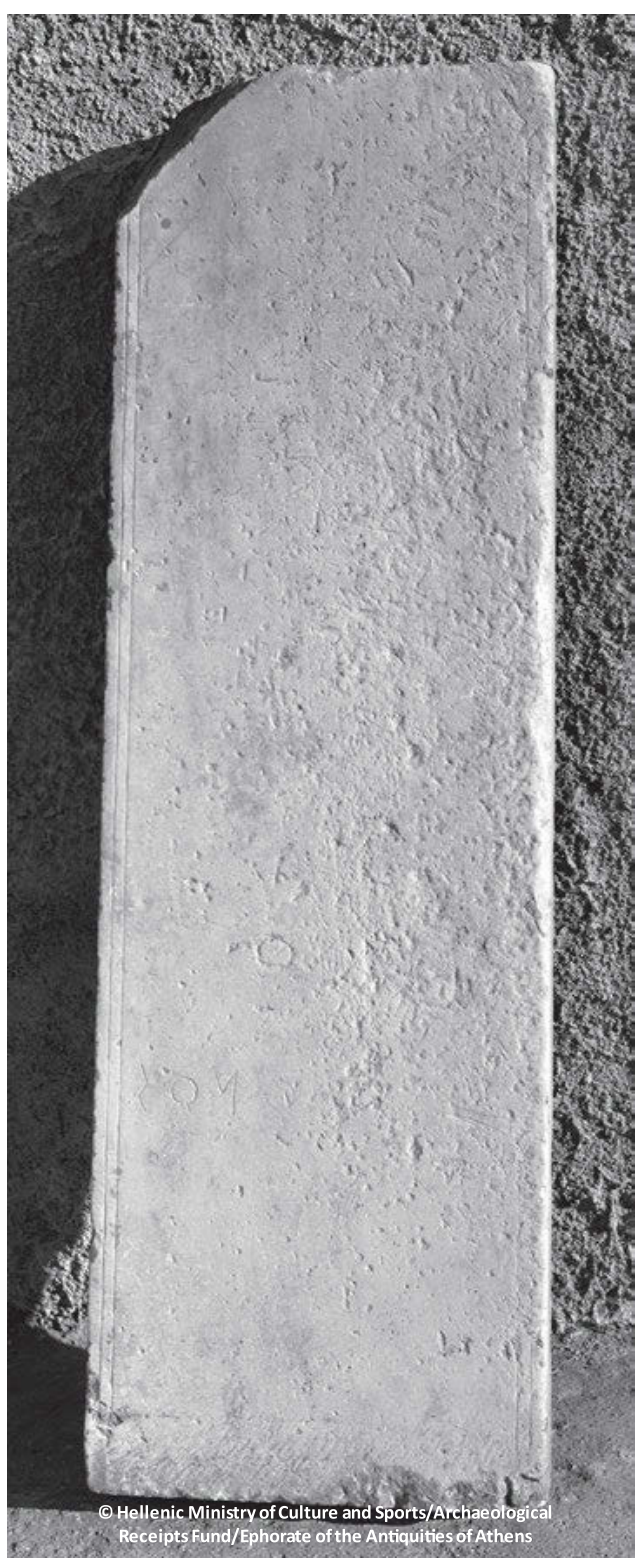

Abb. 1.4: Grabstele des -on vor 520 v. Chr.? (Athen, Agora Museum I.2056).

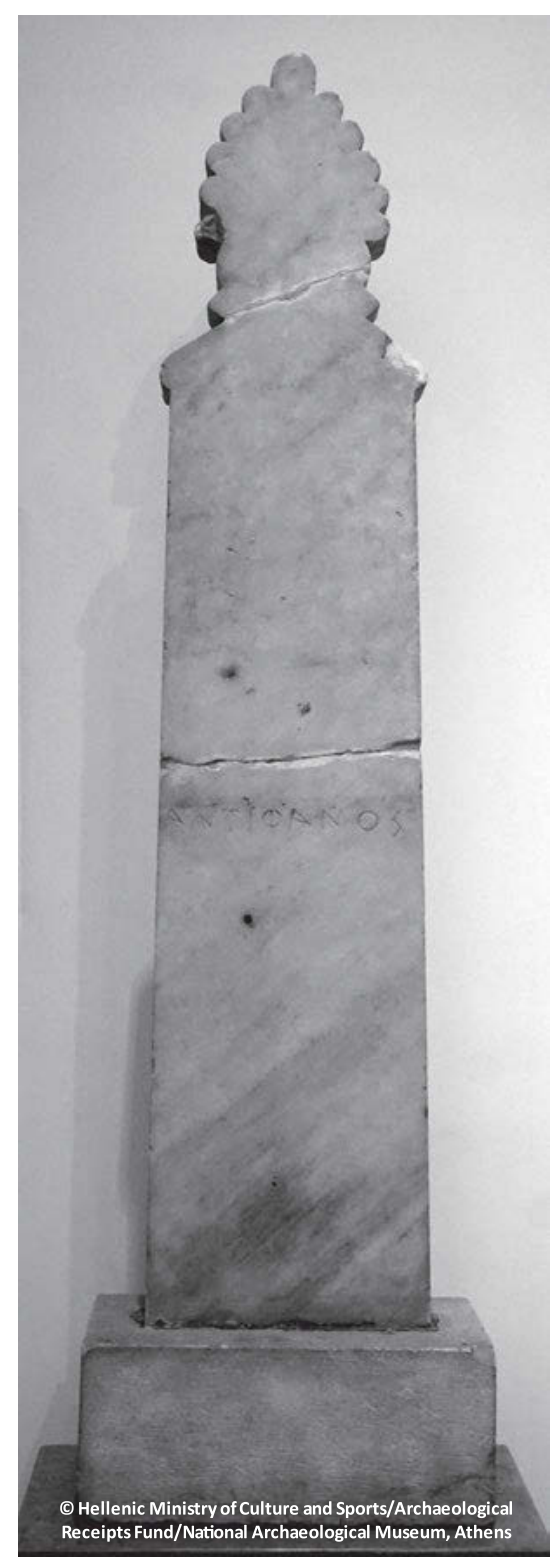

Abb.1.5: Grabstele des Antiphanes um 520 v. Chr. (Athen, Nationalmuseum 86).

freigehalten worden zu sein. Stattdessen bevorzugte man den unteren Bereich auf den Stelen oder die Unterbauten. Weder bei Stelen- noch bei Statuenmonumenten ist aber eine Konvention eines bestimmten ,Inschriftenfeldes‘ am Grabdenkmal festzustellen, da die Position von Inschriften variiert (Stelenbasen vs. Stelen; verschiedene 


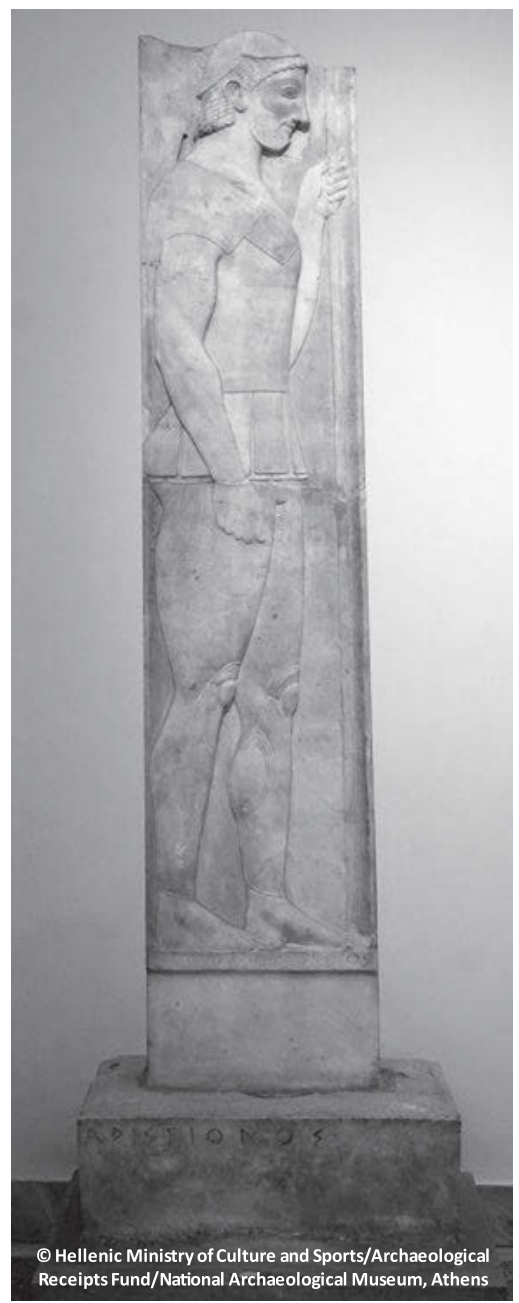

Abb.1.6a-b: Grabstele des Aristion um 520/510 v. Chr. (Athen, Nationalmuseum 29).

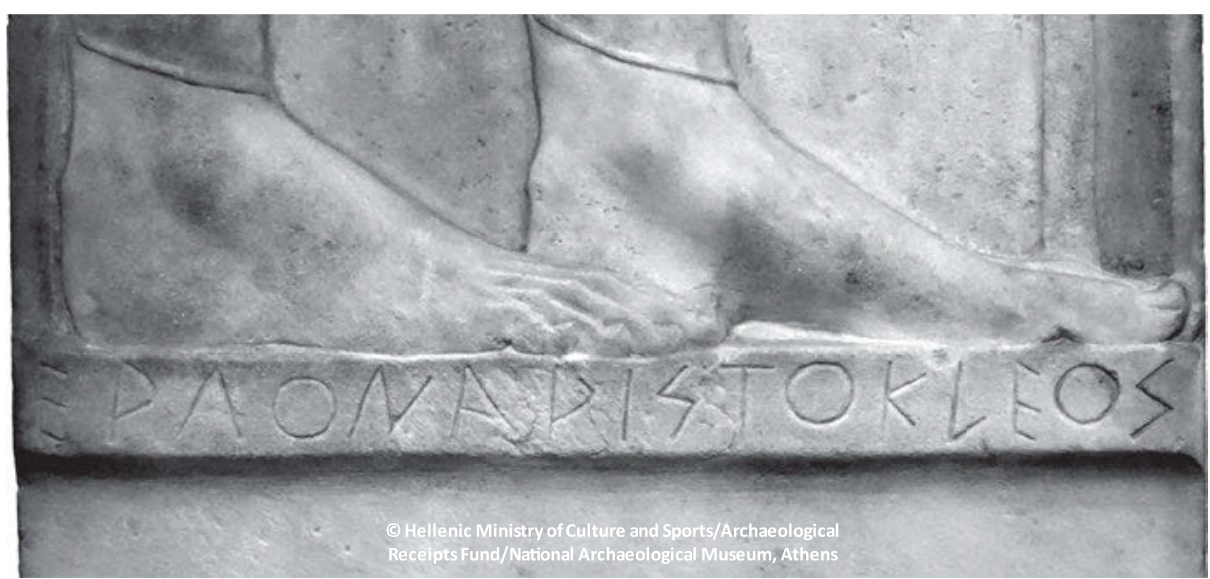




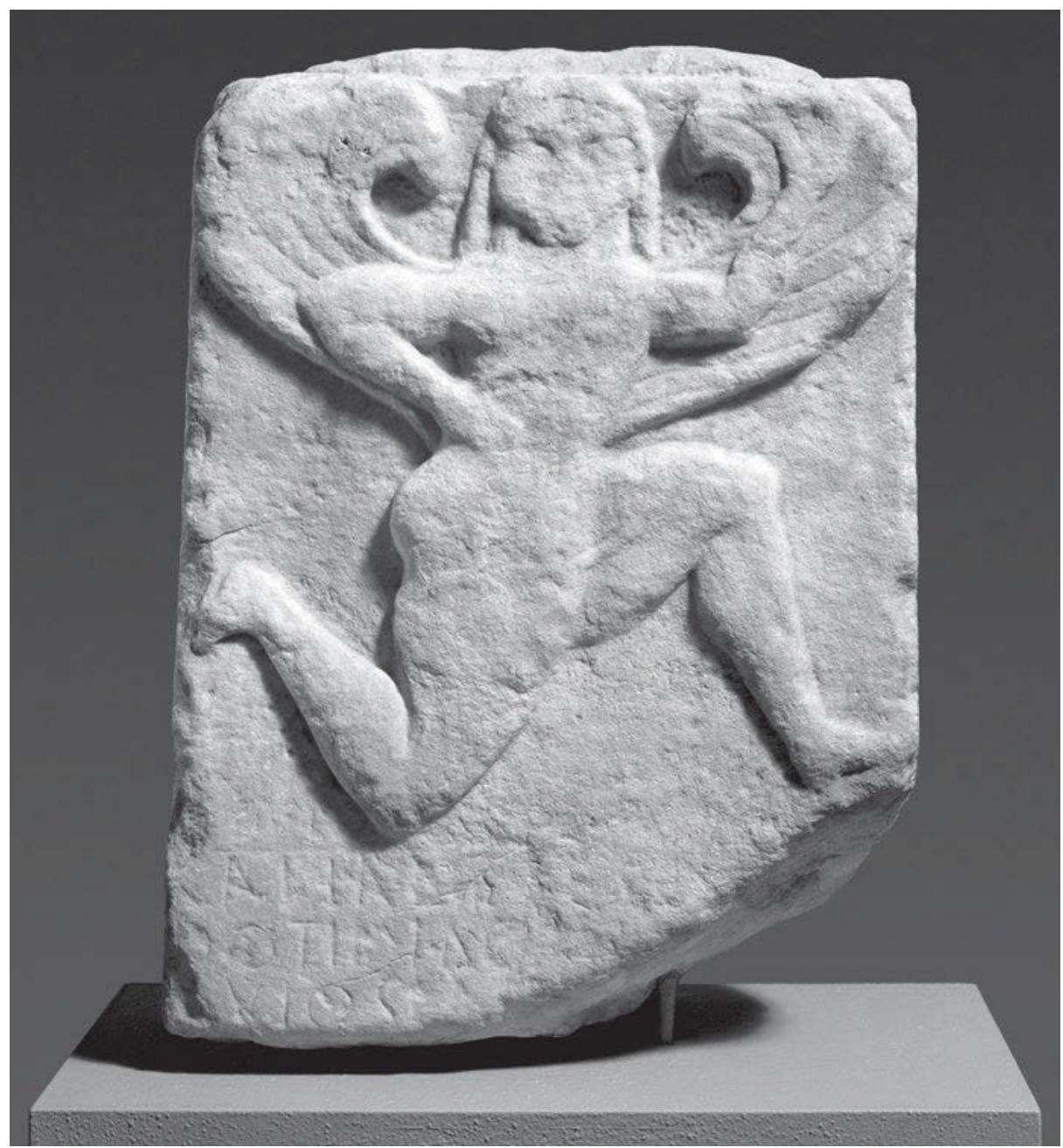

Abb. 1.7: Predellabereich der Grabstele des Kalliades - drittes Viertel des 6. Jhs. v. Chr. (New York, Metropolitan Museum of Art 55.11.4).

Stufen der Stufenbasen für Statue oder Stele). Auch an Säulen- und Pfeilermonumenten treten die Inschriften nicht immer an denselben Stellen auf.

Ein Blick ins benachbarte Böotien zeigt, dass sich dort die archaischen Grabstelen in Bezug auf die Inschriftenposition nur zum Teil von den attischen unterscheiden. ${ }^{111}$ Während in Attika in keinem Falle das direkte Umfeld der Figur beschrieben

111 Bei einer Grabstele in Boston (Museum of Fine Arts Inv. 08.288, Geschenk Fiske Warren 1908; angeblich aus Theben; zweites Viertel 6. Jh. v. Chr. [Richter]; 560/550 v. Chr. [Schild-Xenidou]; Literatur: Richter 1961, 22 Nr. 28, 156 Nr. 28 [M. Guarducci] Abb. 83-85, 199; Schild-Xenidou 2008, 154, $236 f$. Kat. 2 Taf.2) findet sich der Rest einer Inschrift über der im Relief angegebenen männlichen Figur: 
wird, gibt es in Böotien hierfür zwei Beispiele. So zeigt die Grabstele des Mnasitheos aus Akraiphia (Abb.1.8) die Grabinschrift direkt neben der Figur und die Bildhauerinschrift im Predellabereich. ${ }^{112}$

Die Zeilen der Grabinschrift verlaufen von oben nach unten, wobei die Buchstaben der Figur abgewandt sind, da sie rechtsläufig geschrieben ist. Diese Position im Verhältnis zur Figur erinnert an das attische Grabmonument des Neilonides (Abb. 1.2), das zunächst einer genaueren Betrachtung wert ist: ${ }^{113}$ Dort fügt sich die Bildhauerinschrift links auf der Blockseite in einen hochrechteckigen Bereich ein und unterstützt durch ihre vertikale Orientierung und ihre rechtsläufige Schreibung die Separierung dieses Bereiches von der Figur daneben. ${ }^{114}$ Rechts neben der Figur wird ein anderer, diesmal querrechteckiger Bereich durch die mehrzeilige Grabinschrift definiert. Da zwischen den drei Elementen Inschrift - Figur - Inschrift kein formaler Bezug besteht, sind sie in dieser Hinsicht als eigenständige Elemente der Blockgestaltung zu verstehen; inhaltlich könnte zwar der Betrachter/Leser durch die Nähe der Inschriften und des Bildes in der gemalten Figur den Vater Neilon ${ }^{115}$ oder den Bildhauer Endoios erkennen, wenn ihm die (schlecht erhaltene) Ikonographie der sitzenden Figur hierfür passend erschien, formal ist jedoch weder die eine, noch die andere Verbindung forciert. Von ebenfalls keiner signifikanten Verbindung zwischen Inschriften und Text ausgehend schlug etwa Catherine Keesling sogar vor, dass es sich um eine Darstellung des Gottes Hades handeln könnte. ${ }^{116}$ Sie nahm jedoch durchaus an ohne dies jedoch näher auszuführen -, dass durch die Nähe der Bildhauerinschrift

Sie überliefert nur zwei Buchstaben ( $\Theta \mathrm{O}[---)$, die wohl den Anfang des Namens des Verstorbenen bildeten, der von unten nach oben geschrieben wurde. Auf der Grabstele des Agathon und Aristokrates aus Thespiai steht eine kurze Grabinschrift in der unteren Zone der Stele direkt unter den Figuren: Athen Nationalmuseum Inv. 32; um 520 v. Chr. (Richter); 510/500 v. Chr. (Schild-Xenidou); Literatur: Richter 1961, 50 Nr. 75, 170f. Nr. 75 (M. Guarducci) Abb. 171, 213; Maria Salta, in: Despinis/Kaltsas 2014, 404f. Kat. I.1.369 Abb. 1223, 1224; Schild-Xenidou 2008, 155, 237f. Kat. 3 Taf. 2; IG VII 1890; I Thespiai 490. $\mathrm{Zu}$ den wenigen erhaltenen archaischen Grabstelen aus Böotien siehe Schild-Xenidou 2008, 6-17, 235-240 Kat. 1-6 Taf. 1-3.

112 Theben, Archäologisches Museum Inv. 28200, um 520-510 v. Chr., aus Akraiphia: Andreiomenou

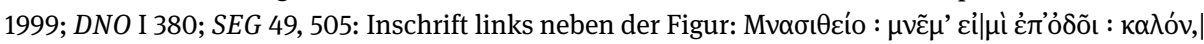

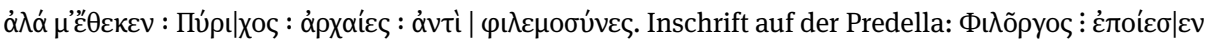
(Ich bin das schöne Grabmal des Mnasitheios am Wege; aber geweiht hat mich Pyr(rh)ichos zum Dank für alte Freundschaft. Philourgos hat <es> gefertigt; Übs. DNO I 380 / K. Hallof - S. Kansteiner); vgl. zur Stele: Andreiomenou 2000; Andreiomenou 2006; Schild-Xenidou 2008, 155f., 239f. Kat. 6 Taf.3; Estrin 2016.

113 Vgl. Anm. 82. Diese Verbindung zog auch Andreiomenou 2000, 97 und deutete sie als Werkstattzusammengehörigkeit.

114 In der archaischen attischen Vasenmalerei wird dagegen bei Namensbeischriften die Schreibweise (rechts- oder linksläufig) häufig so angepasst, dass sich die Grundlinie der Buchstaben an der Figur befindet. Dies ergibt sich aus den beiden von Wachter beschriebenen Platzierungskonventionen von Namensbeischriften (Wachter 2001, 228 §104f.). Ich danke Georg Gerleigner für diesen Hinweis. 115 Vgl. Raubitschek 1939b, 67.

116 Keesling 1999, bes. 536-545 mit Referenz zu den älteren Identifizierungen der Figur als Gottheit. 


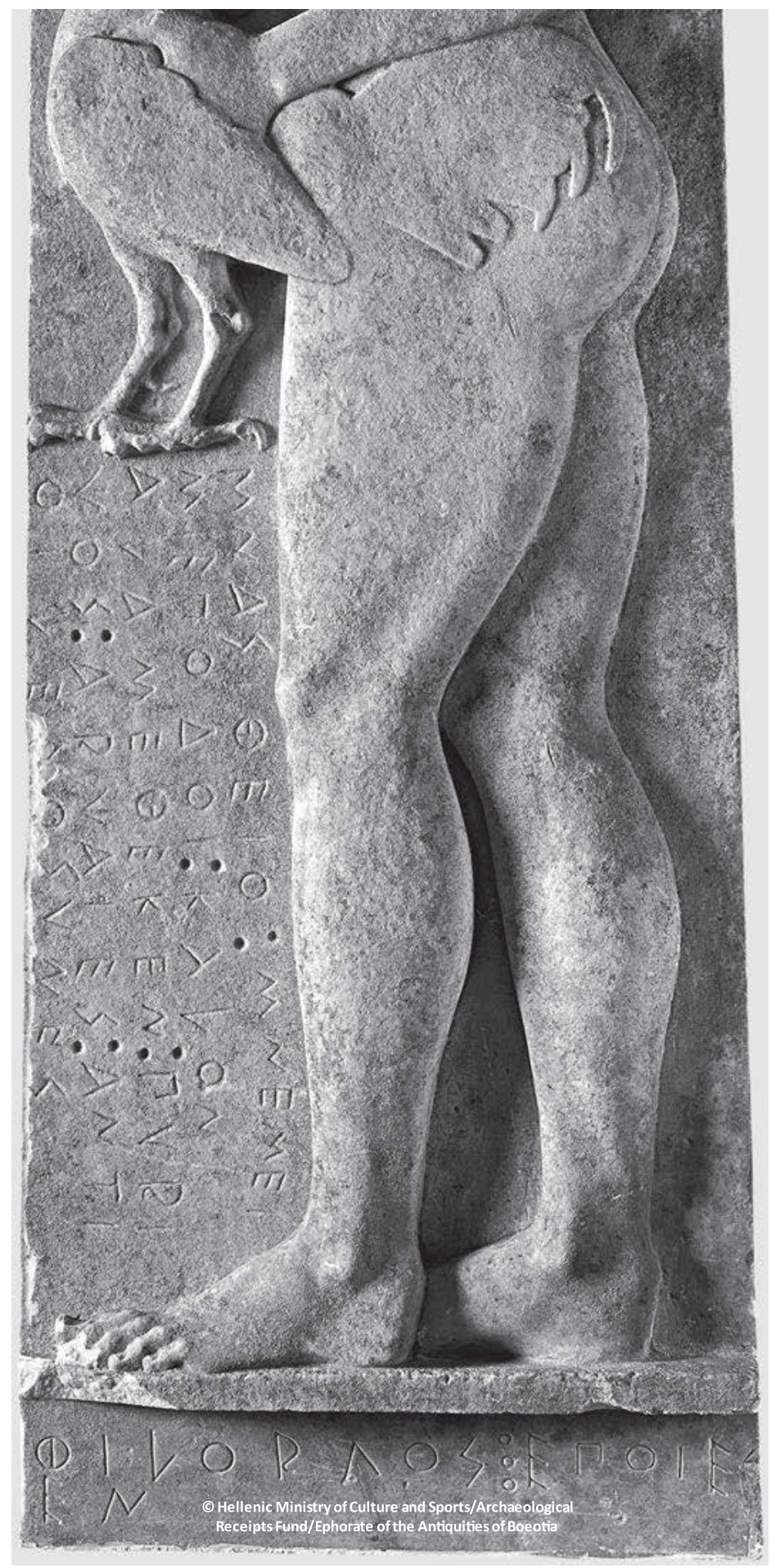

Abb.1.8: Unterer Teil der böotischen Grabstele des Mnasitheos aus Akraiphia um 520/510 v. Chr. (Theben, Archäologisches Museum 28200). 
des Endoios zur Sitzfigur nahegelegt würde, dass dieser auch das Bild gemalt habe. ${ }^{117}$ Anhand der formalen Gestaltung kann diese These weder verifiziert, noch falsifiziert werden. Unbestritten ist, dass durch die Nähe von Inschrift und Bild eine Verknüpfung stattfinden konnte. Dagegen kann anhand des erhaltenen Materials nicht erwiesen werden, dass, um eine inhaltliche Verbindung herzustellen, Inschriften möglichst nah an das jeweilige Bild gebracht wurden - es genügte offenbar die Anbringung an demselben Monument. Das Grabmal des Neilonides ist damit kein erklärungsbedürftiger Sonderfall, bei der die Nutzung der Blockfläche für zwei Inschriften und ein Bild eine enge - inhaltliche - Verbindung nahelegen würden. Vielmehr wird der Platz auf der Blockfläche, wie es u. a. bei Stelen üblich ist, formal in verschiedene ,Felder‘ unterteilt und diese gefüllt.

Ganz ähnlich scheint auch die Nähe der Grabinschrift zur Figur auf der Stele des Mnasitheos keinen besonderen Zusammenhang mit der Figur neben ihr nachzuweisen - unterscheidet sich doch auch der Textinhalt nicht von dem attischer Epigramme, die nicht immer in unmittelbarster Figurnähe angebracht wurden. Eine Verbindung zwischen dem in der Inschrift genannten Mnasitheos und der Figur ist allein schon durch die Anbringung auf demselben Monument gewährleistet und wäre demnach auch gegeben, wenn sich die Grabinschrift auf der Basis der Stele befunden hätte. Formal als Beischrift zur Figur ist demnach aber das Epigramm nicht zu verstehen.

Während diese Grabstele sich demnach nicht von den attischen unterscheidet, belegt die Grabstele des Dermys und des Kitylos aus Tanagra ${ }^{118}$ (Abb.1.9a-c) tatsächlich ein anderes Konzept und eine bewusste formale Bezugnahme zwischen Namen und Figuren: Dort ist zwar die Grabinschrift im Stelenbereich unter den beiden Figuren angebracht, wo sie horizontal orientiert von der Vorderseite der Stele auf ihre rechte Nebenseite weiterläuft. Zusätzlich schrieb man aber jeweils neben den Beinen jeder Figur einen Namen im Nominativ ein und schuf so eine unmittelbare Nähe zwischen Figur und Namensnennung im Sinne einer Beischrift, wie es an keinem attischen Beispiel überliefert ist. ${ }^{119}$ Auf diese Besonderheit wird an späterer Stelle noch einmal eingegangen.

117 Keesling 1999, 511; auch bereits Raubitschek 1939b, 63. S. auch die Übs. in DNO I 368: Endoios schuf auch diesen $<$ Sitzenden $>$.

118 Athen Nationalmuseum Inv. 56; aus Tanagra, Nekropole von Kokali; um 600 v. Chr. (Richter) bzw. 580/570 v. Chr. (Schild-Xenidou). Zur Stele: Richter 1961, 13 Nr. 9, 155f. Nr. 9. (M. Guarducci) Abb. 31-33, 192-195; Schild-Xenidou 2008, 153f., 235f. Taf. 1; Georgia Kokkorou-Alevras, in: Despinis/Kaltsas 2014, 377-379 Kat. I.1.352 Abb.1178-1183. Zur Inschrift: IG VII, 579 (mit Lit.); CEG I 109.

119 Jeffery vermutete jedoch für die frühe Stele der Keramo (Athen, Epigraphisches Museum Inv. 10646, Mitte/zweite Hälfte 7. Jh. v. Chr.: Jeffery 1962, 129 Nr. 22 Taf. 36c; IG I³ 1194) aufgrund der Schriftführung, dass diese an dargestellten Figuren orientiert waren: Jeffery 1961, 44f. Belegbar ist diese Hypothese am Erhaltenen nicht. 


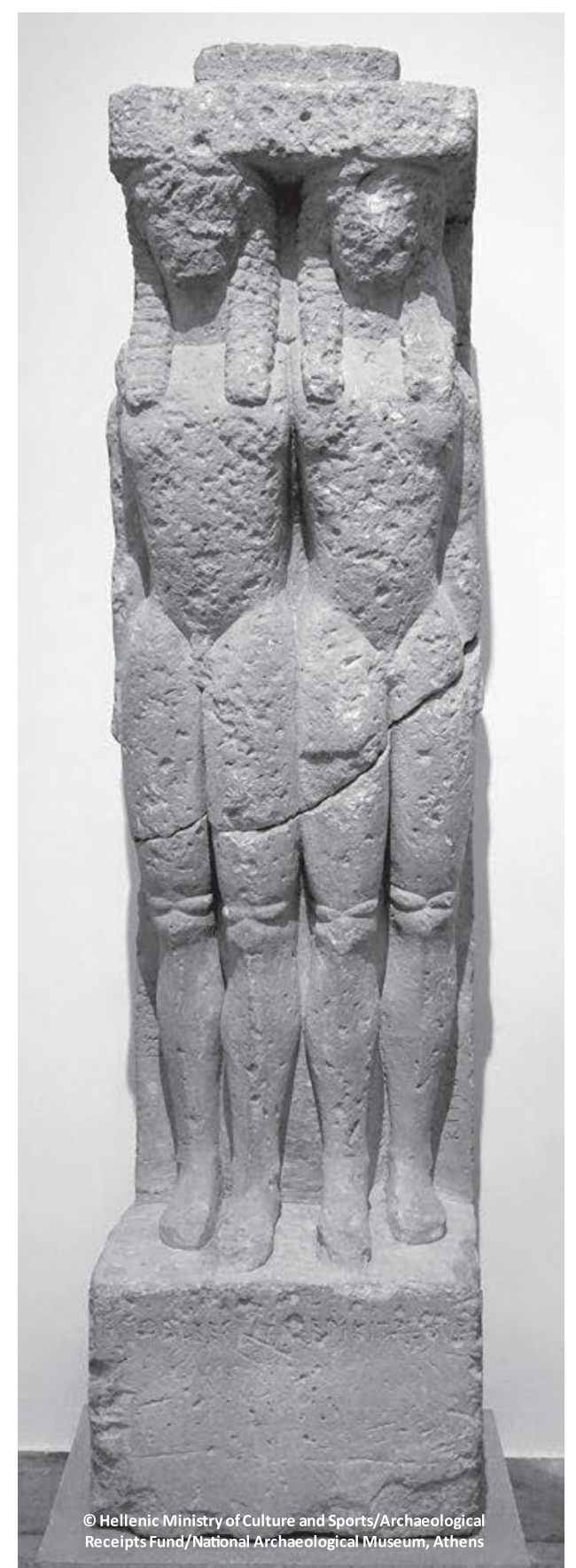

Abb.1.9a-c: Böotische Grabstele des Dermys und des Kitylos aus Tanagra um 580/570 v. Chr. (Athen, Nationalmuseum 56).
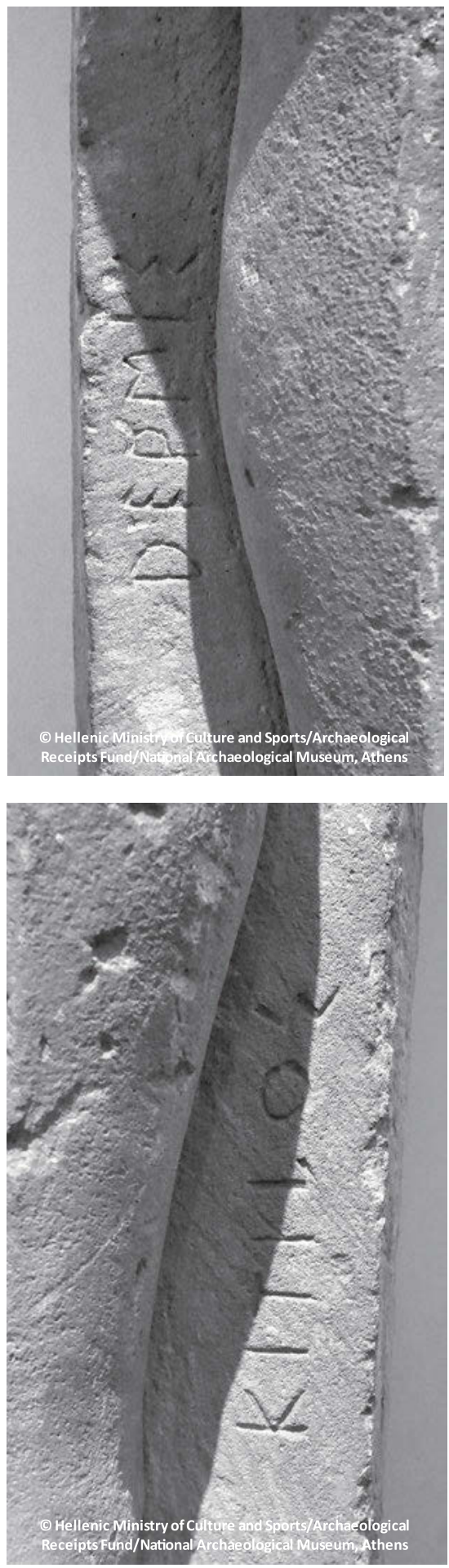


\section{Begründung der Inschriften-Positionen}

Welche Gründe gab es aber dann für die Lage der Inschrift am Grabmal, wenn sie in formaler Hinsicht nicht als Beischriften zum Bild zu verstehen sind - war etwa die Länge der Inschriften oder doch ein allgemeiner Zusammenhang zur gezeigten Figur ausschlaggebend? Lässt sich vielleicht sogar ein Unterschied zwischen Grab- und Bildhauerinschriften fassen?

Als Test können zunächst die Inschriften an Stelenmonumenten herangezogen werden, da sich an ihnen aufgrund der vielen möglichen Anbringungsorte auf Stelenschaft und Stelenunterbau mögliche Bezüge zur Länge der Inschrift oder zur Figur überprüfen lassen.

Die erhaltenen Stelenbasen ${ }^{120}$ belegen in Verbindung mit den erhaltenen Stelen, dass es keine Präferenz für unterschiedliche Inschrifteninhalte (Grab- oder Bildhauerinschrift) oder Inschriftenlängen an bestimmten Orten der Grabmonumente gab. Auf der mehr Platz bietenden Stelenbasis steht genauso nur die Angabe des Namens des Verstorbenen, wie mitten auf dem Schaft der Stele. ${ }^{121}$ Längere, mehrzeilige Grabinschriften finden sich zwar häufig auf den Basen, kommen aber auch auf der Stele oder Platte direkt vor. ${ }^{122}$ Auch die Bildhauerinschriften sind sowohl auf der Stelenbasis als auch auf dem Stelenschaft eingemeißelt. ${ }^{123}$ Auf der Stele bot sich aufgrund der Kürze der Bildhauerinschrift offenbar zudem die Leiste unterhalb der Figur an. An dieser Stelle schrieb man jedoch in keinem Fall die Grabinschrift, ${ }^{124}$ auch wenn sich

120 Kissas führt 25 sichere Beispiele in seinem Katalog auf: Kissas 2000, 38f. A 3 Abb. 6 (IG $\mathrm{I}^{3} 1209$ ), 40f. A 5 Abb. 9 (IG I3 1206; CEG I 35), 41 A 6 (IG I3 1207; CEG I 33), 41f. A 7 Abb. 10 (IG I3 1219), 44f. A 11 Abb. 13 (IG I $\mathrm{I}^{3}$ 1194bis; CEG I 13), 48-50 A 16 Abb. 18-21 (IG I3 1213; CEG I 43), 57-59 A 23 Abb. 33-36 (IG I3 1266; CEG I 32), 59 A 24 Abb. 37 (IG I3 1204; CEG I 28), 59f. A 25 Abb. 38 (IG I3 1243; CEG I 40), 60 A 26 (IG I3 1349), 65f. A 35 (IG I3 1276), 66 A 36 Abb. 43 (IG I I $^{3} 1380$; CEG I 66; DNO I 367), 67f. A 38 Abb. 44, 45 (IG I3 1231; CEG I 70), 247f. C 1 Abb. 335 (IG I $\left.\mathrm{I}^{3} 1238\right), 249$ C 4 (IG I3 1277; CEG I 68), 249f. C 5 (IG I 1241 ; CEG I 25), 250f. C 8 (IG I3 1216; CEG I 45), 251 C 9 (IG I3 1259), 253 C 12 Abb. 339 (IG I' 1229; CEG I 54; DNO I 377), 253f. C 13 Abb. 340 (IG I ${ }^{3}$ 1222), 254 C 14 Abb. 341 (IG I3 1271; CEG I 56), 255 C 15 (IG I3 1223; CEG I 59), 255f. C 16 (IG I $\mathrm{I}^{3} 1257$; CEG I 53), 256 C 17 Abb. 342 (IG I3 1256), 258 C 20 (IG I3 1260; CEG I 72). 121 Vgl. Kat. 1.1, Kat. 1.3 gegenüber etwa Kissas 2000, 38f. A 3 Abb. 6 (IG I 1209), 256 C 17 Abb. 342 (IG $\left.\mathrm{I}^{3} 1256\right)$.

122 Auf Basen: Kissas 2000, 40f. A 5 (IG I3 1206; CEG I 35), 41 A 6 (IG I3 1207; CEG I 33), 41f. A 7 (IG I ${ }^{3}$ 1219), 44f. A 11 (IG I $\mathrm{I}^{3} 1194 \mathrm{bis}$; $C E G$ I 13), 48-50 A 16 (IG I $\mathrm{I}^{3} 1213$; CEG I 43), 57-59 A 23 (IG I3 1266; CEG I 32), 59 A 24 (IG I3 1204; CEG I 28), 59f. A 25 (IG I3 1243; CEG I 40), 66 A 36 (IG I3 1380; CEG I 66; DNO I 367), 67f. A 38 (IG I 1231; CEG I 70), 249 C 4 (IG I3 1277; CEG I 68), 249f. C 5 (IG I3 1241; CEG I 25), 250f. C 8 (IG I3 1216; CEG I 45), 253 C 12 (IG I3 1229; CEG I 54; DNO I 377), 254 C 14 (IG I 1271; CEG I 56), 255 C 15 (IG I3 1223; CEG I 59), 255f. C 16 (IG I $\mathrm{I}^{3}$ 1257; CEG I 53), 258 C 20 (IG $\mathrm{I}^{3} 1260 ;$; $C E G$ I 72). Auf Stelen oder Platten: Kat. 1.9, Kat. 1.10, Kat. 1.11, Kat. 1.12, Kat. 1.18.

123 Auf der Basis: Kissas 2000, 66 A 36 Abb. 43 (IG I3 1380; CEG I 66; DNO I 367), 253 C 12 Abb. 339 (IG I3 1229; CEG I 54; DNO I 377), 253f. C 13 Abb. 340 (IG $\left.\mathrm{I}^{3} 1222\right)$; auf der Stele vgl. die oben genannten Beispiele.

124 Schmaltz vermutete aufgrund von Unregelmäßigkeiten, dass diese Partie bei der Stele des Aristion (Kat. 1.2) überarbeitet wurde und ursprünglich eine andere Inschrift trug; diese soll aber nicht der 
diese nur auf den Namen des Verstorbenen im Genetiv beschränkte. Das Grabmal des Aristion (Kat. 1.2) präsentiert sogar auf der Leiste unter der Figur die längere Bildhau-

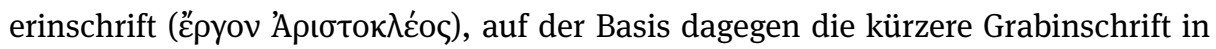
Form des Namens im Genetiv ('Apıбtíovos) (Abb.1.6a-b; 1.16). Die Lage der Inschriften am Grabmal ist demnach nicht primär durch die Textlänge bedingt, auch wenn natürlich die Länge immer Einfluss nahm. Genauso wenig scheint der unterschiedliche Textinhalt eine unterschiedliche Position bedingt zu haben: Bildhauerinschriften wie Grabinschriften finden sich mit Ausnahme der Leiste unter der Figur variabel in denselben Bereichen auf der Stele und der Basis. ${ }^{125}$

Es gibt zudem keinen konsequenten räumlichen Zusammenhang zwischen der Figur und der Grabinschrift, obwohl letztere ja in der Regel den Namen des Verstorbenen nennt. Dies fällt besonders dadurch auf, dass eine räumliche Nähe beider Elemente durch die Gliederung der Stele in verschiedene Bereiche durchaus möglich gewesen wäre. Abgesehen von dem zuvor beschriebenen Phänomen, dass Inschriften trotz vorhandenem Platz nicht in derselben Partie der Stele wie die Figur angebracht wurden, bezeugen dies auch die Leisten direkt unter den Figuren, die in keinem Fall eine der kürzeren Grabinschriften belegen. Solche Inschriften stehen dagegen durchaus auch auf den Unterbauten. ${ }^{126}$ Die Position der Grabinschriften an Stelenmonumenten unterscheidet sich damit in Bezug auf das Verhältnis von Figur und Inschrift nicht von der an Statuenmonumenten im Grabbereich. Auch bei Inschriften an Letzteren wird, wie zuvor dargelegt, nicht konsequent auf die oberste Stufe oder den Deckblock/das Kapitell und damit in direkter Nähe zur Figur geschrieben.

Gerade bei den Stelenmonumenten lässt sich damit keine Konvention der Inschriftenpositionen an einer bestimmten Stelle belegen, wie es insgesamt auch bei den Stufenmonumenten keine Konvention der Anbringung auf der obersten Stufe gab. Gegenüber diesem Negativergebnis fällt ein anderer Aspekt deutlich ins Auge, der uns näher an die Gründe für die unterschiedlichen Positionen von Inschriften heranführt: Grab- und Bildhauerinschriften nutzten dieselben Bereiche am Monument wie der Figur nebengeordnete Bilder und Ornamente. ${ }^{127}$ Im Predellabereich der Stelen

Name des Verstorbenen gewesen sein, der in der ersten Phase der Stele bereits der erhaltene Name API $\Sigma$ TIONO $\Sigma$ war: Schmaltz 2005, 170. Zur Überarbeitung der Stele u. a. Schmaltz 2005 mit Verweis auf weitere Literatur. Hierfür zieht er auch die unterschiedlichen Schreiberhände der Inschriften heran, s. hierzu aber in Anm. 158.

125 Bildhauerinschriften auf Stelenbasen: Kissas 2000, 66 A 36 Abb. 43 (IG I 1380; CEG I 66; DNO I 367), 253 C 12 Abb. 339 (IG I ${ }^{3}$ 1229, CEG I 54; DNO I 377). Auf dem Stelenkörper (wohl Predellabereich) eingebunden in das Grabepigramm: Kat. 1.12. Auf der Leiste unter der Figur Kat. 1.2, 1.6, 1.16. Vielleicht auch auf der Grabstele Kat. 1.5, wobei hier die Inschrift nur sehr fragmentiert erhalten ist.

126 Kissas 2000, 38f. A 3 Abb. 6 (IG I3 1209) (Grabmal der Kleto; Stele), 42f. A 8 Abb. 11 (IG I 1195) (Grabmal des Sosineos; Stele), 63f. A 30 Abb. 41 (IG I ${ }^{3}$ 1232) (Grabmal des Antidotos; Kouros), 68 A 39 Abb. 46 (IG I ${ }^{3}$ 1244) (Grabmal des Aristodikos; Kouros), 256 C 17 Abb. 342 (IG I3 1256) (Grabmal des Aristion; Stele), 257f. C 19 Abb. 343, 344 (IG I³ 1217) (Grabmal des Kedeidos; Kouros).

127 Zum Funktionieren der Inschriften auf archaischer Skulptur und dem Vergleich zu Ornamenten: Dietrich 2017a, 298-309. 
konnten ebenso figürliche Bilder wie Inschriften angebracht werden, ${ }^{128}$ auf Leisten in gleicher Weise Inschriften wie Ornamentbänder. ${ }^{129}$ Diese Variabilität der Ausgestaltung der verschiedenen Monumentbereiche neben der Figur als Hauptbild zeigen auch die Blöcke der Quader- oder Stufenbasen sowie Pfeilerdeckblöcke, von denen sowohl beschriftete als auch mit figürlicher Darstellung bemalte oder reliefierte Exemplare erhalten sind. ${ }^{130}$

Dieses Phänomen kann sich darin begründen, dass nicht die tatsächliche Fertigung in zwei (oder mehr) Bestandteilen (Basis und Stele beziehungsweise Basis und Statue) eine konzeptionelle Teilung des Grabmals vorgibt, sondern vielmehr offenbar nur der Bereich der Figur von dem Bereich des Unterbaus unterschieden wurde. Auf der Stele gehört so visuell die Predella noch zum ,Unterbau' der Figur und trägt dementsprechend wie auch bisweilen die obersten Stufen der Basen bildliche Darstellungen oder Inschriften. ${ }^{131}$ Damit wird auch klar, warum sich die Optionen der Beschriftung von Grabmonumenten mit Stelen (Inschriften auf der Stele oder auf ihrem Unterbau) nicht gegenseitig ausschließen, wenn es eine Grabinschrift und eine Bildhauerinschrift gab. ${ }^{132}$ Bei diesen strebte man nämlich eine Separierung vonein-

128 Siehe etwa Kat. 1.12 gegenüber u. a. Athen, Nationalmuseum Inv. 2687, um 560 v. Chr.: Richter 1961, 22 Nr. 27 Abb. 83, 84 (Relief); New York, Metropolitan Museum of Art Inv. 38.11.13, um 520 v. Chr., Richter 1961, 32f. Nr. 45 Abb.126, 128 (Flachrelief), hier Abb.1.19; Rom, Museo Barracco Inv. unbekannt, um 525 v. Chr.: Richter 1961, 45f. Nr. 64 Abb. 154 (Relief); Athen, Nationalmuseum Inv. 1772, um 550 v. Chr.: Richter 1961, 48 Nr. 70 Abb. 159, 160 (gemalt); Athen, Agoramuseum Inv. S 1276a, 3. Viertel des 6. Jhs. v. Chr.: Richter 1961, 48f. Nr. 71 Abb. 163, 164 (gemalt).

129 Inschrift auf Abschlussleiste des Kapitells (Kat. 1.14) gegenüber Ornamenten auf der Abschlussleiste des Kapitells (vgl. etwa Athen, Nationalmuseum Inv. 41, Mitte 6. Jh. v. Chr.?, New York, Metropolitan Museum of Art Inv. 17.230.6, um 560 v. Chr.: Richter 1961, 18-20 Nr. 20, 21 Abb. 66-69, 74; vgl. auch Boston, Museum of Fine Arts Inv. 40.576, um 535/530 v. Chr.: Richter 1961, 29 Nr. 38 Abb. 110-114). Inschrift auf Leiste unter der Figur (Kat. 1.2, 1.5, 1.6, 1.16) gegenüber Ornamenten auf der Leiste unter der Figur (vgl. etwa Athen, Nationalmuseum Inv. 3071, um 530 v. Chr.: Richter 1961, 33 Nr. 46 Abb. 129, 176). Ähnlich ist dies in der Vasenmalerei etwa im Falle der attischen Kleinmeisterschalen, bei denen die gemalten Buchstaben wie Ornamente angeordnet sind (Hinweis N. Dietrich): vgl. Lissarrague 1990, 62. Diesbezüglich zu Kleinmeisterschalen auch: Wachter 2004; Heesen 2016. Vgl. zu gemalten ,Inschriften“ in der korinthischen Vasenmalerei als alternative Möglichkeit zu Ornamenten: Osborne/ Pappas 2007, bes. 145-147.

130 Die Grabinschrift wird im Falle einer reliefierten Stelenbasis in Athen, Kerameikos Museum Inv. P 1001 (Kissas 2000, 43f. A 10 Abb. 12) dann auf der Stele selbst angebracht gewesen sein. Die Deckblöcke von Pfeilerbasen können entweder beschriftet (Kissas 2000, 70f. A 41 Abb. 48, 49; IG I3 1344), beschriftet in Kombination mit einer bildlichen Darstellung (Kissas 2000, 71-73 A 42 Abb. 50, 51; IG I ${ }^{3}$ 1214; CEG I 42; DNO I 368) oder nur reliefiert gewesen sein (Kissas 2000, 74f. A 43 Abb. 52-54, 75 A 44 , 76 A 45 Abb. 55). Vgl. zu den reliefierten Basen: Kosmopoulou 2002, 43-55, 164-174.

131 Zum Zusammenhang zwischen Predellabereich der Stelen und reliefiertem Basisbereich siehe Kosmopoulou 2002, 50, 54.

132 Das Grabmonument des Aristion, eines der wenigen erhaltenen Fälle, bei denen die Stele zusammen mit der zugehörigen Basis erhalten ist, zeigt auf der Basis dessen Namen im Genetiv, während die Bildhauerinschrift sich auf der Leiste unter der Figur findet: Kat. 1.2. 
ander an, wie an späterer Stelle ausführlicher besprochen wird. Die Basis inklusive des Predellabereichs der Stele bot verschiedene Flächen, die man zur Ausgestaltung des Monuments durch Inschriften, Ornamente und weitere Bilder nutzte.

Zudem steigerte sich diese Ausstattung sowie die Wahl der Steinmaterialien in ihrer Intensität von unten nach oben. ${ }^{133}$ Wie für die unteren Stufen von Stufenbasen keine Reliefierung überliefert ist und diese meist aus einem anderen Stein als Marmor bestehen, ${ }^{134}$ befinden sich an dieser Stelle in der Regel keine Inschriften. Nur in solchen Fällen lassen sich Inschriften greifen, wenn dieser Bereich bereits eine weitere Aufwertung durch eine marmorimitierende helle Stuckierung erfahren hat. ${ }^{135}$ Je reicher also das Grabmal mit gemalten und reliefierten Bildern, Ornamenten und Marmor ausgestattet werden sollte, desto mehr nutzte man hierfür weitere Bereiche im Unterbau.

Inschriften am Grabmal können damit als ein Element der visuell reichen Ausgestaltung des gesamten Grabmonumentes verstanden werden. Sie fügten sich in variable, für Inschrift, Ornament oder Bilder optional nutzbare Partien ein, die sich vor allem im unteren Bereich des Monumentes befinden; war keine figürliche Repräsentation des Verstorbenen auf einer Grabstele dargestellt, beschrieb man auch den mittleren Bereich des Stelenkörpers. Dies deutet bereits an, dass sich die Funktion der Inschriften für das Grabmal keineswegs auf ihren Inhalt beschränkte, sondern dass ihrer ästhetischen Präsentation Bedeutung zugemessen wurde; doch hierzu an späterer Stelle. Für den Moment ist festzuhalten, dass nicht ein möglicher Zusammenhang zur Figur bestimmte, in welchem Bereich des Grabmals die Inschrift eingemeißelt wurde.

\section{Gestaltung der Grabinschrift als formaler Indikator für einen Zusammenhang zwischen Inschrift und Figur?}

Obwohl kein Zusammenhang zwischen Figur und Grabinschrift über eine direkte räumliche Nähe gesucht wurde, könnte ein Zusammenhang auch durch das ,Layout' der Inschrift unterstützt werden, wenn etwa der Name besonders hervorgehoben würde, wie dies etwa bei späteren Ehreninschriften vorkommt. Auf der Basis der

133 Hierauf wies N. Dietrich in einem Vortrag zum Thema „Die Rückseite als ästhetisches Problem. Strategien der Inszenierung figürlicher Pracht in der griechisch-römischen Antike“, gehalten u. a. am 05.06.2013 in Berlin, Humboldt-Universität, Winckelmann-Institut, hin.

134 Vgl. etwa den Materialwechsel in dem vierstufigen Unterbau eines Grabmonumentes aus Vourva (Athen, Nationalmuseum Inv. 81, um 550/540 v. Chr.: Kissas 2000, 46f. A 13 Abb. 17; IG I³ 1251; CEG I 18; DNO I 359) oder bei dem mehrstufigen Unterbau des Grabmonument des Kroisos, um 530 v. Chr. (Athen, Nationalmuseum Inv. 4754 und $3851 \alpha, \beta$, y: Pavlina Karanastasis, in: Despinis/ Kaltsas 2014, 207-211 I.1.185 $\alpha$ Abb. 658-663 (mit Lit.); Kissas 2000, 54f. A 20 Abb. 28-30; IG I³ 1240; CEG I 27).

135 Vgl. die vier Fälle, bei denen es sich nach Kissas um eine beschriftete untere Stufe einer Stufenbasis handelt: Kissas 2000, 56f. A 22 (IG I³ 1205; CEG I 38), 64 A 31 (IG I³ 1226; CEG I 61), 64f. A 32 Abb. 42 (IG I3 1227; CEG I 60), 65 A 33 (IG I3 1236; CEG I 73). Alle bestehen aus Kalkstein, bei drei der vier ist die Stuckierung nachgewiesen (A 22, A 31, A 33), für A 32 ist eine Stuckierung anzunehmen. 
frühhellenistischen Ehrenstatue für Menander im Dionysos-Theater in Athen ist so der Name von den Seiten eingerückt und dabei zentriert auf dem Postament eingemeißelt, während die Bildhauerinschrift weiter unten in kleinerer Schriftgröße die gesamte Postamentbreite ausfüllt (Abb. 0.3b). ${ }^{136}$ Sehr ähnlich verhält sich die Inschrift auf der wenig später als 350 v. Chr. entstandenen Basis einer Ehrenstatue für Philoumene von der Athener Akropolis. ${ }^{137}$ Hier unterstützt das Layout die Hervorhebung der Namen, was damit vielleicht sogar eine zusätzliche Verbindung zwischen dem Namen und der Statue bedingt haben kann: In der ersten Zeile steht nämlich allein und zentriert der Name der Philoumene. Gleichzeitig bildet der Name den Beginn der Weihinschrift an Athena, die sich in der zweiten und dritten Zeile fortführt. Ebenso wie Philoumene ist auch der Name der Athena durch eine Zentrierung und Alleinstellung in der dritten Zeile hervorgehoben.

Die archaischen Grabinschriften zeigen dagegen keine Größenunterschiede einzelner Wörter oder Textpartien (mit Ausnahme zweier Bildhauerinschriften im Verhältnis zur Grabinschrift) ${ }^{138}$ und mit Ausnahme der Absetzung der Bildhauerinschrift, auf die im Folgenden noch näher eingegangen wird, keine Absetzung einzelner Teile des Textes von anderen. ${ }^{139}$ So ist keine Betonung des Namens des Verstorbenen durch Absetzung, Größenunterschied oder Position an besonderen Stellen wie dem Anfang der ersten Zeile einer Inschrift festzustellen. In einzelnen Fällen mag es eine derartige Intention gegeben haben: Auf der Basis des Grabmonuments des Aischros im Athener Kerameikos Museum (Abb.1.10) ${ }^{140}$ beginnt die kurze Inschrift mit den Namen des Verstorbenen im Genetiv. Während die Buchstabenabstände in der Inschrift sonst auffällig unregelmäßig sind und sogar innerhalb eines Wortes stark variieren, setzte der Schreiber nach dem Namen ein Dreipunkt-Zeichen, wohl um diesen abzusetzen. Solche Zwei- oder Dreipunkt-Zeichen werden aber nicht nur für die Absetzung von Namen verwendet, ${ }^{141}$ sondern stehen grundsätzlich mit dem Textinhalt beziehungsweise seiner Struktur in Verbindung, da sie Texteinheiten ${ }^{142}$, einzelne

136 Zur Basis des Ehrenmonuments (Inv. NK 279) und der Inschrift (IG II/III2 3777; DNO III 2387) siehe u. a.: Fittschen 1991, 268-270; Papastamati-von Moock 2007, bes. 277-280 mit Abb.1, 2; Taf. 36-38.

137 Athen, Akropolis Inv. 2970, s. Matthaiou 1994, 174-182 Abb. 10.1, 10.4 (SEG 44, 136; DNO III 1843). 138 Kissas 2000, 61f. A 28 (Philergos; IG I ${ }^{3}$ 1365; CEG I 52; DNO I 378), vgl. Viviers 1992, 103-113 Abb. 18; Hurwit 2015, 127; Kissas 2000, 63f. A 30 Abb. 41 (Kallonides; IG I³ 1232; DNO I 411). S. hierzu auch unten.

139 Eine Möglichkeit der visuellen Separierung wäre die unterschiedliche farbige Fassung. Hierfür sind für die archaischen Grabinschriften meines Wissens nach keine Belege erhalten. Meist findet sich alleine Rot in den Buchstaben; hierzu weiter unten.

140 Athen, Kerameikos Museum Inv. I 189, um 520 v. Chr.: Kissas 2000, 61 A 27 Abb. 39 (IG I I3 1366).

141 Kissas 2000, 43 A 9 (IG I3 1196, CEG I 14; DNO I 358), 46f. A 13 Abb.16, 17 (IG I3 1251; CEG I 18; DNO I 359); vgl. Lougovaya-Ast 2017, 28, 35.

142 Kissas 2000, 43 A 9 (IG I3 1196, CEG I 14; DNO I 358), 46f. A 13 Abb.16, 17 (IG I³ 1251; CEG I 18; DNO I 359), 54f. A 20 Abb. 28-30 (IG I I $^{3} 240$; CEG I 27), 57-59 A 23 Abb. 33-36 (IG I3 1266; CEG I 32), 59 A 24 Abb. 37 (IG I3 1204; CEG I 28), 60 A 26 (IG I $\left.\mathrm{I}^{3} 1349\right), 61$ A 27 Abb. 39 (IG I3 1366), 65f. A 35 (IG I3 1276), 


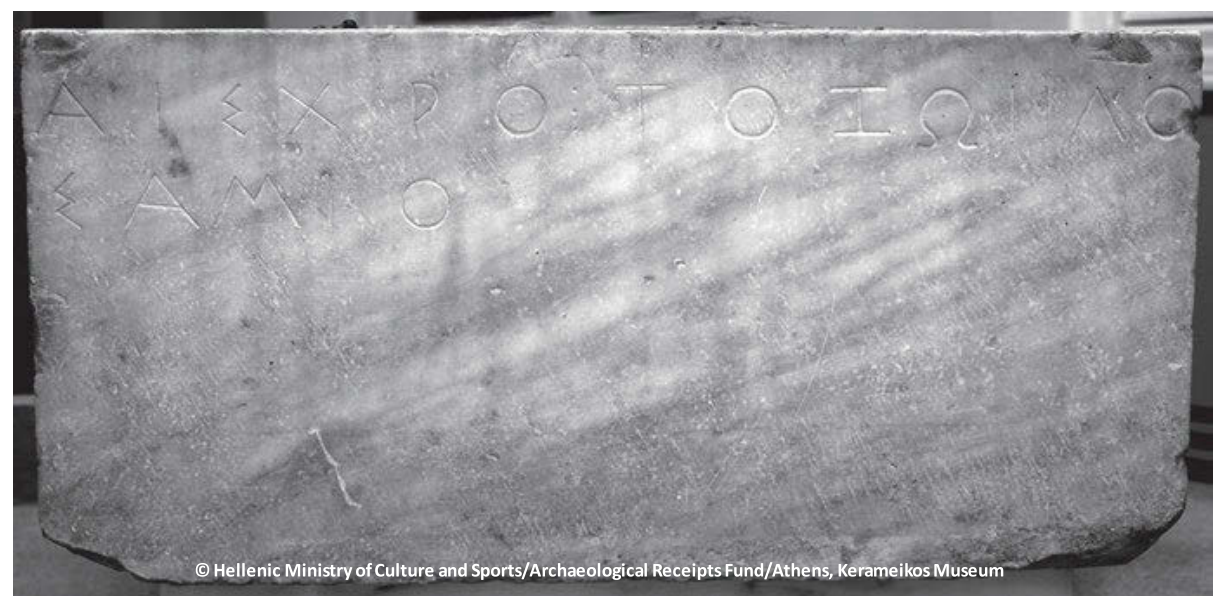

Abb.1.10: Basisblock des Grabmonumentes des Aischros, um 520 v. Chr. (Athen, Kerameikos Museum I 189).

Wörter ${ }^{143}$ oder, dann auch zum Teil als einzige Interpunktion in der Inschrift, Metrumgrenzen ${ }^{144}$ markieren. ${ }^{145}$ Der Betrachter kann die Bedeutung des Zwei- oder Dreipunkt-Zeichens aber erst während des Lesevorgangs auflösen, da es nicht nur für eine spezifische Funktion etabliert ist.

Durch die Verwendung des einzelnen Dreipunkt-Zeichens nach dem an erster Stelle stehenden Namen des Aischros stellte man bei diesem Beispiel den Namen durchaus prominent heraus. Nimmt man den auf der Basis aufgestellten - heute verlorenen - Kouros dazu, könnte der Betrachter des Grabmals beim Ansehen der Figur

70f. A 41 Abb. 48, 49 (IG I3 1344), 79f. A 48 Abb. 61 (?) (IG I3 1264), 249f. C 5 (?) (IG I3 1241; CEG I 25), 253 C 12 Abb. 339 (IG I $\mathrm{I}^{3}$ 1229), Kat. 1.12.

143 Kissas 2000, 43 A 9 (IG I3 1196, CEG I 14; DNO I 358), 46f. A 13 Abb. 16, 17 (IG I ${ }^{3}$ 1251; CEG I 18), 50 A 17 Abb.22 (IG I3 1234; CEG I 69), 54f. A 20 Abb.28-30 (IG I' 1240; CEG I 27), 57-59 A 23 Abb. 33-36 (IG I3 1266; CEG I 32), 59 A 24 Abb. 37 (IG I3 1204; CEG I 28), 60 A 26 (IG I3 1349), 61 A 27 Abb. 39 (IG I3 1366), 64f. A 32 Abb. 42 (IG I3 1227; CEG I 60), 65f. A 35 (IG I3 1276), 253 C 12 Abb. 339 (IG I3 1229; CEG I 54; DNO I 377), Inschrift auf einem Kapitell, das eine Grabstele bekrönte (Kat. 1.14).

144 Als Interpunktion nur für Metrumgrenzen: Kissas 2000, 39f. A 4 Abb. 7, 8 (IG I I 1200; CEG I 19), 41f. A 7 Abb. 10 (IG I3 1219), 44f. A 11 Abb. 13 (3 x) (IG I3 1194bis; CEG I 13), 50 A 17 Abb. 22 (IG I3 1234; CEG I 69), 62f. A 29 Abb. 40 (2x) (IG I3 1357; CEG I 58), 66 A 36 Abb. 43 (2x) (IG $\mathrm{I}^{3} 1380 ;$; CEG I 66), 249 C 4 (IG I3 1277; CEG I 68); im Kontext mehrerer Punkt-Zeichen: Kissas 2000, 43 A 9 (IG I3 1196; CEG I 14; DNO I 358), 46f. A 13 Abb. 16, 17 (IG I3 1251; CEG I 18; DNO I 359), 54f. A 20 Abb. 28-30 (IG I3 1240; CEG I 27), 57-59 A 23 Abb. 33-36 (IG I3 1266; CEG I 32), 59 A 24 Abb. 37 (IG I I $^{3} 1204$; CEG I 28), 253 C 12 Abb. 339 (IG I3 1229; CEG I 54; DNO I 377). Zu den Zeichen im Rahmen von Versinschriften u. a. Dihle 2008; vgl. aber auch die in der folgenden Anm. genannten Verweise.

145 Vgl. zu den Punktzeichen und ihrer Verwendung: Lougovaya-Ast 2017; Kaczko 2016, 39f. ad Nr. 8; Dihle 2008; Ecker 1990, 236-239; Threatte 1980, 73-84; bes. zu ihrer Bedeutung in der HekatompedonInschrift: Butz 2010, 55-75. Bes. zu Beispielen in archaischen Akropolis-Weihinschriften: Raubitschek in $D A A$, S. 441-444. 
und Entziffern der Inschrift einen engen Text-Bild-Bezug annehmen; dies wird jedoch nur die grundsätzlich bestehende Verbindung zwischen Name und Figur an diesem Monument, die sich beide auf die Person des Verstorbenen beziehen, bestätigt haben. Da sich ein solches Vorgehen aber nur in einzelnen Fällen nachweisen lässt - das Grabmal des Antilochos ${ }^{146}$ wäre ein vergleichbarer Fall -, ist dies zwar wie beschrieben für die Rezeption des gesamten Monumentes und das Entstehen von Text-Bild-Bezügen ein bemerkenswertes Beispiel, es lässt sich aber vor dem Hintergrund der sonstigen Verwendung von Punkt-Zeichen in Inschriften keine etablierte Layoutstrategie zu diesem Zweck nachweisen.

In diesem Zusammenhang stellt sich auch die Frage, wo in der Inschrift überhaupt der Name des Toten genannt wird. In den meisten Fällen präsentiert die erste Zeile der Inschrift den Namen. Dies ist jedoch vor allem durch das Inschriftenformular bestimmt, etwa in den Fällen, wenn die Grabinschrift mit „sêma des N. N.“ beginnt. Dabei gibt es aber keine Regel, gemäß der dieser besonders oft am Anfang der Zeile oder an andere Stelle steht. ${ }^{147}$ In mehreren Fällen wird der Name des Verstorbenen sogar durch das Blockende getrennt und in der zweiten Zeile fortgeschrieben. ${ }^{148}$ Dies zeigt, dass, obwohl der Name des Verstorbenen von entscheidender Bedeutung für das Grabmonument war, dieser in der Gestaltung der Inschrift nicht grundsätzlich besonders hervorgehoben wurde. Auch hier sind also unterschiedliche Faktoren für die Position des Namens anzunehmen, unter denen in einzelnen Fällen wie bei Aischros auch der Wunsch nach einer Hervorhebung des Namens gewesen sein dürfte.

Ähnliches zeigte bereits die Lage der ganzen Inschrift am Grabmal. Der Name konnte zwar durch die Position der Inschrift gleichzeitig mit der dargestellten Figur wahrgenommen werden; wie die Inschriften auf den Stufenbasen und auf den Stelen

146 Auf dem obersten Block der Stufenbasis, die eine Säule und darauf möglicherweise einen Kouros trug, steht in vier Zeilen die Versinschrift, die mit dem Namen des Antilochos im Genetiv beginnt, der von der fortführenden Inschrift durch ein Zweipunktzeichen abgesetzt wird. Dies ist die einzige Interpunktion in der Inschrift. Eine besondere Nähe der Inschrift (und damit des Namens) zu dem auf der Säule vielleicht zu rekonstruierenden Kouros wurde aber offenbar nicht gesucht, da die Inschrift auf der Stufenbasis und nicht auf dem Kapitell steht. Stand auf der Säule aber ursprünglich kein Kouros, wird der Betrachter die Hervorhebung des Namens rein textimmanent verstanden haben. Athen, Epigraphisches Museum Inv. 10647, 10648, 10649, drittes Viertel des 6. Jhs. v. Chr. Zur Basis und der Inschrift: Kissas 2000, 51 A 18 Abb. 23-26 (IG I³ 1208; CEG I 34; DNO I 347); vgl. auch Lougovaya-Ast 2017, 35.

147 Für eine quantitative Untersuchung bieten sich die bei Kissas (Kissas 2000) aufgeführten Statuen- und Stelenbasen mit Inschriften an: Von den 37 Basisblöcken mit Inschriften, bei denen der Name erhalten ist, findet sich der Name in 30 Fällen in der ersten Inschriftenzeile; davon bestehen aber sechs nur aus dem Namen, bei fünf wird der Name durch das Blockende getrennt und führt sich in der zweiten Zeile fort. Die einzelnen Namensnennungen ausgenommen, die hierfür nicht aussagekräftig sind, findet sich nur bei neun Exemplaren der Name als erstes Wort der ersten Zeile.

148 Kissas 2000, 59f. A 25 Abb. 38 (IG I 1243; CEG I 40), $70 \mathrm{f}$. A 41 Abb. 48, 49 (IG I3 1344), 71-73 A 42 Abb. 50, 51 (IG I3 1214; CEG I 42; DNO I 368), 250f. C 8 (IG I3 1216; CEG I 45), 258 C 20 (IG I3 1260; CEG I 72). 
gezeigt haben, wählte man aber nicht immer den Bereich, der der Figur am nächsten lag, zur Anbringung der Inschrift.

Aus diesem Befund lässt sich daher keine positive Evidenz für einen die archaischen attischen Grabmäler kennzeichnenden formalen Zusammenhang zwischen Figur und Name feststellen, der sich mit den formalen Strategien von Beischriften in der attischen Vasenmalerei vergleichen ließe. Vielmehr scheinen bei diesen Inschriften andere Aspekte wie etwa die Homogenität der Inschriftenzeilen und die dadurch erreichte ornamenthafte Wirkung auf die Position der Inschriften Einfluss genommen zu haben, wie an späterer Stelle dargelegt wird.

\section{Position der Bildhauerinschrift im Verhältnis zur Grabinschrift}

In diesem Zusammenhang ist noch einmal auf die Position der Bildhauerinschriften zurückzukommen, da wir hierbei die Frage nach der Gestaltung und Lage von Inschriften in Bezug auf unterschiedliche Textinhalte untersuchen können. Es wird sich zeigen, dass sich Bildhauerinschriften in den meisten Fällen mithilfe unterschiedlicher gestalterischer Mittel von der Grabinschrift absetzten. Bevor aber die Gründe dieser Trennung im Fokus stehen, sind einige Anmerkungen zur Inschriftgestaltung und dem Textinhalt der Grabinschriften vorauszuschicken. Grabinschriften sind entweder im Versmaß oder in Prosa verfasst. Und sie enthalten in fast allen Fällen einen direkten Verweis auf das Grabmal selbst, welcher zugleich den Namen des Verstorbenen angibt. ${ }^{149}$ Sollte auf dem Grabmal neben der Grabinschrift eine Bildhauerinschrift angebracht werden, standen sich also unterschiedliche Inschrifteninhalte in oftmals verschiedener metrischer Struktur gegenüber. Bildhauerinschriften sind insgesamt an mindestens $19^{150}$ archaischen attischen Grabmonumenten erhalten, wobei

149 Vgl. zu den Typen der Grabinschriften: Sourvinou-Inwood 1995, bes. 147-180. Die Nennung des Grabmals kann entweder eingebettet sein in einen weiteren Kontext, wenn etwa die Errichtung des Grabmals durch eine bestimmte Person thematisiert wird, wie am Grabmal des Epikles, Athen Epigraphisches Museum Inv. 10645, drittes Viertel des 6. Jhs. v. Chr. (IG I ${ }^{3}$ 1243): Ṭỏ

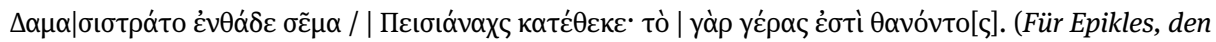
Sohn des Damasistratos, hat hier das Grabmal Peisianax errichtet. Der Ruhm aber gebührt dem Toten. Übs. auf Grundlage der Übs. von K. Hallof [leicht verändert]); siehe auch Kissas 2000, 59f. A 25 Abb. 38. Oder die Nennung des Grabmals erfolgt als Ausgangspunkt der Trauer um den Verstorbenen beziehungsweise der Erinnerung an ihn, etwa am Grabmal des Thrason, Athen, Epigraphisches Museum Inv. 10639, drittes Viertel des 6. Jhs. v. Chr. (IG I3 1204): Kissas 2000, 59 A 24 Abb. 37. Einen Verweis auf den Ort des Grabes gibt es seltener, vgl. etwa Grabmonument des Alkimachos, Athen, Kerameikos Museum Inv. I 326, drittes Viertel des 6. Jhs. v. Chr. (IG I³ 1234; Kissas 2000, 50 A 17 Abb. 22). Im Falle des Grabmonument des Tetichos, Athen, Epigraphisches Museum Inv. 10650, ca. Mitte 6. Jh. v. Chr. (IG I ${ }^{3}$ 1194bis; Kissas 2000, 44f. A 11 Abb.13) wird das Grabmal oder das Grab nicht direkt erwähnt, bleibt aber dennoch Bezugspunkt im Epigramm: Sourvinou-Inwood 1995, $148 \mathrm{f}$.

150 Siehe im Folgenden. Bei Kissas 2000, 46 A 12 Abb. 14, 15 (IG I³ 1242; DNO I 372) ist jedoch unklar, ob es sich tatsächlich um eine Bildhauernennung handelt. 
ein Beispiel zu fragmentiert erhalten ist, um den Zusammenhang zur Grabinschrift untersuchen zu können: ${ }^{151}$

Darunter sind sieben Grabmäler, die die Bildhauerinschriften in einem von der Grabinschrift separierten Bereich zeigen: Dabei ist bei drei Nennungen des Bildhauers Aristion die Bildhauerinschrift auf einer anderen Basisseite angebracht (Abb. 2.13b). ${ }^{152}$ In mindestens drei weiteren Fällen anderer Bildhauer steht sie auf einer Leiste unter der Figur auf einer Stele (Abb.1.6b), ${ }^{153}$ während die Grabinschrift in einem anderen Feld eingemeißelt wurde. Hier schließt sich auch das Grabmonument des Neilonides ${ }^{154}$ an, bei dem Bildhauerinschrift und Grabinschrift zwar dieselbe Seite des Pfeilerdeckblocks nutzen, diese Blockseite jedoch durch eine Figur in zwei Bereiche getrennt wird (Abb.1.2).

An den anderen elf Grabmälern teilen sich beide Inschriften auch denselben Bereich, also beispielsweise dieselbe Basisseite. Hier wurde aber meist zwischen beiden visuell getrennt: Als zwei Teile waren sie erkennbar durch eine signifikant unterschiedliche Buchstabengröß $\mathrm{e}^{155}$, einen Abstand zueinander ${ }^{156}$ oder einen neuen

151 Kissas 2000, 253f. C 13 Abb. 340 ( $I G \mathrm{I}^{3}$ 1222).

152 Kissas 2000, 47 A 14 (IG I3 1261; CEG I 24; DNO I 348), 51 A 18 Abb. 23-26 (IG I3 1208; CEG I 34; DNO I 347), 51-54 A 19 Abb. 27 (IG I3 1211; CEG I 41; DNO I 349).

153 Kat. 1.2. Eine Stele in New York (Kat. 1.16) zeigt eine ähnliche Position. Hier ist jedoch unbekannt, wo sich die Grabinschrift befunden hat. Auch eine Grabstele im Athener Kerameikos Museum (Kat. 1.6) zeigt eine Bildhauerinschrift auf einer Leiste unter der (sitzenden) Figur; Willemsen ergänzte hier Aristokles als Bildhauer: Willemsen 1970, 36-38. Da der untere Abschluss der Stele erhalten ist, wird sich die Grabinschrift wahrscheinlich auf der Basis befunden haben. Ob die sehr fragmentierte Inschrift auf einer weiteren Grabstele (Kat. 1.5) tatsächlich die Reste einer Bildhauerinschrift trägt, wie vorgeschlagen wurde (Willemsen 1970, 35f.), ist allerdings nicht gesichert.

154 Siehe Anm. 82.

155 Kissas 2000, 61f. A 28 (Philergos; IG I³ 1365; CEG I 52; DNO I 378), vgl. Viviers 1992, 103-113 Abb.18; Hurwit 2015, 127; Kissas 2000, 63f. A 30 Abb. 41 (Kallonides; IG I³ 1232; DNO I 411). Zu der unterschiedlichen Schriftgröße kann in einigen Fällen auch das Bemühen, die Blockbreite zu füllen, geführt haben, siehe weiter unten.

156 Kissas 2000, 70f. A 41 Abb. 48, 49 (Aristokles; IG I3 1344; DNO I 375), neben dem Zeilenabstand wies auch das fehlende rote Band auf eine Trennung hin. Kissas 2000, 79 A 47 (Aristion von Paros zugeschrieben; IG I3 1269; CEG I 36; DNO I 350): eine Kannelur Abstand (vgl. Raubitschek 1939b, Abb. 17 oben). Kissas 2000, 253 C 12 Abb. 339 (Aristokles; IG I³ 1229; CEG I 54; DNO I 377). Auf den ersten Blick scheint die Inschrift Zeilen vollständig zu füllen; es gibt nur einen Zwischenraum in der zweiten Zeile, der durch zwei Punkt-Zeichen getrennt ist. Rechts des Zwischenraums steht gehend vom rechten Blockrand geschrieben. Gemäß dem Textinhalt und dem elegischen Distichon gehört dieses Wort an das Ende der ersten Zeile. Der Textinhalt und damit der zweite Teil des elegischen Distichons führt dann mit Beginn an der linken Blockseite fort und läuft dann in der dritten Zeile der Inschrift weiter. Bei diesem Block gibt die Lücke in der zweiten Zeile dem Leser den Hinweis darauf, dass der rechts davon befindliche Teil, der retrograd geschrieben ist, noch der ersten ,Zeile‘ zugehört. Ein solches Vorgehen - die formale Zuordnung von Wörtern oder Wortteilen zur ersten Zeile durch das retrograde Schreiben am rechten Blockrand, lässt sich mehrfach feststellen (vgl. auch Kissas 2000, 46f. A 13 Abb. 16, 17 [IG I³ 1251; CEG I 18; DNO I 359], 64f. A 32 Abb. 42 [IG I³ 1227; CEG I 60], 
Zeilenbeginn ${ }^{157}$, wenn die vorherige Zeile nicht vollständig gefüllt wurde, was ebenfalls einen visueller Marker für das inhaltliche Ende darstellt. Dabei treten die Phänomene auch kombiniert auf. Die Differenzierung musste deutlich erkennbar sein ein geringfügiger Größenunterschied der Buchstaben oder eine andere, aber ähnliche Schreiberhand bei sonst homogenem Gesamteindruck dürfte nicht dazu geführt haben, dass der Betrachter ohne die Inschrift zu lesen den inhaltlichen Unterschied erkannt hätte. ${ }^{158}$

Unter den fünf Fällen, in denen sich keine auffällige Differenzierung feststellen lässt, ${ }^{159}$ sind zwei, die die Bildhauernennung in den Vers der Grabinschrift integrieren: Im Fall der Grabinschrift für eine weibliche Verstorbene ${ }^{160}$ bildet so die Bildhauernennung des Phaidimos den zweiten Teil des Pentameters des elegischen Distichons. Auf der Stele des Archias und seiner Schwester (Kat. 1.12, Abb.1.11), deren Grabinschrift in drei jambischen Trimetern verfasst ist, ist die Bildhauernennung des Phaidimos ebenfalls Teil des Verses. ${ }^{161}$

65f. A 35 [IG $\left.\mathrm{I}^{3} 1276\right]$ ), auch wenn in diesen Fällen der Text damit endet. Diese Fortführung machte jedoch eine betonte Lücke notwendig.

157 Kissas 2000, 46 A 12 Abb.14, 15 (IG I3 1242; DNO I 372) (hier ist aber unklar, ob es sich um eine Bildhauerinschrift handelt: vgl. die Anmerkungen in DNO I zu Nr.372).

158 Kissas 2000, 55f. A 21 Abb. 31, 32 (Aristokles; IG I 1218; CEG I 50; DNO I 376) Die Bildhauerinschrift ist etwas größer und soll von anderer Hand geschrieben sein: Willemsen 1963, 136; DNO I zu Nr. 376. Der geringfügige Größenunterschied fällt kaum ins Gewicht. Die unterschiedliche Schreiberhand dürfte dem Leser erst bei sehr genauem Betrachten aufgefallen sein (vgl. E und P), da sich andere Buchstaben kaum unterscheiden und die Bildhauerinschrift sich formal eher in ein homogenes Bild einfügt, berücksichtigt man Verteilung und grundsätzliche Anordnung der Buchstaben. Die Unterschiede in der Buchstabengröße sind auch bei folgenden Beispielen eher nachrangig: Kissas 2000, 70f. A 41 Abb. 48, 49 (Aristokles; IG I3 1344; DNO I 375); Kissas 2000, 253 C 12 Abb. 339 (Aristokles; $I G \mathrm{I}^{3}$ 1229; $C E G$ I 54; DNO I 377). Inwiefern die leichten Unterschiede in den Inschriften IG $\mathrm{I}^{3} 1256$ (Kissas 2000, 256 C 17 Abb. 342; DNO I 374 = Kat. 1.2) und SEG 49, 505 (Andreiomenou 1999; DNO I 380) tatsächlich eine andere Schreiberhand bedeuten, scheint mir nicht zwingend. Vielleicht bedingte auch die unterschiedliche Größe der Buchstaben oder die Orientierung der Inschrift die Unterschiede. Schmaltz dagegen geht von einer unterschiedlichen Schreiberhand bei der Grabstele des Aristion (Kat. 1.2) aus, was er als Argument für eine Zweiphasigkeit der Inschriften heranzieht: Schmaltz 2005, 170. Dies überzeugt vor dem Beispiel des Grabmals des Xenophantos (Kissas 2000, $55 f$. A 21 Abb. 31, 32; IG I3 1218; CEG I 50; DNO I 376) und der Stele für Mnasitheos (Andreiomenou 1999; SEG 49, 505; $D N O$ I 380) nicht restlos, da diese ebenfalls Unterschiede zeigen, jedoch keine anderen Hinweise auf eine Zweiphasigkeit vorliegen.

159 Kissas 2000, 43 A 9 (Phaidimos; IG I3 1196; CEG I 14; DNO I 358), 46f. A 13 Abb. 16, 17 (Phaidimos; $I G \mathrm{I}^{3}$ 1251; CEG I 18; DNO I 359), Kat. 1.12 (Phaidimos), Kissas 2000, 66 A 36 Abb. 43 (Endoios; IG I3 1380; CEG I 66; DNO I 367), 55f. A 21 Abb. 31, 32 (Aristokles; IG I3 1218; CEG I 50; DNO I 376), vgl. Anm. zuvor. 160 Athen, Nationalmuseum Inv. 81, um 550/540 v. Chr.: Pavlina Karanastasis, in: Despinis/Kaltsas 2014, 43-46 Abb. 72-77; Kissas 2000, 46f. A 13 Abb. 16, 17; IG I3 1251; CEG I 18; DNO I 359.

161 Die Wortwahl ist auf den ersten Blick ungewöhnlich, da Phaidimos' Anteil an der Herstellung

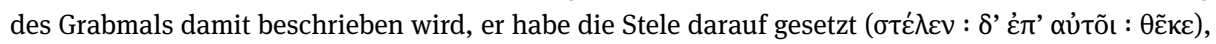

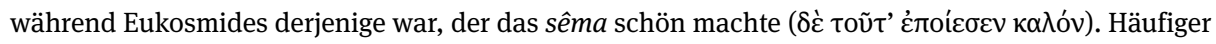

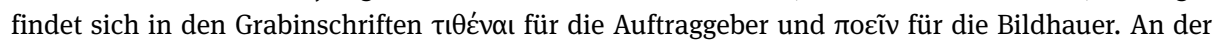


Eine solche Integration bezog die Leistung des Bildhauers in den Inhalt der Grabinschrift ein. Dieses Vorgehen war nicht oft möglich, da Bildhauerinschriften sich nur schwer in ein Versmaß einfügen ließen. Sie bestehen in der Regel nur aus dem Namen und einer Form von roعĩv.

Bei den drei anderen Fällen bestand keine auffällige Differenzierung zwischen beiden Inschriften wie bei den Beispielen zuvor. Es lässt sich jedoch auch bei ihnen eine Separierung nachweisen. Der Unterschied wird jedoch erst während des genaueren, intensiven Betrachtens beim Entziffern der Inschrift und dem damit in Verbindung stehenden Leseakt sichtbar. Hier sind einerseits die Zwei- oder Dreipunkt-Zeichen zuzurechnen, wenn diese zwischen Grabinschrift und Bildhauerinschrift stehen, wie es das Grabmal des Chairedemos und das der Lampito (Abb.1.12) bezeugen. ${ }^{162}$

Bei beiden steht ein solches Zeichen zwischen der im elegischen Distichon verfassten Grabinschrift und der nicht in einem Versmaß verfassten Bildhauerinschrift. Es strukturiert die ganze Inschrift also in verschiedene Teile, genau wie das Zeichen bereits die Grabinschrift in Hexameter und Pentameter gliedert. Da die Zwei- oder Dreipunkt-Zeichen nicht, wie zuvor dargelegt, ausschließlich Grabinschrift und Bildhauerinschrift trennen, ist diese ästhetische Differenzierung für den Betrachter ohne das Lesen nicht zu verstehen. Zunächst deutet das Zeichen durch seinen auffälligen visuellen Effekt allein eine Strukturierung des Textes an, die aber erst im Lesevorgang aufgelöst werden kann. Bis zu diesem Zeitpunkt sind die Inschriften jedoch ästhetisch homogen und damit als Einheit verstanden.

Auch beim Grabmonument des Xenophantos (Abb.1.13) gab es trotz direktem Anschluss der Bildhauerinschrift an die Grabinschrift eine ästhetische Unterstützung für die inhaltliche Trennung der Bestandteile der Inschrift(en). Beide unterscheiden sich

Identität des Phaidimos als Bildhauer besteht aber kein Zweifel (vgl. zu ihm die Bildhauerinschriften DNO I 358-360). Es ist m. E. unwahrscheinlich, dass Eukosmides ein zweiter Bildhauer war (siehe zu

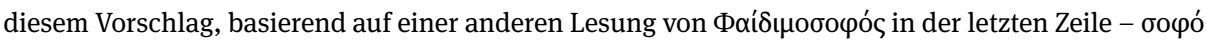
als duale Form бo $\varphi \omega ́$ und dies retrograd geschrieben: Löschhorn 2007, 272-274 Anm.16). Vielmehr wird es sich hierbei um den Auftraggeber gehandelt haben (siehe so auch Klaus Hallof und Sascha

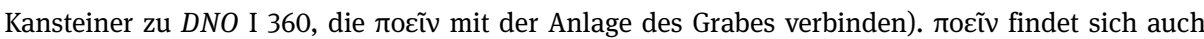
in anderen archaischen Grabinschriften für die Auftraggeber: siehe u. a. das Grabmal des -erylides: Kissas 2000, 64 A 31 (IG I3 1226; CEG I 61); das Monument des Menekrates auf Corfu: CEG I 143; Ecker 1990, 88-110; das Monument des Praxiteles in Troizen: IG IV 800; CEG I 139; Ecker 1990, 120-131; eine Inschrift aus der Nähe von Methana: CEG I 137; von Premerstein 1909; Häusle 1980, 2f.; das Grabmonument des Idameneus aus Camirus/Rhodos: IG XII 1, 737; Gallavotti 1975/1976, 73-76. Siehe hierzu auch demnächst Reinhardt (im Druck).

162 Grabmal der Lampito: Athen, Epigraphisches Museum Inv. 10643, 4. Viertel des 6. Jhs. v. Chr.: Kissas 2000, 66 A 36 Abb. 43; IG I ${ }^{3}$ 1380; CEG I 66; DNO I 367. Bei dem Grabmal des Chairedemos (New York, Metropolitan Museum of Art Inv. 16.174.6, um 560/550 v. Chr.: Kissas 2000, 43 A 9; CEG I 14) kann nach $I G \mathrm{I}^{3} 1196$ ein solches Punkt-Zeichen ebenfalls an dieser Stelle rekonstruiert werden. Im Basisblock befindet sich in der letzten Zeile genau an dieser Stelle eine ausgebrochene Partie. Aufgrund der Wörter im Umfeld und der Größe der Lücke passt hier genau ein Dreipunkt-Zeichen hinein, wie es auch in den Zeilen zuvor mehrfach vorhanden ist. 


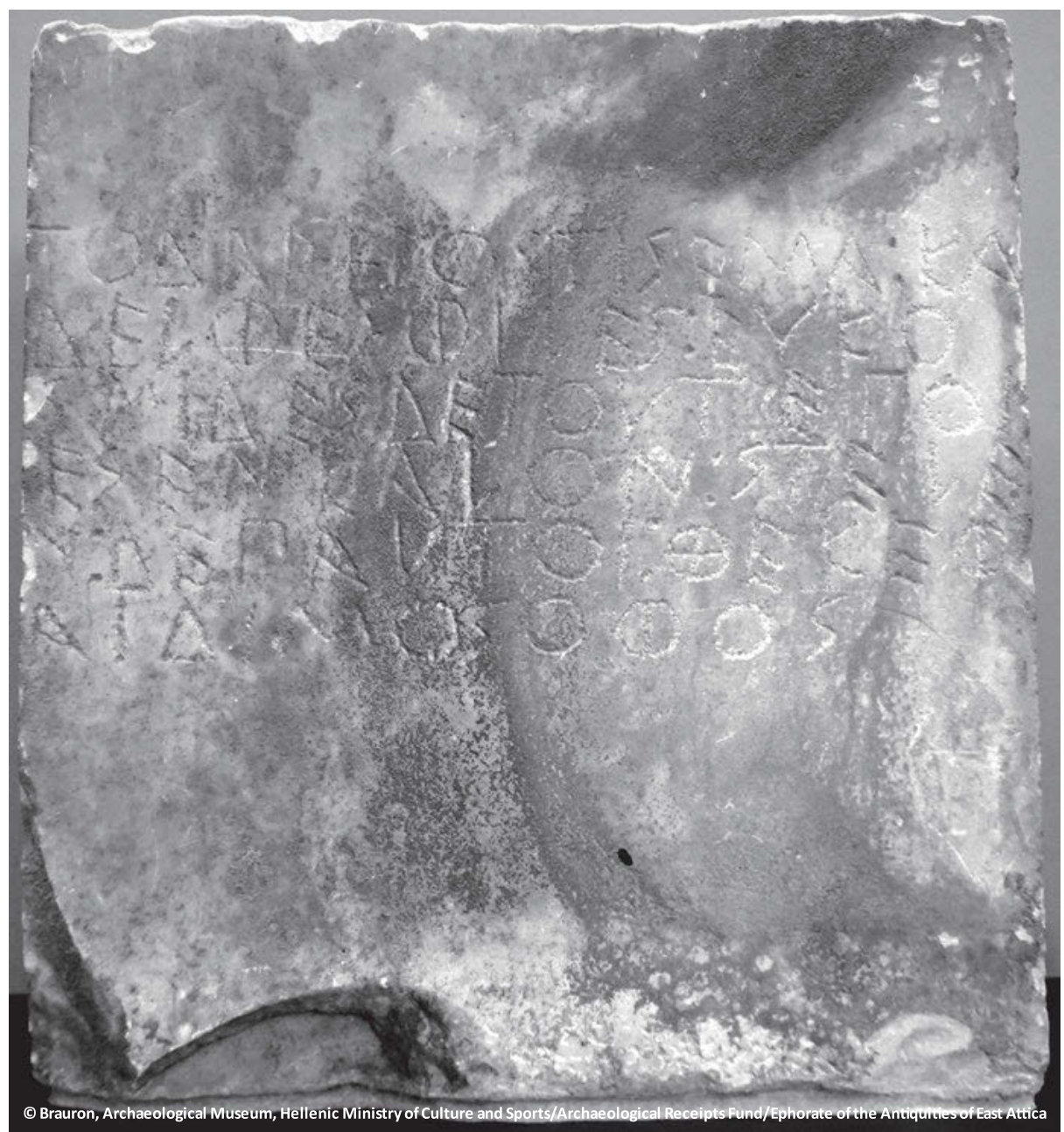

Abb.1.11: Grabstele des Archias und seiner Schwester um 540 v. Chr. (Brauron, Archäologisches Museum BE 838).

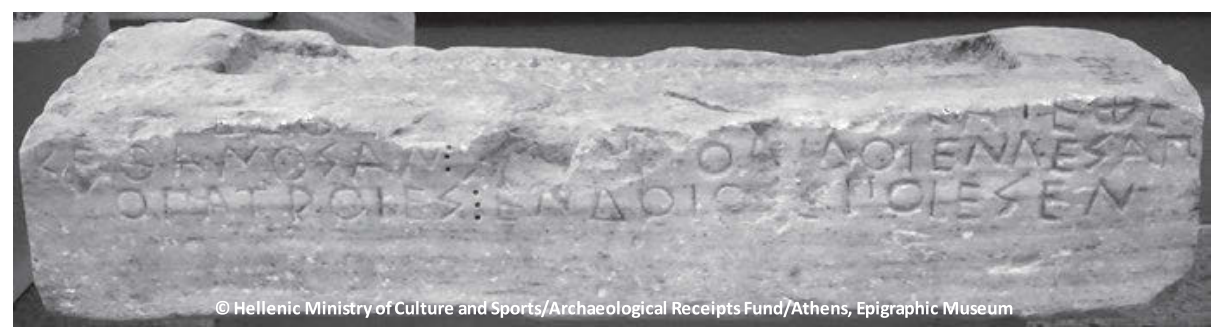

Abb.1.12: Basisblock des Grabmonumentes der Lampito, 4. Viertel des 6. Jhs. v. Chr. (Athen, Epigraphisches Museum 10643). 


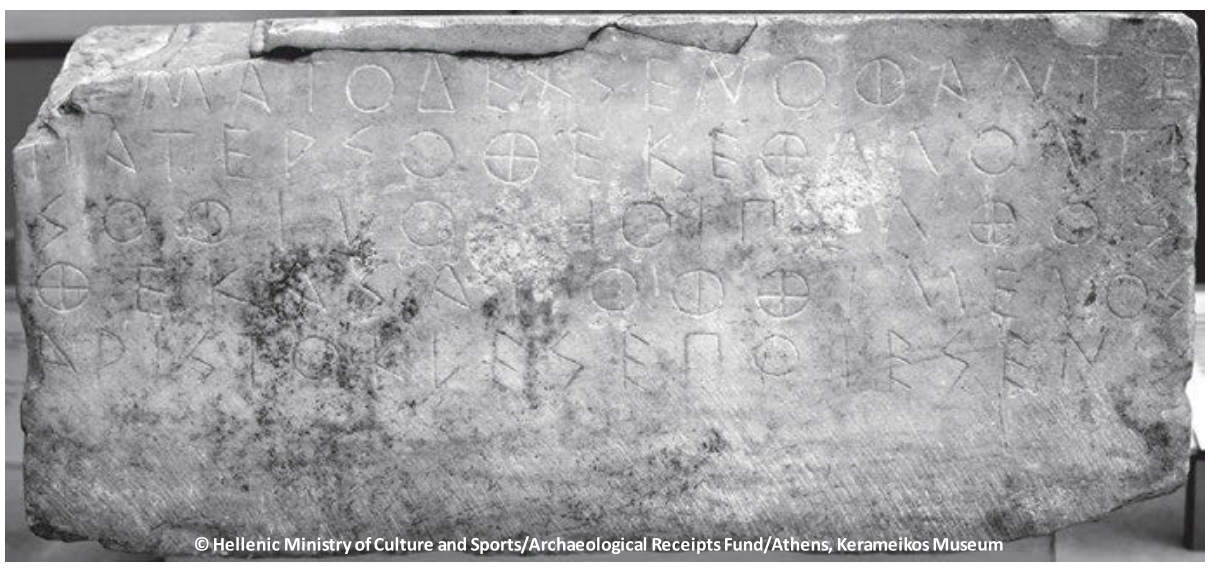

Abb.1.13: Basisblock des Grabmonumentes des Xenophantos um 530/520 v. Chr. (Athen, Kerameikos Museum I 389).

nämlich geringfügig in ihrem Schriftbild, was mit einer unterschiedlichen Schreiberhand erklärt wird. ${ }^{163}$ Die Bildhauerinschrift ist wenig größer und die einzelnen Buchstaben sind teilweise unterschiedlich geschrieben. Trotzdem sind die Unterschiede nicht so signifikant, dass der primär homogene Eindruck der Inschrift gestört würde, der vor allem durch die ähnliche Verteilung und Anordnung der Buchstaben entsteht. Bei genauerem Betrachten dürfte durchaus ein Unterschied aufgefallen sein, etwa in der Schreibweise des Epsilon und des Rho.

Wie ist es aber zu erklären, dass man sich bemühte, die Bildhauerinschrift und die Grabinschrift zu separieren? Die Ursache hierfür kann nicht gewesen sein, dass es problematisch war, einen nicht-metrischen Inschriftenteil an einen im Metrum verfassten Teil anzubinden. Denn die Separierung lässt sich auch dann fassen, wenn die Grabinschrift selbst in keinem Versmaß verfasst wurde. ${ }^{164}$ Ebenso wenig kann die Separierung auf unterschiedliche Schreiber zurückgeführt werden, da es sich in den meisten Fällen um dieselbe Schreiberhand handelt. ${ }^{165}$ Die formale Absetzung von der

163 Athen, Kerameikos Museum Inv. I 389, um 530/520 v. Chr.: Kissas 2000, 55f. A 21 Abb. 31, 32 (IG I 1218; CEG I 50; DNO I 376) (Aristokles). Zu den Unterschieden: Willemsen 1963, 136; DNO I zu Nr. 376 (S. 286). 164 Vgl. Kissas 2000, 63f. A 30 Abb. 41 (IG I³ 1232); evtl. Kissas 2000, 70f. A 41 Abb. 48 (IG I3 1344), Kat. 1.3. $165 \mathrm{Zu}$ dieser Annahme könnte die Bezeichnung Bildhauersignatur missverständlich verleiten. Nur bei der Basis des Grabmals des Xenophantos (Athen, Kerameikos Museum Inv. I 389, um 530/520 v. Chr.: Kissas 2000, 55f. A 21 Abb. 31, 32; IG I³ 1218; CEG I 50; DNO I 376) handelt es sich offenbar sicher um eine andere Schreiberhand - ob dies die Hand des Bildhauers war, muss völlig unklar bleiben, genauso wenig wie man entscheiden kann, ob die Grabinschriften immer von professionellen Schreibern eingeschrieben wurden oder ob dies auch der Bildhauer leistete. Vgl. zu den Votivmonumenten und der grundsätzlichen Trennung zwischen Bildhauer und Schreiber: Raubitschek in DAA, S. 436f. Vgl. eine Studie zu drei klassischen Praxiteles-Basen (Athen, Agora Inv. I 4165 = DNO III 1976; Athen, Agora Inv. I 4568 = DNO III 1974; Athen; Magazin der 3. Ephorie Inv. $\Lambda 6866=D N O$ III 1975) und der Frage nach der Beteiligung des Bildhauers am Schreiben der Bildhauerinschrift: Tracy 2008. 
Grabinschrift zeigt vielmehr an, dass beide als zwei voneinander unabhängige und eigenständige Elemente des gesamten Grabmonumentes galten, die wie Ornamente und Bilder die verschiedenen Partien des Grabmals ausgestalteten. Wenn sie in demselben Feld angebracht wurden, strebte man eine ästhetische Separierung an, genau wie dies der Fall ist, wenn Inschriften und Bilder sich einen Bereich wie eine Quaderseite oder den Predellabereich auf einer Stele teilten. Eine solche ,Kombination` zwischen Bild und Inschrift ist nur in wenigen Fällen überliefert. ${ }^{166}$ Auf der Grabstele des Kalliades (Abb. 1.7) (Kat. 1.15), ist im Predellabereich eine Gorgo dargestellt, unter deren Knie eine kurze Grabinschrift steht. Durch eine leichte Vertiefung wurde hier ein Feld für die Inschrift separiert und damit vom Bild getrennt. Die Inschrift nennt „Kalliades, Thoutimides' Sohn. “ (siehe Anhang Kat. 1.15), was natürlich in keiner Weise auf die daneben gezeigte Gorgo zu beziehen ist, sondern auf die Person, der das ganze Grabmal gewidmet ist, und die im verlorenen Hauptfeld der Stele wohl durch eine Figur repräsentiert wurde.

Auch auf dem Pfeilerdeckblock des Neilonides-Grabmals ${ }^{167}$ (Abb.1.2) lässt sich auf einer Seite des Blockes eine Kombination aus Bild und Inschriften fassen. Wie zuvor bereits beschrieben, sind alle Partien als formal eigenständige Bereiche auf der Quaderfläche charakterisiert: Die Bildhauerinschrift links am Block verläuft von oben nach unten, wobei die Rechtsläufigkeit der Inschrift eine Abwendung von der nach rechts gewandten Figur mit sich bringt. Diese Orientierung der Inschrift lässt auf einen eigens definierten Bereich schließen, da sich bei den Inschriften an den archaischen Grabdenkmälern die Orientierung nach der Form der beschriebenen Fläche richtet, worauf an späterer Stelle noch zurückzukommen ist. Die Bereiche der Bildhauerinschrift, des gemalten Bildes und der rechts daneben angebrachten, horizontal orientierten Grabinschrift sind damit klar differenziert. Hier ist zwar theoretisch denkbar, dass die im Bild gezeigte sitzende Figur durch die nebenstehende Grabinschrift als der Vater (und zugleich Stifter) Neilon identifiziert werden könnte. ${ }^{168}$ Eine solche direkte inhaltliche Bezugnahme kann aber aufgrund fehlender Vergleiche nur als Rezeptionsmöglichkeit festgestellt, nicht aber als Begründung für eine konzeptionelle Nähe von Bild und Inschriften erschlossen werden. Vielmehr findet die singulär erhaltene Konstellation auf der Blockseite schon eine Begründung in der auf Stelen greifbaren Aufteilung von Flächen in Figur-, Ornament-, und Inschriftenbereiche.

Wie die räumliche Nähe daher für die Text-Bild-Kombinationen keine überzeugende, gesuchte inhaltliche Verbindung nachzuweisen vermag, gilt dies auch für die Text-Text-Kombinationen; hierfür wäre ein weiterer Hinweis an den Betrachter/Leser notwendig, wie es in seltenen Fällen durch die oben beschriebene Einbindung der Bildhauerinschrift in den Vers der Grabinschrift geschehen ist, die ihre Entsprechung in der formalen Anbindung der Bildhauerinschrift an die Grabinschrift findet. Die

166 Vgl. zudem die Grabstele des Mnasitheos (siehe Anm. 112).

167 Siehe Anm. 82.

168 Vgl. Raubitschek 1939b, 67. Siehe auch zuvor. 
Eigenständigkeit der Bildhauerinschrift und ihre formale Gleichwertigkeit zu anderen Inschriften sowie Ornamenten oder Bildern ist auch der Grund, warum sich das Phänomen der Absetzung verschiedener Inschrifteninhalte nicht auf Grabdenkmäler archaischer Zeit aus Attika beschränkt, sondern auch an den in Hinblick auf den Monumentaufbau verwandten Votivmonumenten des 6. und 5. Jhs. v. Chr. von der Athener Akropolis nachzuweisen ist. Nur ein zahlenmäßig geringer Anteil überliefert keine auffällige visuelle Separierung, wie Antony Raubitschek herausstellte. ${ }^{169}$

Mit der variablen Position der Bildhauerinschrift und ihrer formalen Eigenständigkeit wird noch einmal deutlich, dass, wie über die Lage der Grabinschrift keine unmittelbare räumliche Nähe zur Figur gesucht wurde, dies auch die Bildhauerinschrift nicht tat. Anders als dies bei einigen späteren Bildhauerinschriften durch ihre auffällige Position am Werk vermutet werden kann, ${ }^{170}$ lässt sich hier anhand der Präsentation der archaischen Inschriften nicht plausibel nachweisen, dass eine Beziehung zwischen dem Bildhauer und seinem Werk mit ästhetischen Mitteln betont werden sollte. Es genügte offenbar, eine grundsätzliche Verbindung herzustellen, indem man den Bildhauernamen an einer Stelle des Grabmals anbrachte.

\section{Name und Figur}

Sowohl die Grabinschriften als auch die Bildhauerinschriften stellen demnach keine explizite Nähe zur Figur her, sondern sind wie die Ornamente und Bilder formal eigenständige Bestandteile des Monumentes, die in einem bestimmten Rahmen variabel, aber der zentralen Figur nachgeordnet positioniert werden konnten. Wäre eine formale Zuordnung, die über die Anbringung an demselben Monument hinausgeht, aber überhaupt notwendig, um die Figur mit dem Namen zu verbinden? Oder wird bereits durch die Präsenz von Bild und Inschrift an demselben Grabmal deutlich, dass das Bild des Verstorbenen in Form der Figur mit dem jeweiligen Namen der Inschrift konkret benannt wird? Gegen ein solches enges Verhältnis zwischen Text/Name und Bild/Figur im Sinne einer Namensbeischrift sprechen mehrere Gründe: Zum einen sind in anderen archaischen Bildmedien wie der Vasenmalerei formale Zuordnungen zwischen Text und Bild durchaus als Strategie etabliert, Figuren konkret zu benennen. Hiergegen könnte man einwenden, dass eine solche Möglichkeit bei den statuarischen Grabdenkmälern nicht in der gleichen Weise gegeben war. Der Name war

$169 D A A$, S. 435f. Zu den Bildhauern DAA, S. 479-525.

170 Vgl. die in DNO I, S. XXIX in Anm. 107 genannten Beispiele. Vgl. auch die Diskussion um die Bedeutung vor allem der Wortwahl, aber auch der Position der Bildhauerinschrift auf derselben Seite des Deckblockes des Grabmonument des Neilonides (siehe Anm. 82), auf der sich auch eine gemalte Figur befand; Endoios habe den Kouros auf der Basis gefertigt und die sitzende Figur auf dem Deckblock gemalt: Keesling 1999, 511, 526f. mit weiterer Literatur. M. E. lässt sich ein Zusammenhang zwischen beiden nicht belegen. 
aber, wie zuvor dargelegt, auch innerhalb der Inschrift auf den Basen meist nicht besonders hervorgehoben, obwohl durchaus für andere Aspekte visuelle Marker verwendet wurden. Der Blick auf die Grabstelen hat darüber hinaus deutlich gemacht, dass auch dort, wo eine unmittelbare Nähe zwischen Text und Bild möglich gewesen wäre, diese Möglichkeit nicht genutzt wurde. Unbekannt war die formale Zuordnung von Namen in Bereich der Grabstelen nicht, wie die zuvor besprochene singuläre böotische Grabstele des Dermys und des Kitylos belegt (Abb.1.9a-c). ${ }^{171}$ Neben den formalen Indizien sprechen gegen einen engen Text-Bild-Bezug die weiteren Beispiele von Grabmälern für mehrere Personen. Zwei Figuren führten nämlich auch bei böotischen Grabstelen nicht konsequenterweise dazu, diese als konkrete Repräsentationen unterscheiden zu wollen, ${ }^{172}$ wie ein weiteres Beispiel zeigt:

Eine Stele aus Thespiai ${ }^{173}$ (Abb.1.14) mit zwei Figuren überliefert nämlich nur eine gemeinsame Inschrift unter den Figuren (Erinnerungsmal für Agathon und Aristokrates) ohne, dass in irgendeiner Weise deutlich würde, ob und wenn ja, welchen Namen der Leser mit welcher Figur verknüpfen sollte.

Bei den attischen Grabdenkmälern gibt es für eine direkte formale Bezugnahme zwischen Namen und Figuren wie bei der Grabstele des Dermys und Kitylos keinen Beleg. Durch die Anbringung an demselben Monument war aber natürlich gewährleistet, dass Name und Figur derselben Person zugeordnet war. Attische Grabdenkmäler sind bis auf wenige Ausnahmen nur für eine Person errichtet worden und zeigten dadurch meist nur eine Figur auf der Stele oder als Statue. Bei zwei Stelen, der berühmten Geschwisterstele New York/Berlin/Athen (Abb.1.3) ${ }^{174}$ und der Stele für Archias und seine Schwester (Kat. 1.12, Abb.1.11), war die Zuordnung der Namen und der Figuren zu den jeweils Verstorbenen durch die Geschlechterdifferenz eindeutig. ${ }^{175}$

171 Vgl. zuvor Anm. 118. Souvinou-Inwood verweist hier richtig darauf, dass die Namen die Darstellungen (representations) der Verstorbenen identifizieren würden, dass aber nicht das Grabmonument mit Dermys und Kitylos identifiziert werden konnte, da die Figuren nur Teil eines größeren Ganzen wären: Sourvinou-Inwood 1995, $164 \mathrm{f}$.

172 Schild-Xenidou sah dagegen ein Bedürfnis, zwei Tote im Bild zu unterscheiden: Schild-Xenidou 2008, 154.

173 Vgl. zuvor Anm.111.

174 Zur Stele: New York, Metropolitan Museum of Art Inv. 11.185a-c, f, g + Berlin, Antikensammlung, Staatliche Museen zu Berlin, SPK Inv. Sk 1531 + Athen, Nationalmuseum Inv. 4518 (Giorgos Despinis, in: Despinis/Kaltsas 2014, 401 Kat. I.1. 365 Abb. 1216). Zur Stele u. a.: Richter 1961, 27-29 Abb. 99,

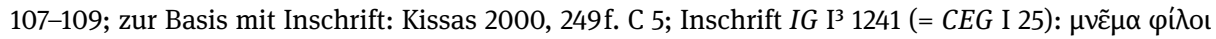

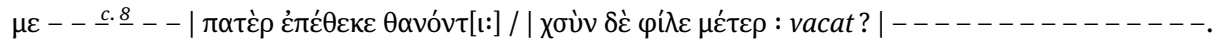
(Mich setze als Denkmal für den lieben toten - - - der Vater, zugleich aber auch die liebe Mutter - - -.). 175 Unklar bezüglich des Geschlechts der Kinder (und hinsichtlich der Namensnennung) ist die fragmentierte Grabinschrift auf dem Grabmonument, das Kylon seinen Kindern errichtete. Es trug ehemals eine relativ schmale Stele (Breite der Einlassung: $29 \mathrm{~cm}$ ): Athen, Epigraphisches Museum Inv. 13314, drittes Viertel 6. Jh. v. Chr.: Kissas 2000, 57-59 A 23 Abb. 33-36. Inschrift IG I3 1266 (= CEG I 32):

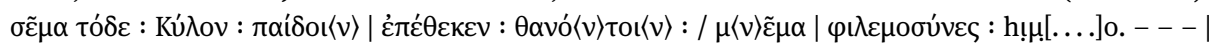
vacat - -. (Dieses Grabmal hat Kylon den beiden toten Söhnen gesetzt, ein Denkmal der Liebe ...). 


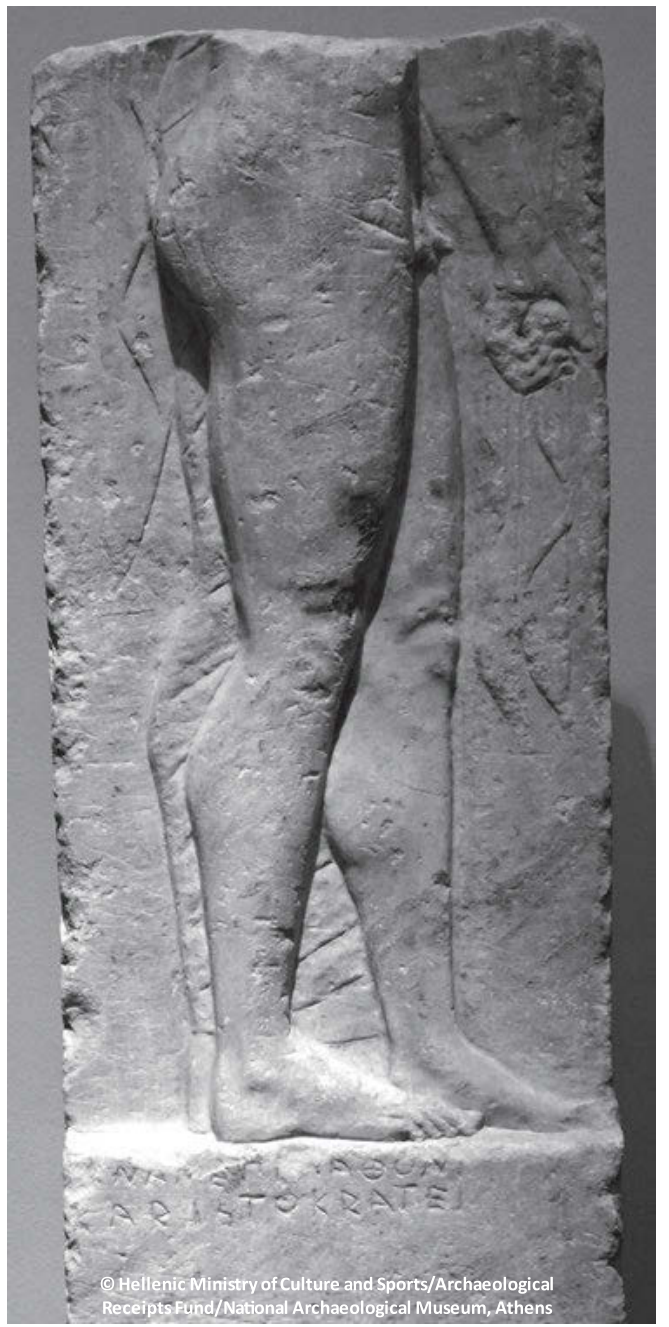

Abb.1.14: Böotische Grabstele des Agathon und Aristokrates aus Thespiai um 510/500 v. Chr. (Athen, Nationalmuseum 32).

An dem Grabmal für die Brüder Philoitios und Ktesias bestand dagegen jedoch keine eindeutige Identifizierbarkeit zwischen den Namen und jeweils einer bestimmten Figur. ${ }^{176}$ Denn nach den Einlassspuren in der Oberseite des Basisblocks zeigte das Grabmal eine mittig angebrachte Stele und zwei flankierende Säulen. Die Figuren waren wahrscheinlich gemeinsam auf der Stele dargestellt. ${ }^{177}$ Aber auch wenn zwei kleinere

176 Athen, Epigraphisches Museum Inv. 13290, um 500 v. Chr.: Kissas 2000, 67f. Nr. A38 Abb.44,

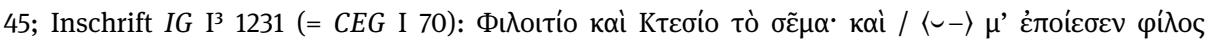

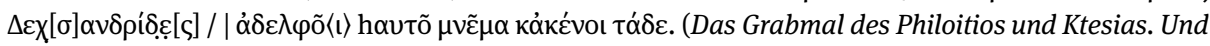
mich hat der liebe Dexandrides gefertigt, diese (Reliefs) als Denkmal an seinen Bruder und an jenen.). 177 So Kissas 2000, 68. Von einer zusätzlichen Anbringung von Namensinschriften auf der Stele bei jeder Figur ist mangels Vergleichen bei attischen Beispielen nicht auszugehen. 
Kouroi auf den Säulen gestanden hätten, ${ }^{178}$ wäre hier keine eindeutige Identifizierung vorgegeben gewesen. Vielmehr war von Bedeutung, dass jeder Verstorbene hier wie auf der Stele aus Thespiai in einer, aber nicht in einer bestimmten figürlichen Darstellung repräsentiert wurde. Die Inschrift legte hierbei für den Betrachter nicht fest, welche Figur mit welchem Namen zu verbinden war.

Diese Beispiele zeigen, dass die Grabinschriften nicht als Beischriften zu den Figuren verstanden wurden. Vielmehr beziehen sich Figur und Grabinschrift jeweils auf die Person des Verstorbenen. ${ }^{179}$ Hierfür spricht auch der Text der Inschriften, die den Namen des Verstorbenen gerade im Kontext figürlicher Darstellungen üblicherweise nicht im Nominativ wie bei Namensbeischriften üblich, ${ }^{180}$ sondern als Genetivattribut zu sêma nennen. ${ }^{181}$ Dieses sêma ist nicht allein die dargestellte Figur, sondern das ganze Grabmonument, zu dem nicht nur die Stele/Statue mit der anthropomorphen Figur, sondern auch der Unterbau und weitere Gestaltungselemente gehören. ${ }^{182}$ In der Rezeption des ganzen Grabmals stellte der Betrachter/Leser natürlich durch das Lesen des Namens bei dem Betrachten der Figur eine Verbindung her bzw. konnte dies tun. Durch die Einzelfigur stellte sich wohl in den meisten Fällen die Frage nach dem Bezug der Figur zur Person überhaupt nicht, so dass vielleicht eine Präzision des Bezuges nicht als notwendig erachtet wurde, auch wenn eine solche mit formalen Mitteln hätte erreicht werden können. Dass aber auch die Stele aus Thespiai und das Grabmal für die Brüder Philoitios und Ktesias eine solche Präzision nicht suchten und diese Frage offenblieb, warnt vor einem vorschnellen Urteil über einen Text-Bild-Zusammenhang der anderen Beispiele. Vielmehr zeigt sich hier, wie wenig es bei den gezeigten Figuren um semantisch klar definierte Bilder ging, die für den Betrachter weniger Anreiz für die eigene Deutung gegeben hätten. ${ }^{183}$

178 Vgl. Karusos 1961, 68 (Kat. II C 4).

179 Anders scheint dies bei den späteren, klassischen attischen Grabreliefs zu sein, bei denen die Namen (dann bezeichnenderweise im Nominativ) in vielen Fällen direkt den Figuren beigeschrieben werden. Erst die Namensbeischrift macht dabei erkennbar, welche Figur der oftmals vielfigurigen Bilder mit der verstorbenen Person verbunden werden sollte. Es gibt hier jedoch auch Ausnahmen, die nach Schmaltz vermuten lassen, dass auch bei klassischen Grabreliefs Figur und Name nicht in jedem Fall als Einheit gedacht werden müssen: vgl. hierzu Schmaltz 1979, bes. 16.

180 Vgl. Sourvinou-Inwood 1995, 163-166. Häusle führt einige attische Inschriften mit dem Namen im Nominativ an (Häusle 1979, 114f. mit Anm. 245) und schlug vor, dass eine solche Namensnennung (nicht als Abkürzung, sondern vollständig gedacht) bedeuten kann, dass der Name das Bild des Toten oder eine Beischrift zu einem realen oder gedachten Bild ist: Häusle 1979, 117-121. Dagegen Sourvinou-

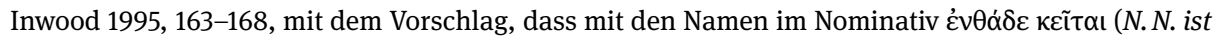
hier bestattet) abgekürzt sei und es keine Identifizierung zwischen Figur und Verstorbenen über den Namen im Nominativ gebe. Häusle schließt eine mögliche Abkürzung nicht aus: Häusle 1979, 121.

181 Die Nennung des sêma kann auch entfallen und es wird nur der Name im Genetiv genannt, wie bei dem Grabmonument des Aristodikos (Athen, Nationalmuseum Inv. 3938, um 500 v. Chr.: Kissas 2000, 68f. A 39 Abb. 46, 47; IG I 1244).

182 Vgl. Sourvinou-Inwood 1995, 167.

183 Vgl. Dietrich 2018a, 203-226, bes. 219. 


\section{Das Monument im Zentrum}

Da also die Gestaltung der Inschriften keine Begründung in Zusammenhang mit der am Grabmal gezeigten Figur findet, soll nun danach gefragt werden, welchen Eindruck die ästhetischen Phänomene der Inschriften in Bezug auf das ganze Grabmal erzeugen und wie dies verstanden werden kann.

Wie die Gestaltung einer Inschrift Bedeutung für das Objekt erzeugen kann, das die Inschrift trägt, ist im Bereich der archaischen Plastik etwa von Katharina Lorenz untersucht worden. ${ }^{184}$ Sie legte am Beispiel des Isches-Kouros ${ }^{185}$ dar, dass die auf dem vorgesetzten Bein des Kouros eingemeißelte Inschrift auf das Bewegungspotenzial der Figur hinweist. ${ }^{186}$ Da bei männlichen Figuren, unabhängig ob Kleinbronze oder überlebensgroße Statue, oftmals auf die Oberschenkelpartien geschrieben wurde, ${ }^{187}$ evozierte man hier offenbar eine Fokussierung des Betrachterblicks auf diesen Bereich. Oberschenkel, Glutäen und Knie sind gerade die Bereiche des männlichen Körpers, die als Ausgangspunkt der körperlichen Leistungsfähigkeit gelten. ${ }^{188}$ Die Inschrift kann daher durch ihre Position auf und durch ihre Orientierung an der Form der Beine/Oberschenkel diesem Bereich Bedeutung zuschreiben und das spezifische Verständnis des Körpers unterstützen; und dies sogar unabhängig vom Inhalt der Votivinschrift.

Lässt sich eine vergleichbare ästhetische Funktion von Inschriften auch bei den attischen Grabmonumenten fassen? Hierfür ist noch einmal $\mathrm{zu}$ betonen, dass die

184 Lorenz 2010. Vgl. auch Dietrich 2017a, 305-308 zum Zusammenhang der Position von Inschrift und dem Betrachten des Gewandes bei Koren.

185 Samos, Vathy Museum Inv. 77, 580/570 v. Chr.: Kyrieleis 1996. Zur Inschrift: Günter Neumann, in: Kyrieleis 1996, 45f.; IG XII 6, 2, 560. Zum Problem der Datierung der Inschrift in Relation zur Statue siehe Kyrieleis 1996, 65-67.

186 Lorenz 2010, 135.

187 Vgl. Freyer-Schauenburg 1974, 71f. Vgl. großformatig: Beinfragment eines Kouros aus Samos (Inschrift begann auf dem Oberschenkel und reichte bis unter das Knie: Samos, Heraion Inv. II S 223 und unbekannt, 550-540 v. Chr.: Freyer-Schauenburg 1974, 95 Kat. Nr. 49 A/B Taf. 35 (= IG XII 6, 2, 558D); Kouros aus Samos (Inschrift zweizeilig auf dem linken Oberschenkel): Samos, Vathy Museum Inv. 69, um 560 v. Chr.: Freyer-Schauenburg 1974, 69-73 Kat. 35 Taf. $20-22$ (= IG XII 6, 2, 586). Kleinformatig etwa: Sog. Mantiklos-Apoll, Boston, Museum of Fine Arts Inv. 03.997: Comstock/Vermeule 1971, 16f. Kat. 15 mit Abb. (=CEG I 326). Spätarchaische Bronzestatuette eines Kouros in Olympia, Archäologisches Museum. Inv. B 11555 (beschriftet entlang des linken Beines): Sinn 1989; Kyrieleis 2003, $148-$ 152 Abb.113-118; zur Inschrift: SEG 37, 363; SEG 39, 400; SEG 53, 426; NIVOl, Nr.36. Bronzestatuette eines Diskobol, Athen Nationalmuseum Inv. 7412 (Inschrift auf dem linken Oberschenkel): Schmaltz 1980, 154-156 Kat. 420 Taf. 24; Wolters/Bruns 1940, 38 Nr. 26 (= IG VII, 3590). Bronzestatuette (Inschrift auf beiden Beinen): Berlin, Antikensammlung, Inv. Misc. 7100: Neugebauer 1931, 100f. Nr. 206 Abb. 31 Taf. 35; Foucart 1879, 139f. Nr. 3 (= IG VII, 2455).

188 Vgl. die Anmerkungen Stählis zur Bedeutung der Hervorhebung der Knie bei Kouroi wegen der dortigen Verortung der Zeugungskraft und der Attraktivität von Oberschenkeln und Glutäen: Stähli 1999, 103 mit Anm. 79. 
Inschriften in diejenigen Bestandteile des Monumentes eingemeißelt wurden, die gerade nicht zum Bereich der Figur, sondern zu ihrem aufwändigen Unterbau gehören. Dieser Unterbau der Statuenmonumente sowie bei Stelenmonumenten der gesamte Aufbau inklusive oberem Abschluss charakterisiert das Grabmonument durch seine Anleihen an Bauteilen (geschichtete Quader, Pfeiler, Säule, Kapitell) als eine Konstruktion, die wie ein Gebäude errichtet wurde. An diesem Monument sind verschiedene Partien definiert - einerseits der Bereich der Figur auf der Stele oder der Statue auf dem Monument, andererseits nebengeordnete Felder, die variabel mit Bildern, Ornamenten und Schrift ausgestaltet werden konnten oder allein das Material zeigten. Nicht nur die bevorzugte Position der Inschriften im unteren Bereich des Grabmals, sondern auch die im Folgenden noch zu beschreibenden weiteren Phänomene der Gestaltung werden nahelegen, dass es die gebaute Qualität des Grabmals ist, auf das die Inschriften den Blick lenken. Welche Wirkung erzeugte also die Inschrift als Teil der Monumentgestaltung und wie ist dies zu verstehen?

\section{Ausrichtung und Orientierung der Buchstabenketten}

Hierfür ist zunächst das Layout der Inschriften aufschlussreich, denn in dieser Zeit gibt es noch keine Konvention, dass bevorzugt horizontal oder gar konsequent linear geschrieben worden wäre. Die Buchstabenketten folgen in vielen Fällen der Ausrichtung des zu beschreibenden Feldes, wie nicht nur die archaischen Grabdenkmäler, sondern auch die zahlreichen erhaltenen archaischen Votivmonumente von der Athener Akropolis belegen, die den Grabmonumenten in ihrem Aufbau verwandt sind. Ist dabei der konkrete Schriftträger eher querformatig wie ein Pfeilerdeckblock, ein Säulenrundkapitell oder ein Block einer Quader- oder Stufenbasis, wird die Inschrift horizontal geschrieben. Orientiert sich der beschriebene Grund vertikal wie ein Pfeiler-, ein Säulenschaft oder ein Stelenkörper ohne großformatige Figur, verläuft auch die Inschrift vertikal, wobei die Inschrift meist rechtsläufig, seltener linksläufig geschrieben ist. ${ }^{189}$ Bei den Grabstelen kommt es darauf an, in welchem Bereich die Inschrift

189 Dieses Prinzip der engen formalen Orientierung der Inschrift an der Form des Schriftträgers, wie es bei diesen Monumenten zu greifen ist, scheint sich erst langsam ab ca. 500 v. Chr. aufzulösen, wenn nun auch Pfeilerschäfte, die bislang konsequent vertikal beschrieben wurden, mitten auf dem Schaft horizontale Zeilen erhalten: Vgl. etwa datiert an den Anfang des 5. Jhs. v. Chr.: DAA, 297-299 Nr. 278 mit Abb. (IG I³ 632; CEG I 215), 310-313 Nr. 291 mit Abb. (IG I³ 696). Zu Pfeilermonumenten des 6. und 5. Jhs. v. Chr. aus dem Votivbereich von der Athener Akropolis grundlegend: DAA, S. 211-336 Nr.178-316. Bisweilen finden sich auch zuvor im oberen Bereich von Pfeiler- und Säulenschäften horizontale Inschriften, die sich aber an den oberen Rand hängen und sich daher wie abschließende Ornamentbänder horizontal anordnen: vgl. etwa eine Votiv-Säule von der Athener Akropolis (Akropolis Museum Inv. 6968): DAA, 56 Nr.55b mit Abb. (IG I 645). Bei folgenden zwei Beispielen von Stelen - wahrscheinlich ohne Figurendarstellung - waren die Inschriften vertikal orientiert: Kat. 1.4; 1.13. 
angebracht wird. Meist sind dies querrechteckige Partien wie die Predella, so dass die Buchstabenzeilen dementsprechend horizontal verlaufen. Der Deckblock des Neilonides-Monumentes (Abb.1.2) zeigt unterschiedlich ausgerichtete Schriftteile, die nicht, wie zuvor erläutert, mit dem Bezug eines Inschriftenteiles zu dem gemalten Bild zu erklären sind, sondern mit der separierenden Feldaufteilung. Das links der Figur zur Verfügung stehende Feld ist hochrechteckig, das rechts der Figur querrechteckig. Entsprechend sind beide Inschriften orientiert. ${ }^{190}$

Aber nicht nur die Orientierung der ganzen Buchstabenketten folgt dem beschriebenen Grund, sondern auch die Linearität steht damit in Zusammenhang. Diese ist in dieser Zeit (noch) nicht durch eine einheitliche Schreibkonvention bedingt. Vielmehr konnte der Verlauf der Zeilen eine inhaltliche Begründung haben, wie es andere archaische Schriftbeispiele belegen: ${ }^{191}$ In der Plastik ist dies etwa bei dem sogenannten Mantiklos-Apoll, einer bronzenen Votivstatuette, naheliegend, bei dem der Körper der Figur beschrieben ist; die Zeilenführung zeichnet hier die Form der Oberschenkelpartie nach, indem die Inschrift vom rechten Knie ausgehend nach oben läuft und oben umbiegt, den linken Oberschenkel hinabführt, um dann denselben Weg bis zum Ausgangspunkt zu wiederholen. ${ }^{192}$ Während dadurch die Inschrift auf das Bewegungspotenzial des Kouros aufmerksam macht, ${ }^{193}$ stellt die Inschrift auf der spätarchaischen Hermenstele aus Trachones (Abb.1.15), die Kalias den Euphroniden weihte, ${ }^{194}$ den Phallus als zentrales Element der Hermenstele in den Mittelpunkt, indem die Zeilen ihn umrunden. Diese Beispiele zeigen zudem noch einmal deutlich, dass Textinhalt und Gestaltung der Inschrift nicht in engem Zusammenhang zueinander stehen mussten. ${ }^{195}$

Inschriften konnten also in archaischer Zeit die Form desjenigen Elementes aufnehmen, auf dem sie geschrieben sind, und sie konnten durch ihren Verlauf etwas hervorheben. So unterstützt eine vertikale Inschrift auf einem Säulen- oder Pfeilerschaft

190 Zum Neilonides-Grabmal: Anm. 82. So lässt sich dies auch bei der Grabstele des Mnasitheios fassen (vgl. Anm. 112). Unklar ist die Ausrichtung aber bei sehr fragmentarisch überlieferten Grabstelen oder Grabplatten: etwa Kat. 1.19 (zur möglichen vertikalen Orientierung: Wolters 1890, 225).

191 So ist dies etwa bei den Namensbeischriften in der attischen Vasenmalerei greifbar, wo die Namen der Figuren möglichst nah am Kopf der benannten Figur beginnen und von dort ausgehend geschrieben werden, dem Körper folgend oder horizontal fortführend: vgl. Gerleigner 2006, 2. Die Anordnung macht deutlich, dass sich die Inschrift auf die Figur bezieht. Vgl. auch die Namensbeischriften am Fries des Siphnier-Schatzhauses: Brinkmann 1994, Beilage 9-12. Aufgrund von Platzmangel konnten die Namensbeischriften dann auch andernorts - etwa auf der Leiste unter dem Fries in der Nähe der Figur - positioniert werden.

192 Boston, Museum of Fine Arts Inv. 03.997: Comstock/Vermeule 1971, 16f. Kat. 15 mit Abb. Zur Inschrift: CEG I 326; vgl. u. a. Day 2010, 33-48 (v. a. fokussierend auf die Frage nach dem Lesen des Epigramms).

193 Hierzu: Lorenz 2010, 141.

194 Athen, Epigraphisches Museum Inv. 580, Anfang 5. Jh. v. Chr.?: IG I 1007; DNO I 371; vgl. Rückert 1998, 67-69, 232 Anhang II 2 mit Abb. 3.

195 Vgl. auch Dietrich 2017a, 309. 


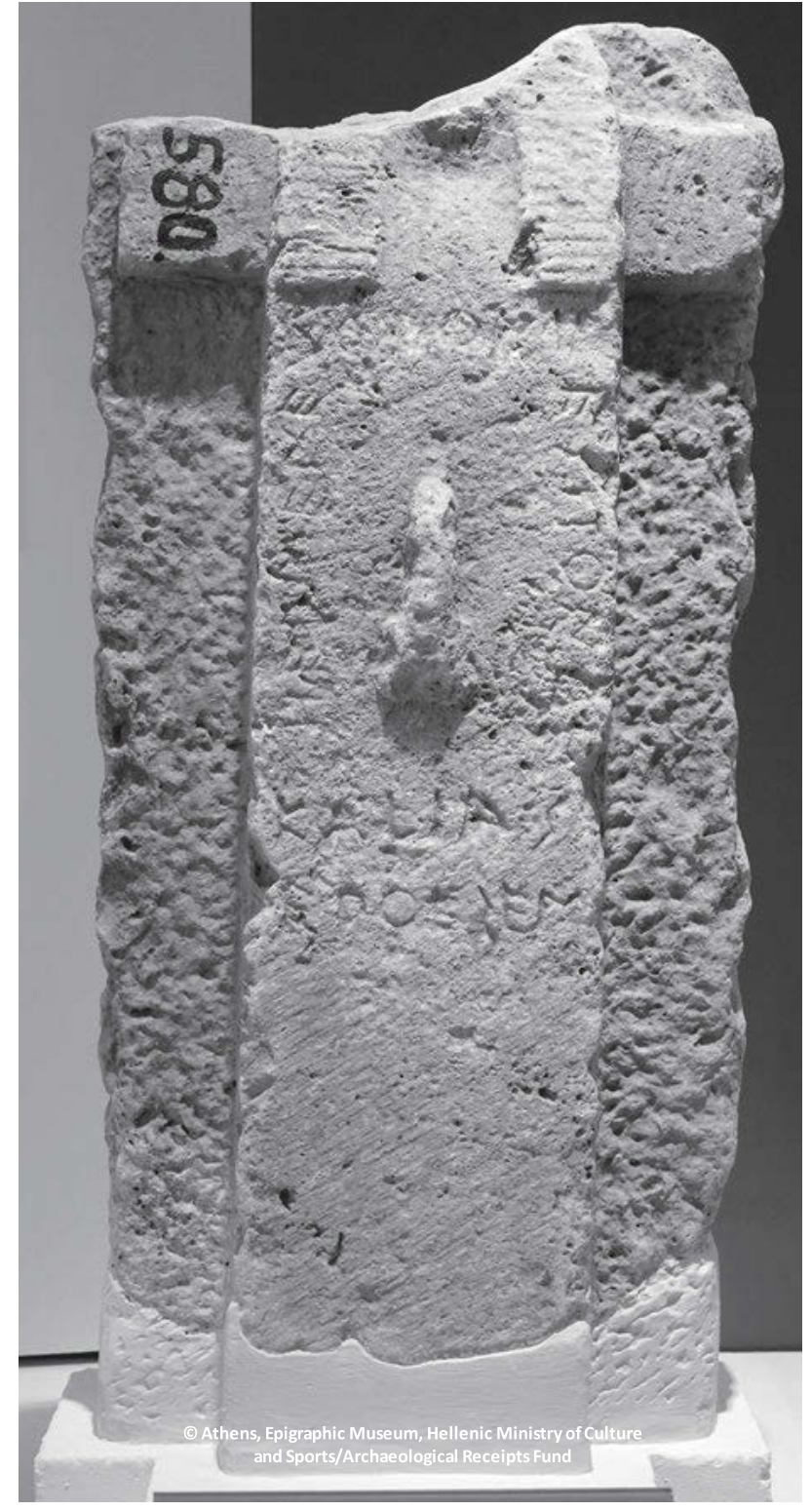

Abb.1.15: Hermenstele aus Trachones, Weihung des Kalias an die Euphroniden (Athen, Epigraphisches Museum 580).

eines archaischen Votiv- oder Grabmonuments ebenso die optische Streckung und das Hochformat der Säule oder des Pfeilers, wie dies auch eine Kannelur vermag. ${ }^{196}$ Die horizontale Anordnung auf einem Quader des stufenförmigen Unterbaus hebt dementsprechend die Schichtung der Steine übereinander hervor.

196 Vgl. zum Funktionieren von Bauornamenten: Grüner 2014 (akzentuierendes Ornament). 


\section{Anordnung der Buchstaben in Bezug zum beschriebenen Bereich}

Aber nicht nur die Orientierung der Inschrift und ihr Verlauf richten sich nach dem jeweils beschriebenen Bereich des Monumentes, sondern auch die Anordnung der Buchstaben. Die Zeilen erstrecken sich an den Basisblöcken soweit als möglich über die gesamte Blockbreite, ${ }^{197}$ meist ohne auf Wortgrenzen ${ }^{198}$ oder, sofern im Versmaß verfasst, auf metrische Strukturen ${ }^{199}$ Rücksicht zu nehmen. Fehlte nur noch ein Teil des Wortes, nachdem der Schreiber am Blockende angekommen war, ist der Rest des Wortes bisweilen retrograd unterhalb des vorherigen Wortteiles geschrieben, so dass er formal diesem Ende zugeordnet wird. ${ }^{200}$ Auch bei längeren Basisblöcken schrieb man konsequent über die gesamte Breite, wie etwa das Beispiel der unteren Stufe der zusammengesetzten Stufenbasis vom Grabmonument des -erylidos aus dem Kerameikos zeigt, auf der die Inschrift in zwei Zeilen auf die gesamte Breite von 2,5 Metern verteilt ist. ${ }^{201}$ Obwohl die gesamte Breite des Feldes genutzt wird, hatte sich noch nicht eine konsequente Planung der Buchstabenabstände durchgesetzt. Dies

197 Vgl. Dietrich 2017a, 311f. Siehe auch zur Trennung von Wörtern Kapitel III, S. 162, dort S. 163-171 zum Prinzip der Fläche als Grundmodul für die Schriftanbringung.

198 Auf Basen: Kissas 2000, 40f. A 5 Abb. 9 (IG I3 1206; CEG I 35), 41f. A 7 Abb. 10 (IG I3 1219), 43 A 9 (IG I3 1196; CEG I 14; DNO I 358), 44f. A 11 Abb. 13 (IG I3 1194bis; CEG I 13), 46 A 12 Abb. 14, 15 (IG I3 1242; CEG I 31), 46f. A 13 Abb. 16, 17 (IG I 1251; CEG I 18; DNO I 359), 50 A 17 Abb. 22 (IG I 1234; CEG I 69), 51-54 A 19 Abb. 27 (IG I3 1211; CEG I 41; DNO I 349), 56f. A 22 (IG I3 1205; CEG I 38), 59 A 24 Abb. 37 (IG I3 1204; CEG I 28), 59f. A 25 Abb. 38 (IG I 1243 ; CEG I 40), 62f. A 29 Abb. 40 (IG I3 1357; CEG I 58), $64 \mathrm{f}$. A $32 \mathrm{Abb} .42$ (IG I3 1227; CEG I 60), 66 A 36 Abb. 43 (IG I3 1380; CEG I 66; DNO I 367), 71-73 A 42 Abb. 50, 51 (IG I $\mathrm{I}^{3}$ 1214; CEG I 42; DNO I 368), 249 C 3 Abb. 336 (IG I 1202; CEG I 21), 249 C 4 (IG I3 1277; CEG I 68), 250f. C 8 (IG I3 1216; CEG I 45), 251-253 C 11 Abb. 337, 338 (IG I3 1225; CEG I 57), 255 C 15 (IG I $\mathrm{I}^{3} 1223$; CEG I 59), 255f. C 16 (IG I3 1257; CEG I 53), 258 C 20 (IG I3 1260; CEG I 72).

199 Auf Basen: Kissas 2000, 39f. A 4 Abb. 7,8 (IG I3 1200; CEG I 19), 41f. A 7 Abb. 10 (IG I3 1219), 43 A 9 (IG I3 1196; CEG I 14; DNO I 358), 44f. A 11 Abb. 13 (IG I3 1194bis; CEG I 13), 46f. A 13 Abb. 16, 17 (IG I3 1251; CEG I 18; DNO I 359), 47 A 14 (IG I3 1261; CEG I 24; DNO I 348), 50 A 17 Abb. 22 (IG I3 1234; CEG I 69), 54f. A 20 Abb. 28-30 (IG I3 1240; CEG I 27), 57-59 A 23 Abb.33-36 (IG I 1266; CEG I 32), 59 A 24 Abb. 37 (IG I3 1204; CEG I 28), 62f. A 29 Abb. 40 (IG I3 1357; CEG I 58), 66 A 36 Abb. 43 (IG I3 1380; CEG I 66; DNO I 367), 71-73 A 42 Abb. 50, 51 (IG I3 1214; CEG I 42; DNO I 368), 249 C 4 (IG I3 1277; CEG I 68), 253 C 12 Abb. 339 (IG I3 1229; CEG I 54; DNO I 377).

200 Kissas 2000, 46f. A 13 Abb.16, 17 (IG I3 1251; CEG I 18; DNO I 359), 64f. A 32 Abb. 42 (IG I 1227; CEG I 60), 65f. A 35 (IG $\left.\mathrm{I}^{3} 1276\right)$; zuzurechnen ist in gewisser Weise ein Basisblock der Stele für Oinanthe (Kissas 2000, 253 C $12 \mathrm{Abb} .339$; IG I 1229; CEG I 54; DNO I 377), bei der das noch sinngemäß zur ersten Zeile gehörige Wort $\Theta$ ГАӨРО $\Sigma$ in der zweiten Zeile retrograd am rechten Rand des Basisblockes beginnend geschrieben wird, der Text sich aber in der zweiten Zeile am linken Rand mit dem Namen der OINAN@E fortführt. Zwischen dem Ende dieser Zeile und dem letzten Buchstaben von ӨҮГАӨРО $\Sigma$ fügte man einen Abstand sowie zwei Punkt-Zeichen ein. Die Inschrift ist sprachlich problematisch, v. a. bezüglich HE $\triangle$ E und der Sperrung in der zweiten Zeile. Siehe hierzu Hansen ad CEG I 54; auch u. a. Merkelbach 1973.

201 Athen, Kerameikos Museum Inv. unbekannt, 4. Viertel des 6. Jhs. v. Chr.: Kissas 2000, 64 A 31 (IG I3 1226; CEG I 61). 
ist erst mit der sogenannten stoikhedon-Schreibweise ${ }^{202}$ erreicht. Vielmehr lässt sich nicht selten feststellen, dass die Buchstabenabstände zum Blockende hin gedrängter (Abb.1.10) oder gestreckter (Abb.1.16) werden, ${ }^{203}$ um die Breite möglichst zu füllen beziehungsweise alle Buchstaben in der Zeile unterzubringen.

Nur bei der letzten Zeile füllt die Inschrift nicht immer die gesamte Breite des beschriebenen Feldes aus. Hier bedeutet die Lücke das Ende des Textes. Eine Unterstützung der Lesbarkeit im Sinne einer Gliederung nach bestimmten Einheiten stand daher bei der Anordnung der Buchstaben nicht im Vordergrund. ${ }^{204}$

Die Inschriften verhalten sich in ihrer Orientierung, dem Verlauf der Zeilen sowie der Anordnung der Buchstaben vielmehr wie Ornamentbänder und fokussieren so den Betrachterblick auf bestimmte Bereiche und/oder heben die Struktur des jeweiligen beschriebenen Bereiches, etwa der Säulen, der Quader im Stufenbau oder der Leisten auf der Stele, hervor. ${ }^{205}$

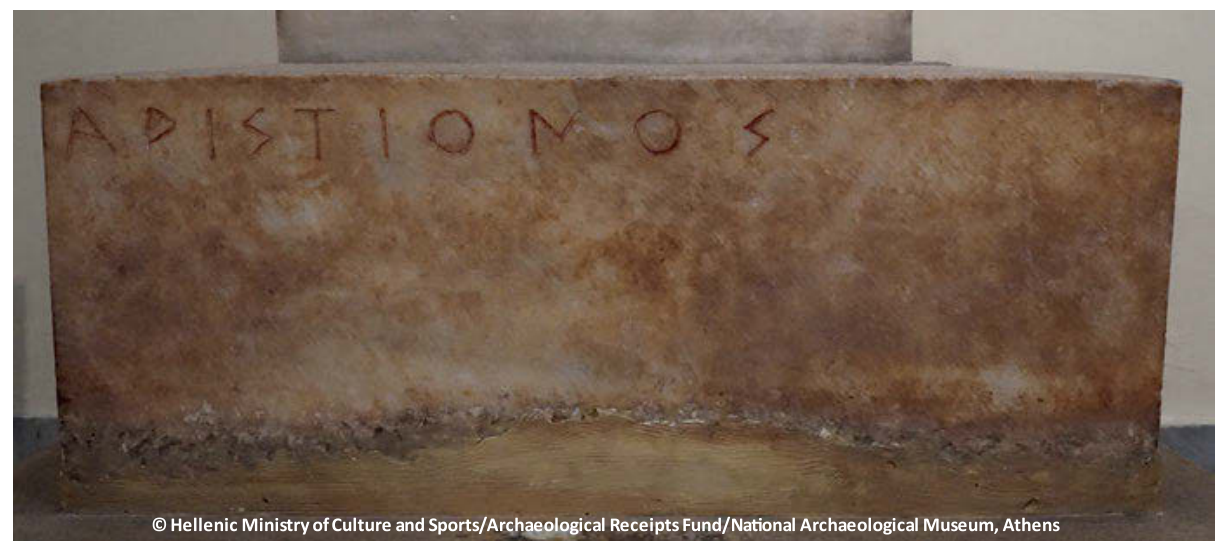

Abb.1.16: Basisblock der Grabstele des Aristion, um 520/510 v. Chr. (Athen, Nationalmuseum 29).

202 Siehe hierzu u. a. Austin 1938; Butz 2010, 77-116 mit Angaben zu älterer Literatur.

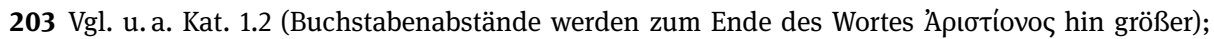
Kissas 2000, 61f. A 28 (Knigge 1969, Taf.36; IG I 1365) (Buchstabenabstände werden zum Ende der zweiten Zeile hin leicht kleiner, in der dritten Zeile größer); Kissas 2000, 55f. A 21 Abb. 31, 32 (Jeffery 1962, Taf. 34e; IG I3 1218; CEG I 50; DNO I 376) (vgl. besonders das Ende der zweiten und dritten Zeile). Auf ein solches Bemühen, den Block möglichst zu füllen, können sich auch einige der Größenunterschiede zwischen Zeilen zurückführen. Zu diesen siehe weiten oben.

204 Vgl. Dietrich 2017a, 310-312 zum Votivmonument des Antenor (IG I³ 628; Kissas 2000, $16 \mathrm{f}$. B 45 Abb.110). Vgl. zum Lesakt und den Möglichkeiten und Einschränkungen in diesem Zusammenhang durch die Gestaltung der Schrift u. a. Berti et al., bes. 639-642.

205 Zur ornamentalen Wirkung von Inschriften und ihrer Berücksichtigung im Kontext einer Revision des traditionellen Ornamentbegriffs: Grüner 2014, 47 (mit Lit.). 


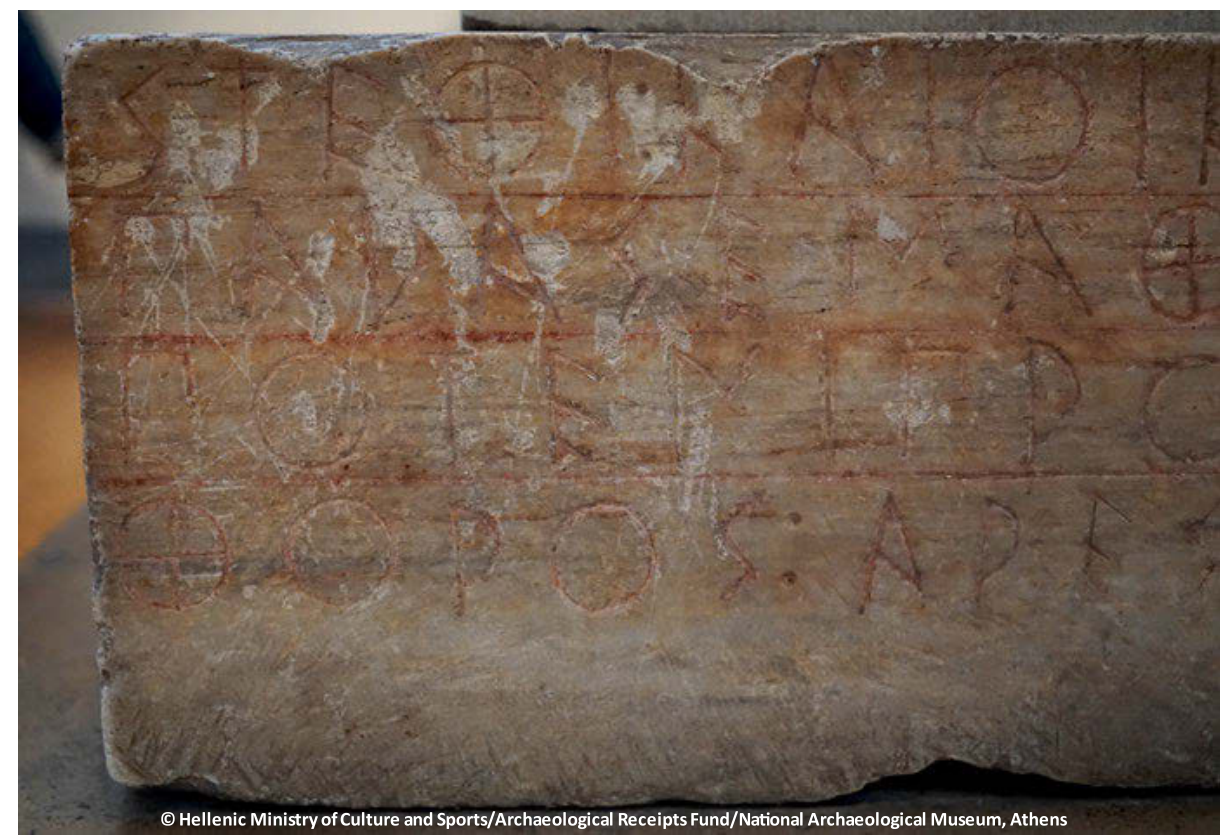

Abb.1.17a: Ausschnitt der Inschrift auf der Basis des Grabmonumentes des Kroisos um 530 v. Chr. (Athen, Nationalmuseum 4754 und $3851 \alpha, \beta, \gamma$ ).

\section{Wirkung der Schrift: Linien, Rahmung, Farbe und Kontrast}

Wie war die Schrift überhaupt zu sehen? Was beeinflusste neben den bereits angesprochenen Elementen des Schriftbildes die Wahrnehmung?

Linien an und bei Inschriften, bekannt meist unter dem Begriff guide-lines ${ }^{206}$, lassen sich mehrfach, aber nicht als häufiges Phänomen nachweisen. Dabei gibt es jedoch deutliche Unterschiede, da zu trennen ist ${ }^{207}$ zwischen feinen Ritzlinien $^{208}$, die durch ihre Berührung mit den Buchstaben sicher mit dem Schreibprozess in Verbindung $\mathrm{zu}$ bringen sind, und tiefer und meist breiter eingekerbten Linien oftmals mit Abstand zu den Buchstaben, die auch mit Farbe deutlich sichtbar gemacht wurden (Abb. 1.17a-b, 3.6). ${ }^{209}$

206 Vgl. u. a. Threatte 1980, 62; DAA, S. 438f.

207 Hierauf wies bereits Raubitschek hin (DAA, S. 439).

208 Vgl. die bei Threatte 1980, 62 und in $D A A$, S. 439 genannten Beispiele. Vgl. auch die Gitter-Angaben als Hilfestellung für die stoikhedon-Schreibweise: Butz 2010, bes. $42-54$ mit Taf. 19-30.

209 Kissas 2000, 39f. A 4 Abb. 7, 8 (IG I3 1200; CEG I 19), 54f. A 20 Abb. 28-30 (IG I3 1240; CEG I 27), 59 A 24 Abb. 37 (IG I 1204; CEG I 28), 70 A 40 (IG I3 1262), 70f. A 41 Abb. 48, 49 (IG I3 1344) (nur gemalt); 249 C 3 Abb. 336 (IG I 1202; CEG I 21). Siehe zudem Kat. 1.8, 1.19. Die Basis Kissas 2000, 249 C 3 Abb. 336 (IG $\mathrm{I}^{3}$ 1202; CEG I 21) zeigt sogar beide Linienarten - während die dickeren Linien die Buchstaben nicht berühren, sondern die Zeilen einfassen, ist in der untersten Reihe eine dünne Risslinie erhalten, die 


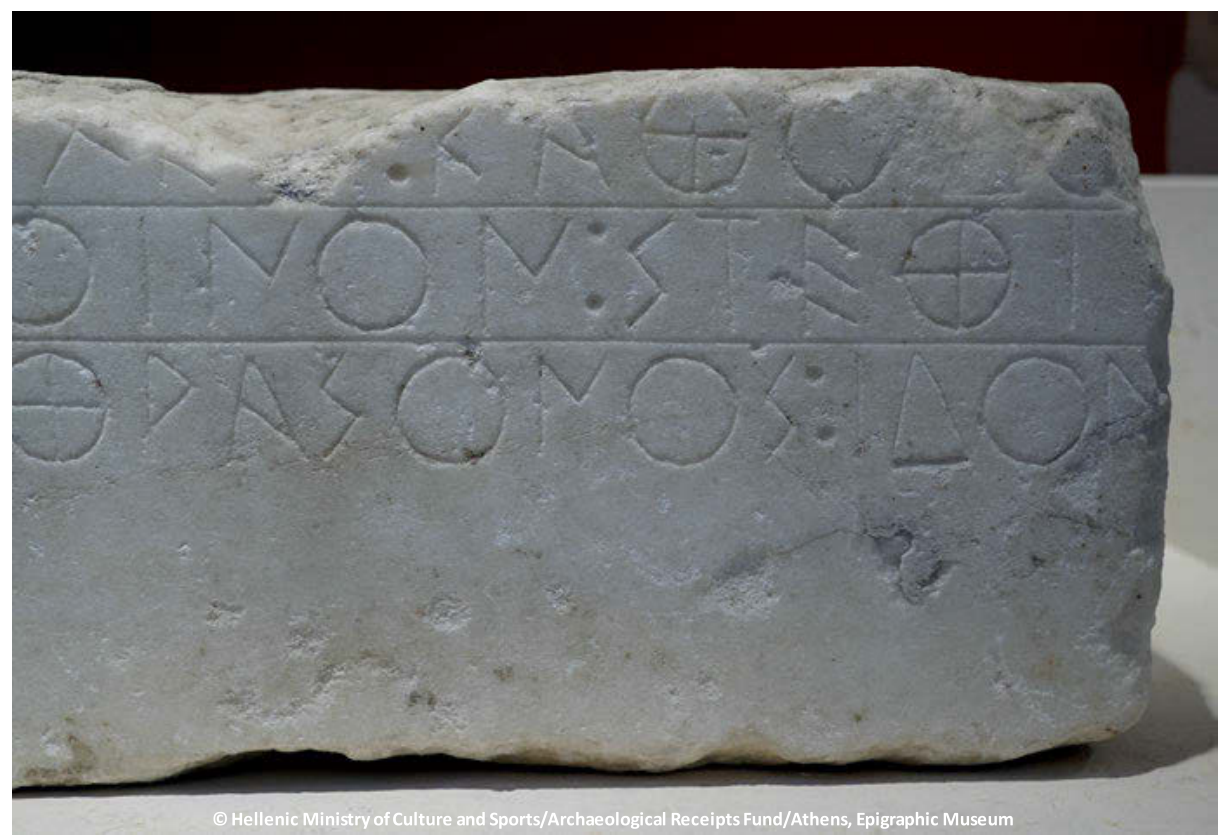

Abb.1.17b: Ausschnitt der Inschrift auf der Basis des Grabmonumentes des Thrason, drittes Viertel des 6. Jhs. v. Chr. (Athen, Epigraphisches Museum 10639).

Es lässt sich nicht ausschließen, dass die prägnanteren Linien ebenfalls als Hilfe für das Schreiben dienten. Sie sind aber so gearbeitet, dass sie als Teil der ästhetischen Gestaltung des beschrifteten Bereichs gelten müssen. ${ }^{210}$ Sie verstärken den Eindruck der Zeilen als Ornamentbänder, die sich über die gesamte Blockbreite ziehen. ${ }^{211}$ Solche sichtbar gemachten Linien können an den attischen archaischen Grabinschriften mit Schreiberhänden in Übereinstimmung gebracht werden. Unter den fünf Beispielen mit derartigen Linien stammen jeweils zwei von demselben Schreiber (Abb.1.17a-b); ${ }^{212}$ die fünfte kann wahrscheinlich ebenfalls einem der beiden Schreiber zugeordnet

die Buchstaben unten berührt: Peek 1942, 80 Anm. 1; Kissas 2000, Abb. 336. Vgl. auch eine spätarchaische Inschriftenplatte einer Weihung aus Ikaria mit Linien zwischen den Zeilen, in denen sich noch rote Farbe fand: Robinson 1948, 142 Taf. 35, 3 (IG I³ 1015; CEG I 303).

210 Vgl. Peek 1941, 21 „dekorative Verwendung“.

$211 \mathrm{Zu}$ Linien als Begrenzungen von Schriftstreifen siehe Kapitel III, S.166f.

212 Schreiber 1 (Mason C nach Jeffery): Kissas 2000, 59 A 24 Abb. 37 (IG I 1204; CEG I 28), 54 f. A 20 Abb. 28-30 (IG I 1240; CEG I 27). Die Ähnlichkeit zwischen den beiden Inschriften sowohl im Schriftbild, den Linien, den Punkt-Zeichen und dem Inhalt stellte Jeffery heraus (Jeffery 1962, 132 Nr. 33). Sie wies auf das unterschiedliche P hin: Jeffery 1962, 144 zu Nr. 57. Schreiber 2 (Mason A2 nach Jeffery): Kissas 2000, 39f. A 4 Abb. 7, 8 (IG I³ 1200; CEG I 19), 249 C 3 Abb. 336 (IG I³ 1202; CEG I 21). Vgl. Jeffery 1962, 118f. Nr. 3, 4. 


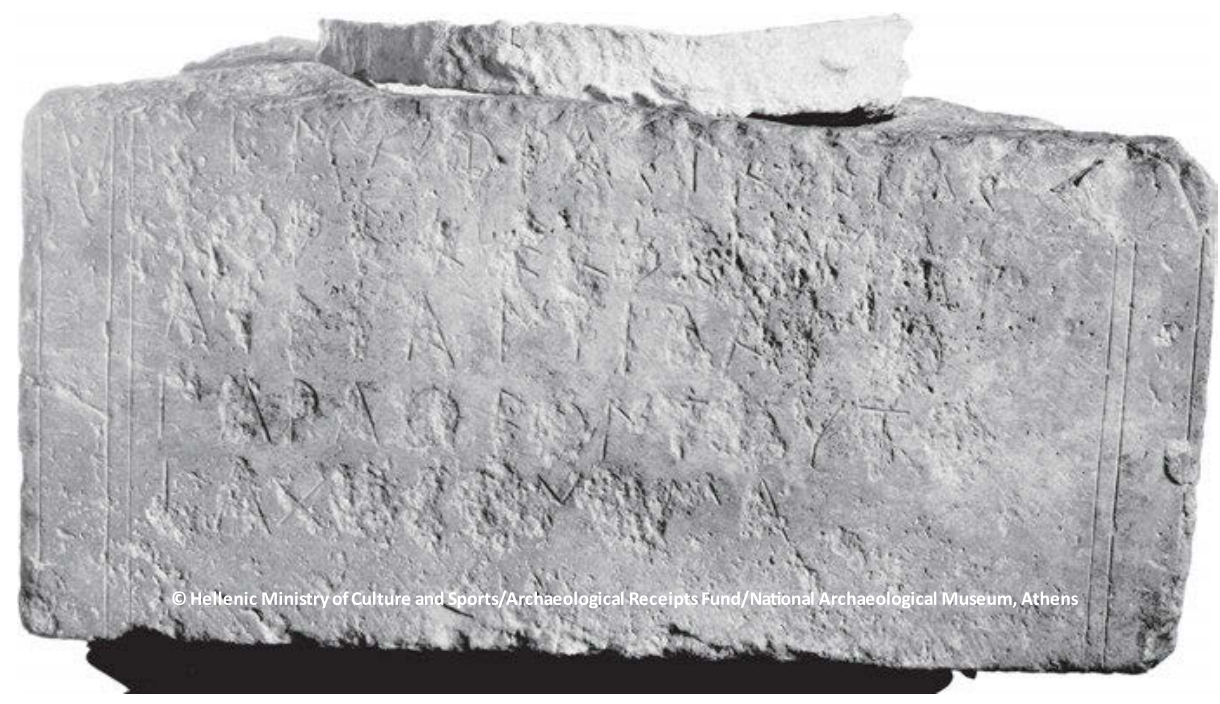

Abb.1.18a: Basis des Grabmonuments der Phrasikleia um 550/540 v. Chr. (Athen, Nationalmuseum 4889).

werden. ${ }^{213}$ Eine weitere Inschrift ${ }^{214}$ überliefert zwei solcher breiter Linien zwischen den Zeilen nur gemalt. Es handelt sich hier also durch die wenigen Beispiele (unter attischen Grabmälern) um Einzelstrategien, das jeweils beschriebene Feld zu gestalten. Diese Aufgabe oblag offenbar demjenigen Handwerker, der die Schrift anbrachte.

Ein weiterer Hinweis auf die Gestaltung des unmittelbaren Umfeldes der Inschrift sind Spuren von Rahmungen. So zeigt die Basis des Grabmals der Phrasikleia (Abb. 1.18a) auf allen Seiten eine Rahmung an der seitlichen und oberen Blockgrenze durch eine Doppellinie und eine einfache Linie; auf der rechten Seite des Blocks gibt es am Rand statt der einfachen Linie eine zweite Doppellinie (Abb. 2.13b). ${ }^{215}$ Die Doppellinie am Rand kehrt in ähnlicher Weise auf einer Grabstele auf der Agora wieder (Abb. 1.18b). ${ }^{216}$ Nach Keesling sind in beiden Fällen rote Farbspuren in diesen Bereichen erhalten, die auf eine rote Rahmung der Blockseiten beziehungsweise der Stele

213 Kissas 2000, 70 A 40 (Mastrokostas 1972, Abb.23; IG $\mathrm{I}^{3}$ 1262) erinnert mit dem T mit der kurzen Querhaste, aber auch mit dem N und dem O deutlich an Kissas 2000, 54f. A 20 Abb. 28-30 (IG I ${ }^{3}$ 1240; CEG I 27) und Kissas 2000, 59 A 24 Abb. 37 (IG I³ 1204; CEG I 28).

214 Kissas 2000, 70f. A $41 \mathrm{Abb} .48,49$ ( $I G \mathrm{I}^{3}$ 1344).

215 Zur Basis und Inschrift: Athen, Nationalmuseum Inv. 4889, um 540 v. Chr.: Kissas 2000, 47 A 14; IG I 1261; CEG I 24; DNO I 348. Vgl. die Abbildungen aller Basisseiten bei Butz 2010, Taf. 46-49; vgl. auch Jeffery 1962, 138f. Nr. 46 mit Abb.14, 15 Taf. 39 a; für ein farbiges Detailfoto: Brinkmann/KochBrinkmann/ Piening 2010, Abb.133. Auf der Vorder- und Rückseite sind aufgrund der Beschädigung im oberen Bereich die oberen Linien verloren, auf den beiden anderen Seiten jedoch erhalten. Vgl. zu den Rahmen der Basisseite auch: Keesling 1999, 520.

216 Kat. 1.1. Zum Vergleich Keesling 1999, 520 Anm. 48. 


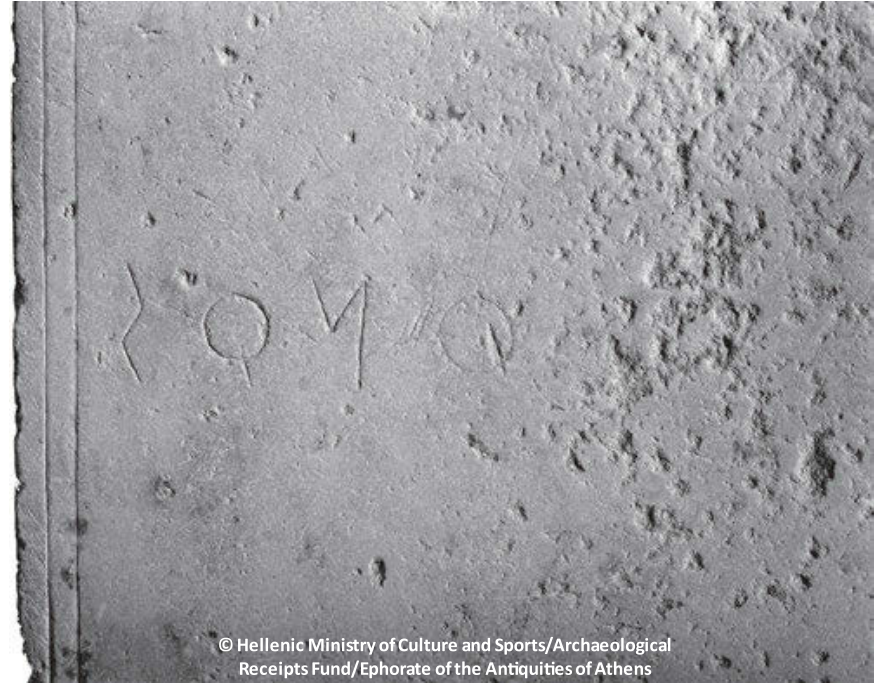

Abb.1.18b: Ausschnitt der Inschrift auf der Grabstele des -on vor 520 v. Chr.? (Athen, Agora Museum I.2056).

schließen lassen; Kaltsas bemerkte ebenfalls rote Farbspuren im Bereich der Doppellinien an der Basis der Phrasikleia. ${ }^{217}$ Wie bereits im Fall der betonten Linien zwischen den Zeilen könnte auch hier eine Übereinstimmung zwischen gestalterischer Besonderheit und der Schreiberhand vorliegen; der Schreiber könnte beiden Stücken derselbe gewesen sein. ${ }^{218}$ Die farbige Rahmung der beschriebenen Fläche ist kein Einzelfall, ${ }^{219}$ obwohl sie aufgrund der Vergänglichkeit der Farbe in vielen Fällen nicht mehr festzustellen ist. Die Grenze zu Linien anderer Funktion ist darüber hinaus schwer zu ziehen. ${ }^{220}$ Sicher ist jedoch, dass der Rahmen keine Einrahmung der In-

217 Keesling 1999, 520 mit Anm.48; Kaltsas 2002b, 9f. Dies ist im Gegensatz zu roten Buchstaben nicht in der aktuellen Farbrekonstruktion der Phrasikleia umgesetzt: Brinkmann/Koch-Brinkmann/ Piening 2010, Abb. 156. Dort wird leider die mögliche Farbigkeit der Streifen und der Buchstaben nicht untersucht. Ältere Farbrekonstruktionen der Phrasikleia beziehen die Basis nicht mit ein: Kaltsas 2002b, Taf. 1; Karakasi 1997, 7a-8b.

218 Vgl. v. a. die feine Ritzung der Buchstaben in Verbindung mit der Form des N, des $\Sigma$ und des O, genauso wie den Zusammenhang der Buchstaben zueinander. Jeffery schreibt die Basis der Phrasikleia (Athen, Nationalmuseum Inv. 4889, um 540 v. Chr.: Nikolaos Kaltsas, in: Despinis/ Kaltsas 2014, 46-51 Abb. 78-89 (mit neuerer Literaturliste); Kissas 2000, 47 A 14; Jeffery 1962, 138f. Nr. 46; IG I³ 1261; CEG I 24; DNO I 348) zwar Mason A1, die Stele (IG I³ 1246; Jeffery 1962, 135 Nr. 38) dagegen Mason A3 zu, sieht aber die Möglichkeit, dass Mason A1 und Mason A3 dieselbe Hand waren: Jeffery 1962, 151.

219 Vgl. die Hinweise auf eine rote Rahmung am Deckblock des Grabmonumentes des Neilonides (siehe Anm. 82) Vgl. hierzu Keesling 1999, 519f. Abb.1; Vgl. Keesling 1999, 518-522 zur Überprüfung der Zeichnung Philadelpheus' (Keesling 1999, Abb.2). Es gab die Rahmung offenbar an zwei Seiten: vgl. Keesling 1999, 526 Anm. 78. Zu einem weiteren Fall vgl. die Anmerkungen von Jeffery 1962, 116 Nr. 1 zu einem roten Rand an der Basis des Grabmals des Sosineos, Athen Epigraphisches Museum Inv. 10634a, zweites Viertel des 6. Jhs. v. Chr. (Kissas 2000, 42f. A 8 Abb.11; IG I 1195).

220 Vgl. das Grabmal des Leanax, Athen, 3. Ephorie Inv. M 662, 4. Viertel des 6. Jhs. v. Chr. (Kissas 2000, 61f. A 28; IG I³ 1365; CEG I 52; DNO I 378), in dessen Beschreibung Viviers 1992, 107 Folgendes 
schrift meint, da er sich auch auf den nicht-beschrifteten Seiten der Phrasikleia-Basis findet und wohl auch an zwei Seiten des Deckblocks des Neilonides-Monumentes ${ }^{221}$ $\mathrm{zu}$ rekonstruieren ist. Er gehört zur Gestaltung der jeweiligen Block-/Stelenseite und ist daher weitgehend unabhängig von der Inschrift, wie die Grabstele von der Athener Agora und die Basis des Neilonides auch dadurch nahelegen, da sich der Rahmen auf die ganze Fläche bezieht und nicht nur auf die Inschrift, die jeweils nur einen Teil der Oberfläche einnimmt. ${ }^{222}$ Vergleichen lässt sich diese Gestaltung des Stelenschaftes und des Basisblockes etwa mit der bisweilen bei archaischen Grabstelen vorkommenden Rahmung durch Ornamentbänder oder Leisten, ${ }^{223}$ oder der Absetzung bestimmter Bereiche durch eine Rahmung innerhalb der Stele, ${ }^{224}$ wie im Fall einer Grabstele in New York (Abb. 1.19), bei der im Predellabereich eine Streitwagenszene im Flachrelief vor dunklem Hintergrund ausgeführt ist, die oben und unten von zwei schmalen roten Streifen gerahmt wird. Der Farbauftrag erfolgte zwischen zwei geritzten Linien. ${ }^{225}$

Die Rahmung einzelner Flächen wirft darüber hinaus die Frage nach der farbigen Fassung der Inschrift und ihres Hintergrundes auf. Die Grabmonumente sind häufig aus unterschiedlichen Steinmaterialien kombiniert, wenn etwa die Basen zum Teil aus Kalkstein waren, die Stelen und Statuen aus Marmor. ${ }^{226}$ Weiter oben wurde bereits angesprochen, dass im Falle der Stufenbasen sich häufiger die Wertigkeit des

erwähnt: „Sur la face antérieure, qui présente un listel d'env. 0,03, travaillé au ciseau et poli, le long des arêtes supérieure et verticales [...]“. Der Schreiber habe dies aber beim Schreiben des Textes nicht berücksichtigt. Vielleicht sind hier zwei Phasen des Arbeitsprozesses zu fassen oder es liegt eine andere Funktion des Streifens vor. Schmale Ritzlinien werden, worauf Keesling hinwies, in der archaischen Plastik grundsätzlich zur Begrenzung von Farbauftrag verwendet: Keesling 1999, 519.

221 Siehe Anm. 82, 219.

222 Vgl. hierzu auch das aufschlussreiche Verhältnis von Inschriften und der Rahmen anbietenden Oberflächengestaltung anathyroseartiger Bearbeitung, siehe den Beitrag von J. Fouquet in diesem Band. Zu den Rahmen der Phrasikleia-Basis und einer möglichen Herkunft dieses Motivs siehe ausführlich Kapitel II, S. 126-131.

223 Vgl. etwa Kat. 1.2 (erhabene Leiste); Stele New York, Metropolitan Museum of Art Inv. 38.11.13, um 520 v. Chr.: Richter 1961, 32f. Nr. 45 Abb.126, 127 (Flechtband), hier Abb.1.19.

224 Vgl. etwa Doppellinie zur Begrenzung eines Ornamentbandes: Stele in New York, Metropolitan Museum of Art Inv. 21.88.179: Richter 1961, 40f. Nr. 55 Abb.141. Stele in Athen, Nationalmuseum Inv. 4477: Richter 1961, 45 Nr. 63 Abb. 145; Maria Salta, in: Despinis/Kaltsas 2014, 485 Nr. I.1. 404 Abb. 1311. Vgl. auch das Fragment eines oberen Stelenabschlusses (Athen, Agora Museum Inv. S 1438: Richter 1961, 30 Nr. 42 Abb. 123), das zwischen Blattband und Voluten zwei doppelte horizontale Linien zeigt. Offenbar gibt es rote Farbspuren (zwischen den beiden Doppellinien?): Harrison 1956, 26. Vgl. auch Ritzlinien auf dem abgesetzten Bereich unter dem Predellabild auf einer Grabstele in Rom, Museo Barracco Inv. unbekannt: Richter 1961, 45f. Nr. 64 Abb. 154.

225 New York, Metropolitan Museum of Art Inv. 38.11 .13 (Fletcher Fund 1938) um 520 v. Chr. Gut erkennbar auf den Abb. Richter 1961, Abb. 126, 128; vgl. auch Brinkmann 2003, Kat. 312 Abb. 312.6.

226 Man kombinierte jedoch auch unterschiedliche Marmorarten, wie das Beispiel des Grabmonumentes des Lyseas im Athener Nationalmuseum zeigt, dessen Basis mit Inschrift aus hymettischem Marmor, die bemalte Stele darauf aus pentelischem Marmor war: Athen, Nationalmuseum Inv. 30, 4. Viertel des 6. Jhs. v. Chr.: Kissas 2000, 255f. C 16 (IG I 1257; CEG I 53). 


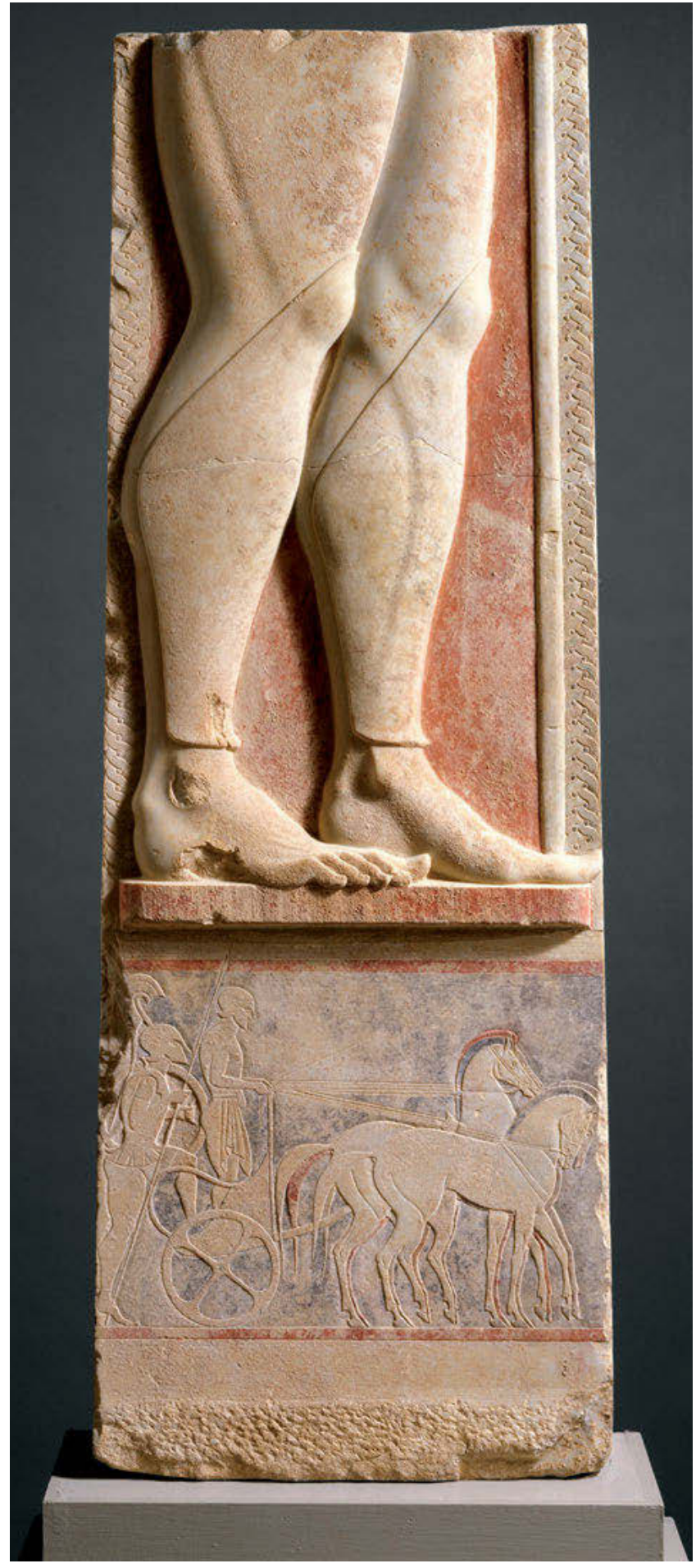

Abb.1.19: Grabstele mit der Darstellung eines Hopliten und einem Predellabild um 520 v. Chr. (New York, Metropolitan Museum of Art 38.11.13). 
Materials von unten nach oben steigert, wenn die unteren Stufen noch aus Kalkstein gearbeitet waren, die oberste jedoch aus Marmor. Bevorzugt scheint man auf Marmor geschrieben zu haben; wurde Kalkstein als Schreibgrund verwendet, stuckierte man offenbar den Block hell. In den Buchstaben der archaischen Grab- wie auch der Votivmonumente haben sich bisweilen rote Farbspuren überliefert, ${ }^{227}$ welche rote Inschriften auf hellem Steingrund nahelegen. Anders als bei den bemalten Grabstatuen und dem Figurenumfeld auf der Grabstele, welche die Farbigkeit des Steins durch eine Hintergrundfarbe negieren, scheint hier bei den Basisblöcken die helle Steinfarbe des Inschriftenträgers beibehalten beziehungsweise durch eine helle Stuckierung imitiert worden zu sein; die farbigen Buchstaben setzten sich davon ab und waren deutlich sichtbar. ${ }^{228}$

Auf den Stelen scheint mithilfe der Hintergrundfarbe zwischen verschiedenen Bereichen unterschieden worden zu sein, wovon eindrücklich das Grabmal des Antigenes zeugt (Abb.1.20). ${ }^{229}$

Die Stele zeigt kein Relief, sondern eine gemalte Figur, die sich hell vor einem roten Hintergrund abhebt. ${ }^{230}$ Die Figur füllt jedoch nicht die gesamte Höhe aus, sondern ,steht' auf einem hellen Bereich, der sich darüber in seinem Erscheinungsbild wohl der Basis anglich. Die Predella konnte jedoch auch, vor allem wenn sie ein Bild zeigte, einen farbigen Hintergrund erhalten, der nicht derselbe sein muss wie der Hintergrund der Figur. Auf der zuvor erwähnten Grabstele in New York (Abb.1.19) ${ }^{231}$ scheint nur ein Teil der Predella im Hintergrund dunkel bemalt gewesen zu sein, so dass ein heller Hintergrund über und unter dem Predellabild als Streifen sichtbar blieb. Sollte hier nicht die ursprüngliche farbige Fassung in diesem Bereich völlig vergangen sein, gibt dies einen Hinweis darauf, dass auch auf den Stelen durch einen hellen Hintergrund in einigen Bereichen auf die steinerne Beschaffenheit aufmerksam gemacht wurde. Dies wäre entscheidend für die Frage nach dem Hintergrund der Inschriften auf dem Stelenkörper. Wenige Hinweise, wie auf der Grabstele des Antiphanes (Kat.1.3; Abb.1.5), lassen vermuten, dass der Inschriftenhintergrund dort

227 Rot u. a. nachgewiesen in: Kissas 2000, 48-50 A 16 Abb.18-21 (IG I 1213; CEG I 43), $54 \mathrm{f}$. A 20 Abb. 28-30 (IG I3 1240; CEG I 27) (vgl. die Angaben bei Jeffery 1962, 143f. Nr. 57), 56f. A 22 (IG I3 1205; CEG I 38) (vgl. die Angaben bei Jeffery 1962, 121 Nr.12), 62f. A 29 Abb. 40 (IG I3 1357; CEG I 58), 250 C 7 (IG I³ 1203; CEG I 22) (vgl. die Angaben bei Jeffery 1962, 121 Nr.10), 256 C 17 Abb. 342 (IG I³ 1256) (vgl. die Angaben bei Jeffery 1962, 141 Nr. 52). Die Farbe wird in den Publikationen nicht konsequent erwähnt. Zu Farbe in archaischen Votivinschriften: Day 2010, 49.

228 Zur Farbigkeit der Buchstaben in den archaischen Weihinschriften von der Athener Akropolis „to enhance legibility and add visual interest“: Day 2010, 49 (vor allem rot, seltener blau und andere Farben).

229 New York, Metropolitan Museum of Art Inv. 15.167, Ende 6. Jh. v. Chr.: Richter 1961, 44f. Nr.61, 169f. Nr. 61 (M. Guarducci) Abb. 147, 210.

230 Weitere Beispiele: Brinkmann 2003, Kat. 128, Kat. 171 Abb.171.1, Kat. 304, Kat. 306, Kat. 307, Kat. 308, Kat. 312 Abb. 312.6 (im Bereich des Kriegers, anderer Farbhintergrund im Predellabild), Kat. 313. 231 Siehe Anm. 225. 


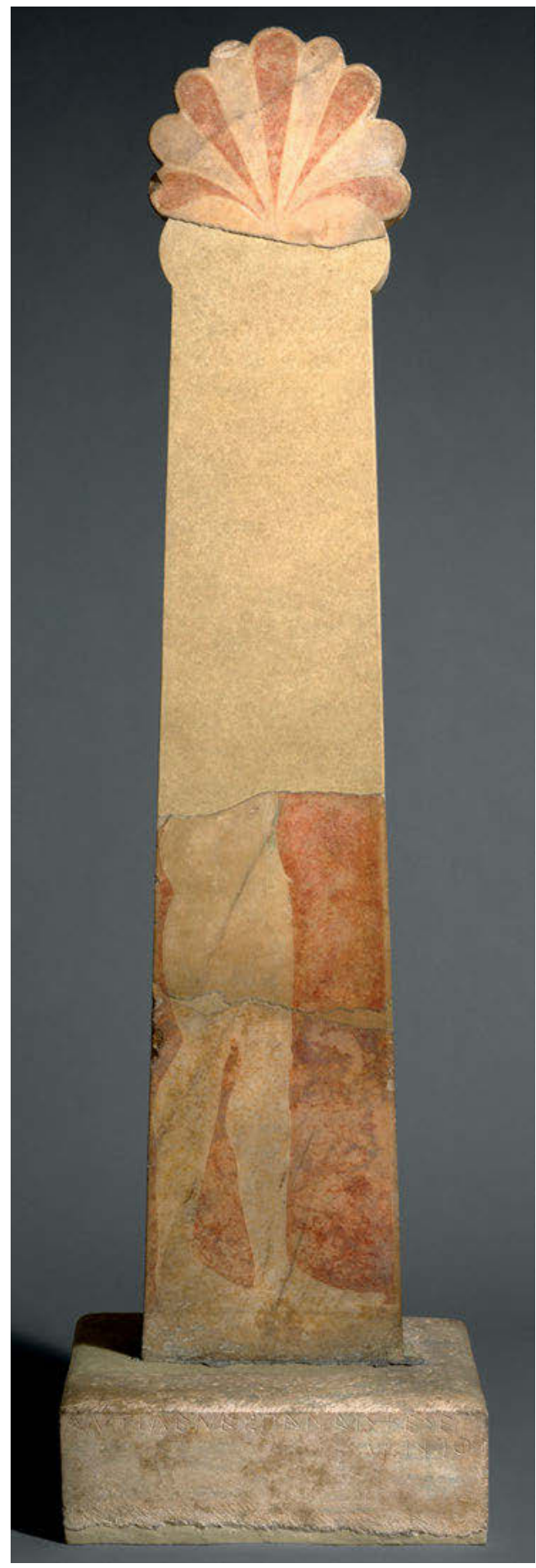

Abb. 1.20: Grabmonument des Antigenes, Ende 6. Jh. v. Chr. (New York, Metropolitan Museum of Art 15.167). 
wie auch im Bereich der Basen hell war. Die Grabstele zeigte im oberen Bereich einen Hahn, von dem ehemals noch Reste der Vorritzung und einige Farbspuren (rot und

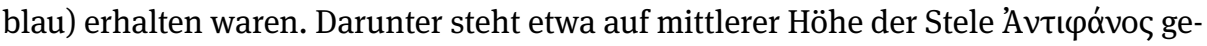
schrieben. Über der Inschrift ist noch heute ein rotes, horizontal verlaufendes Band zu sehen, das das Bildfeld des Hahnes nach unten hin begrenzte und in einem heute nicht mehr sichtbaren - roten Band unterhalb der gemalten Palmette am oberen Stelenabschluss seine Entsprechung fand. ${ }^{232}$ Obwohl der Bereich unterhalb der Inschrift nur unsicher zu rekonstruieren ist, ${ }^{233}$ liegt nahe, dass unterhalb des roten Bandes über der Inschrift mindestens bis unterhalb der Inschrift der Hintergrund hell war. So scheint es, dass zumindest partiell die Stele als marmornes Mal $^{234}$ präsentiert wurde und dass diese Bereiche vor allem die der Inschriften auf der Stele waren, ähnlich wie dies bei den Unterbauten der Monumente der Fall war. ${ }^{235}$

Die beschriebenen Oberflächen sind immer sorgfältig geglättet. Dabei werden allerdings die Flächen nicht nur zum Beschriften geglättet, ${ }^{236}$ sondern vielmehr hierarchisieren die unterschiedlich bearbeiteten Oberseiten die Seiten des Monumentes. ${ }^{237}$ Die Inschrift heftet sich an die privilegierte (,Vorder-')Seite des Monumentes, wodurch eine Verbindung zwischen geglätteter und zugleich beschrifteter Fläche entsteht. Für die Wirkung der Inschrift ist diese Verbindung von entscheidender Bedeutung. Sie setzt sich durch die Farbe deutlich vor einem Hintergrund mit einheitlicher, glatter Textur ab. Dies erhöht die Sichtbarkeit, fordert die Aufmerksamkeit des Betrachters und erhöht natürlich auch die Lesbarkeit. Das scharfe Einschneiden der hervorstechenden Buchstaben in die Oberfläche zerstört jedoch zugleich die zuvor aufwändig hergestellte Oberfläche des Artefaktes - ein visuelles Wechselspiel, das zugleich auf die Zeichen selbst als auch auf das Artefakt und seine Herstellung aufmerksam macht.

Durch die hervorstechenden, eingeschnittenen, rot gefärbten Buchstaben sowie ihre ornamental wirkende Anordnung in der Fläche entsteht also eine komplexe

232 Das obere rote Band ist erwähnt bei Conze 1893, 11 Nr. 22 Taf. XIII. Gut sichtbar auf der Photographie des Deutschen Archäologischen Instituts Abteilung Athen: http://arachne.uni-koeln.de/item/ marbilder/624762 (Stand: 17.08.2018).

233 Brückner hatte auf einer frühen Photographie, die jedoch nicht publiziert ist, offenbar noch Reste einer Malerei in diesem Bereich erkannt, die er zu einem Hund und einer Schlange ergänzte. Wenige Jahre später soll dies jedoch im Original schon nicht mehr sichtbar gewesen sein: Brückner 1886, 89 mit Taf. I,1 (Zeichnung).

234 Vgl. auch zur Farbe weiß für Marmor in Bezug auf den materialen Charakter des Gegenstandes: Mandel 2010, bes. 310-315.

235 Keesling nahm überzeugend für den Deckblock des Pfeilermonumentes des Neilonides an, dass der Hintergrund unbemalt belassen wurde und nur der rote Rahmen der Fläche, die Inschrift und die sitzende Figur gemalt gewesen war: Keesling 1999, $519 \mathrm{f}$.

236 Vgl. dagegen etwa die Anmerkung von Keesling 1999, 526 Anm. 78 zur linken Seite des Deckblocks des Neilonides-Monumentes, dass es dort (und nicht auf der rechten Blockseite) „extra polishing“ vielleicht aus dem Grund gab, weil man dort ursprünglich die Bildhauerinschrift anbringen wollte, sie dann aber doch auf die Vorderseite der Basis schrieb.

237 Vgl. diesbezüglich zur archaischen Plastik: Dietrich 2017a, bes. 292. 


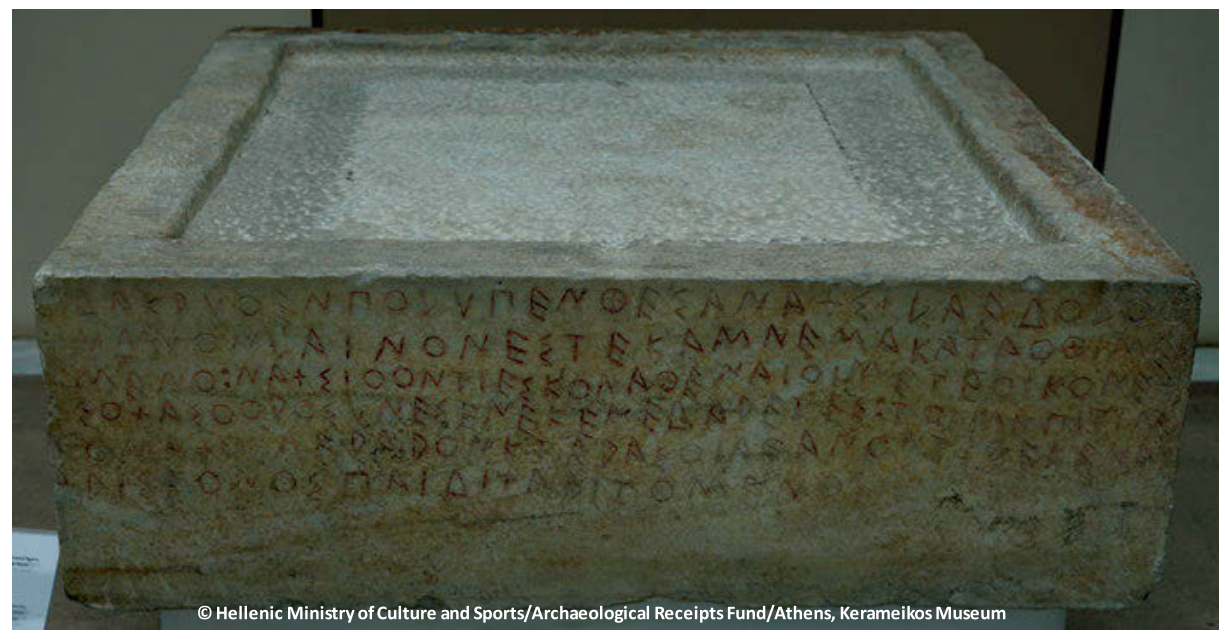

Abb.1.21: Basisblock des Grabmonumentes des Anaxilas, 4. Viertel des 6. Jhs. v. Chr. (Athen, Kerameikos Museum I 388).

Oberfläche (Abb.1.21), die vor das Entziffern/Lesen den ersten Eindruck einer ornamental gestalteten Fläche schaltet. ${ }^{238}$ Diese Betrachtungsintensität, die die Gestaltung der Inschrift einfordert, evoziert einen klaren Fokus auf den jeweils beschriebenen Bereich des Monumentes. Dabei ist es, wie nicht nur durch die Position, sondern auch durch das Schriftbild und die Farbigkeit der Inschrift vor ihrem Hintergrund deutlich wird, gerade das gebaute Monument aus Marmor $^{239}$, auf das der Betrachter aufmerksam gemacht wird. Dieser Kontrast wird beispielsweise deutlich, wenn man sich die farbige Gestaltung der Statuen vor Augen ruft (etwa am Beispiel der Phrasikleia $^{240}$ ), die einen scharfen Gegensatz zu dem hell-marmorfarbenen Hintergrund des Unterbaus bildete (Abb. 1.22).

238 Letztlich ist für den archaischen Leser nicht zu entscheiden ist, ob die Materialität der Inschrift sogar dazu führte, dass auf den ersten Blick die Zeichen sich dem Lesen des Textinhaltes ,widersetzten', bis der Betrachter durch intensives Sehen das sich ihm bietende Bild durch Abstraktion in ein kohärentes Aneinanderreihen von Buchstaben verwandelte, die das Lesen ermöglichte und zum Verständnis des Textinhaltes führte. Vgl. hier die Anmerkungen von A. Assmann zur „resistenten Materialität“ der Schrift und ihre Unterscheidung in Lesen und Starren: Assmann 1988a, bes. 240-242.

239 Vgl. zu weiß/marmorfarben als Verweis auf den materialen Charakter: Mandel 2010, bes. 310-315. 240 Athen, Nationalmuseum Inv. 4889, um 540 v. Chr.; vgl. mit neuer ausführlicher Literaturliste zur Statue, Basis (Kissas 2000, 47 A 14) und Inschrift (IG I³ 1261; CEG I 24; DNO I 348): Nikolaos Kaltsas, in: Despinis/Kaltsas 2014, 46-51 mit Abb.78-89. Vgl. etwa die Farbrekonstruktion Vinzenz Brinkmann, Ulrike Koch-Brinkmann, Helmut Piening, in: Brinkmann/Scholl (2010), 76-83 mit Abb.59, 67 und Brinkmann/Koch-Brinkmann/Piening 2010, Abb.156. Hier fehlt jedoch die rote Rahmung der Basisseiten, die Keesling und Kaltsas nach Farbspuren im Bereich der Doppellinien überzeugend vermuten: Keesling 1999, 520 mit Anm. 48; Kaltsas 2002b, 9f. Zur farbigen Rekonstruktion u. a. Brinkmann/ Koch-Brinkmann/Piening 2010; Schmaltz 2016; Kantarelou/Axiotis/Karydas 2016. 


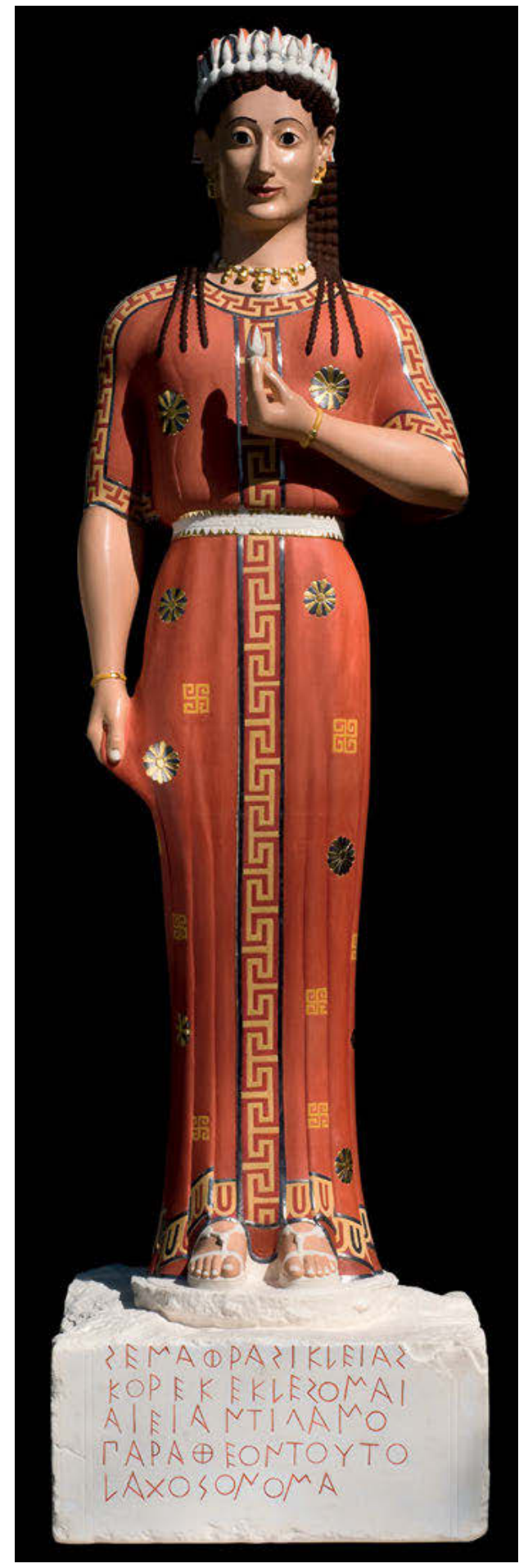

Abb.1.22: Grabstatue der Phrasikleia, Farbrekonstruktion (2010) - die roten Rahmen der Basisseiten sind nicht umgesetzt. Liebieghaus Skulpturensammlung, Frankfurt a. M., Forschungsprojekt Polychromie, Frankfurt am Main, seit 2014 Leihgabe Ludwig-Maximilians-Universität München, Leibnizpreis 2007, O. Primavesi. 
Die Inschriften lenkten den Betrachterblick, der von der Statue und ihrer Farbigkeit durchaus eingefangen gewesen sein dürfte, zusätzlich auch auf den Unterbau. Hier liegt zudem eine Besonderheit der Inschriften im Verhältnis zum Grabmal: Während Ornamente auch aufgemalt sein konnten, ${ }^{241}$ lassen sich keine gemalten Inschriften an archaischen Grabdenkmälern belegen. Durch das Einhauen der Buchstaben gehen der Stein und die Inschrift zusätzlich eine besondere Verbindung ein, die zudem durch den hellen Hintergrund unterstützt wird.

\section{Leitet die Inschrift den Betrachter am Grabmal?}

In gewisser Weise scheint die ästhetische Wirkung der Inschrift als Teil der Monumentgestaltung von größerer Wichtigkeit gewesen zu sein, als formale Strategien zu entwickeln, die die Struktur des Textes veranschaulichten und dadurch das Lesen unterstützten, wie es in späterer Zeit etwa durch Einrückungen oder Zeilenumbrüche greifbar ist (siehe hierzu Kapitel IV, S. 204-210). Das Lesen des Textes ist jedoch nur eine Möglichkeit von Handlungen des Betrachters am Monument, zu dem die Gestaltung der Inschrift aufgefordert oder diese erleichtert haben könnte. ${ }^{242}$ Bei den gleichzeitigen Votivmonumenten auf der Athener Akropolis lassen sich so bisweilen Zusammenhänge zwischen der Gestaltung der Inschrift und einer Bewegung des Betrachters fassen, worauf unter anderem Joseph Day hingewiesen hat. Auf einem Rundkapitell der Weihung des Aischines (Abb.1.23a-b) steht eine dreizeilige Inschrift, die die gesamte Abakushöhe einnimmt: ${ }^{243}$

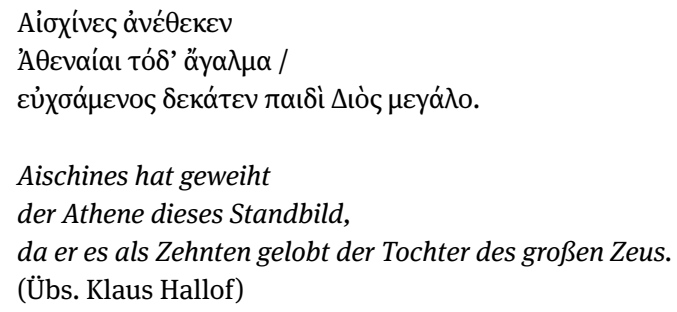

Hier sind in einem von einem Standpunkt erfassbaren Blickwinkel die ersten beiden

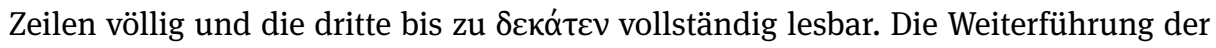
dritten Zeile erfordert es, nach rechts um das Monument herumzugehen. Das an-

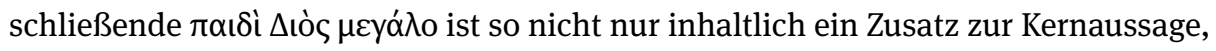
dass Aischines dieses Agalma der Athena als Zehnten geweiht habe, sondern fordert auch den Betrachter auf, sich zu bewegen. Von einem Standpunkt aus konnte der

241 Vgl. etwa auf der Stele des Mnasitheos (Anm. 112): Andreiomenou 2000, 87-89 Abb. 3 Taf. 7, 2.3. 242 Vgl. zum Begriff Affordanz im Kontext von Schrift: Fox/Panagiotopoulos/Tsouparopoulou 2015. 243 Athen, Akropolis Museum Mag. Inv. 3759, um 510/500 v. Chr.: DAA, 50 Nr. 48; Kissas 2000, 201 B 157 Abb. 265, 266; Kaczko 2016, 122-124 Nr. 24 mit Abb. 24a.b; IG I³ 631; CEG I 202. 

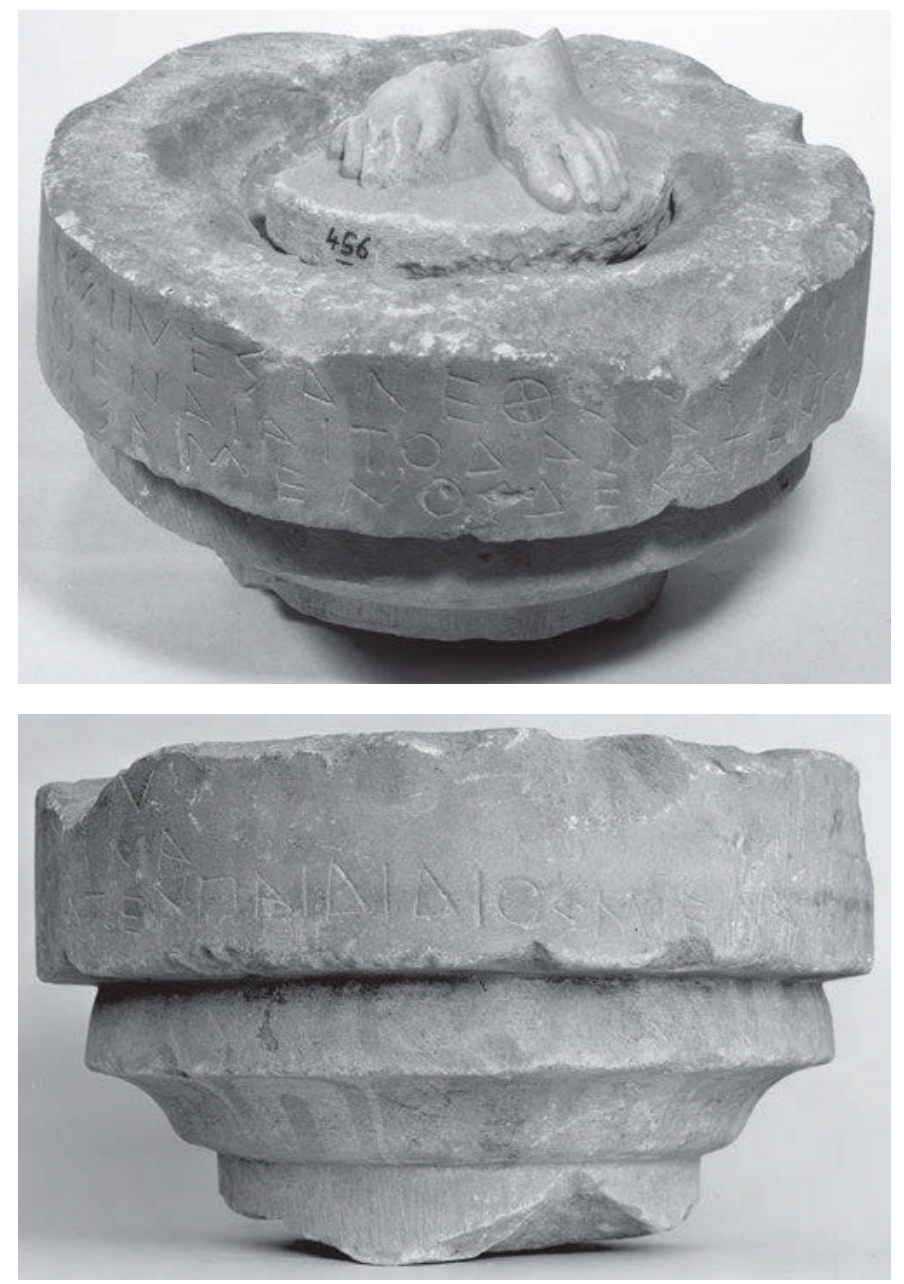

Abb.1.23a-b: Rundkapitell des Votivmonumentes des Aischines an Athena von der Athener Akropolis, um 510/500 v. Chr. (Athen, Akropolis Museum Mag. 3759).

Leser zwar den zentralen Inhalt vollständig erfassen, wusste aber durch die Weiterführung der Buchstaben in der dritten Zeile, dass es zusätzliche Informationen gab, wenn er um die Statue herumging. ${ }^{244}$ Dies wird noch dadurch unterstützt, dass die Inschrift im elegischen Distichon verfasst ist. Der Hexameter endet mit őyo $\lambda \mu \alpha$ am Ende der zweiten Zeile, während der zweite Teil des elegischen Distichons in der drit-

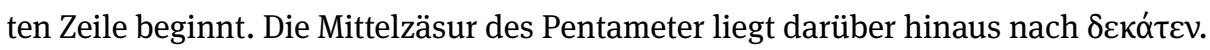
Der Leser der Inschrift wusste daher natürlich, dass der zweite Teil des Pentameters noch folgt, genau wie er die Buchstaben sah, die ihn um das Kapitell herumführten.

244 Vgl. hierzu Day 2010, 58; Berti et al. 2015, 644-646. 
Die visuelle und metrische Zäsur der Inschrift verbindet das Stehenbleiben mit der Aufforderung zum Weitergehen. ${ }^{245}$

Bei den archaischen Grabmonumenten ist dagegen kein Fall bekannt, bei dem der Betrachter eindeutig anhand der Inschriftenposition aufgefordert wurde, um das Monument herumzugehen. Die Grabinschrift war in allen Fällen vollständig auf derjenigen Seite lesbar, auf die die Statuen oder Stelenbilder ausgerichtet sind. ${ }^{246}$ In einigen Fällen ist die Grabinschrift auf einer anderen Seite vollständig oder inhaltlich verkürzt wiederholt. ${ }^{247}$ Diese Fälle sind wohl in Zusammenhang mit einer besonderen Aufstellungssituation zu erklären, etwa mit der Aufstellung an einer Wegkreuzung. ${ }^{248}$

Bei drei Grabdenkmälern, die die Bildhauernennung des Aristion von Paros tragen, ist diese Inschrift an einer anderen Seite der Basis angebracht als die Grabinschrift (Abb.2.13 a.b). ${ }^{249}$ Dies muss man aber nicht so verstehen, dass der Betrachter um das Monument geleitet werden sollte, sondern erklärt sich mit Blick auf die Gesamtgestaltung der Monumente und der zuvor beschriebenen Position von Inschrift, Bildern und Ornamenten. An diesen Monumenten werden nicht nur die Partien der Vorderseite differenziert verziert und gegenüber den anderen Seiten des Monumentes aufgewertet, sondern auch die Seiten des Monumentes zeigen zusätzlichen Aufwand der Ausgestaltung. ${ }^{250}$ Beim Grabmonument der Phrasikleia ist so die Vorderseite der

245 Ähnlich ist hier auch die Weihung des Euthydikos von der Athener Akropolis (Athen, Akropolis Museum Inv. 609, 686, um 480 v. Chr.: DAA, 56f. Nr.56; Kissas 2000, 208 B 163 Abb. 279, 280; IG I³ 758; zum Folgenden auch Keesling 2003, 31f.). Bei einem Standpunkt direkt vor der Statue konnte

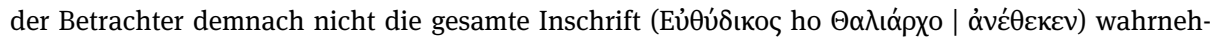

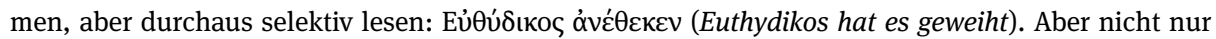
die Fortführung der Inschrift um das Kapitell herum sprach den Betrachter an, um das Monument herumzugehen, sondern auch ein gemalter Wagenfries, der auf dem Chiton der zugehörigen Kore von vorne ausgehend über die Schulter führte (Brinkmann 2003, Kat. 107 mit Abb.107.6-9).

246 Aufschlussreich ist die Ausrichtung der Inschrift und des Bildes auf eine gemeinsame Seite auf der Basis der Reiterstatue am Grabmal des Xenophantos (Athen, Kerameikos Museum Inv. I 389, um 530/520 v. Chr.: Kissas 2000, 55f. A 21 Abb. 31, 32; IG I³ 1218; CEG I 50; DNO I 376). Die Inschrift befindet sich auf der Schmalseite, dementsprechend derjenigen Seite, die die Köpfe von Pferd und Reiter in der Frontalansicht zeigte.

247 Siehe die Beispiele auf Quader- oder Stufenförmigen Unterbauten: Kissas 2000, 42f. A 8 Abb. 11 (IG I 1195); Kissas 2000, 61f. A 28 (IG I³ 1365; CEG I 52; DNO I 378; Abb.: Knigge 1969, Taf. 37,1). Die Beschriftung zweier Seiten eines Grabsäulenschaftes: Kissas 2000, 79 A 47 (= Raubitschek 1939b, 58-62 Nr. 29 mit Abb. 17; IG I3 1269; CEG I 36; DNO I 350). Beschriftung von zwei gegenüberliegenden Seiten einer Grabstele oder Grabplatte: Kat. 1.19. Unklar ist diesbezüglich das Fragment einer archaischen Stele, das an einer Schmalseite wohl wahrscheinlicher mit einer Weihinschrift als einer Stiftungsinschrift für ein Grab und an der Breitseite mit einer Liste von Namen beschrieben ist: Jeffery 1962, 143 Nr. 55 Taf. 39 d (IG I $\mathrm{I}^{3}$ 972).

248 Vgl. Kissas 2000, $42 \mathrm{zu}$ A 8 (IG I 1195).

249 Kissas 2000, 47 A 14 (IG I³ 1261; CEG I 24; DNO I 348), 51 A 18 Abb. 23-26 (IG I3 1208; CEG I 34; DNO I 347), 51-54 A 19 Abb. 27 (IG I³ 1211; CEG I 41; DNO I 349). Siehe zu diesen auch zuvor.

250 Vgl. diesbezüglich zur archaischen Plastik: Dietrich 2017a, bes. 292. Vgl. zur dekorativen Gestaltung von Blockflächen auch ausführlich den Beitrag von J. Fouquet in diesem Band. 
obersten Stufe des Unterbaus sorgfältig geglättet und präsentierte eine Inschrift und eine farbige Umrahmung der Blockfläche. Die rechte Nebenseite überliefert einen ehemals farbigen Rahmen und die Bildhauerinschrift, die anderen Seiten dagegen alleine ehemals farbige Rahmen. ${ }^{251}$ Diesem differenzierten Umgang mit den Gestaltungsmöglichkeiten von Blockpartien und ihrer dadurch möglichen Hierarchisierung lassen sich auch andere Maßnahmen an anderen Beispielen hinzufügen, wie etwa die zusätzliche Reliefierung der Seitenansichten von Pfeilerdeckblöcken, während die Rückseite unreliefiert blieb. ${ }^{252}$ Bei den drei Beispielen mit der Bildhauernennung des Aristion handelt es sich zudem um Unterbauten für Statuen, die selbst auf allen Seiten sorgfältig ausgearbeitet waren und damit grundsätzlich eine Ansicht unterschiedlicher Seiten ermöglichten. In Falle der Stelenmonumente lässt sich im Verlauf des 6. Jhs. v. Chr. eine stärkere Fokussierung auf eine Monumentseite fassen, wie Schmaltz darlegte, da sich die Stelen von einer Pfeilerform hin zu flachen Platten entwickelten und dabei dann nicht mehr alle Stelenseiten gleichermaßen ausgearbeitet und ausgestaltet waren. ${ }^{253}$

Die Inschriften am Grabmal waren also bis auf wenige Ausnahmen ausschließlich der präferierten Hauptansichtsseite des Monuments zugeordnet. Die Grabinschrift mit dem Namen des Verstorbenen findet sich ohne Ausnahme nur auf dieser Seite. Der Betrachter wurde also keineswegs durch unvollständige Inschriften oder Ähnliches dazu veranlasst, um das Monument herumzugehen. Im Gegenteil: Er sollte vielmehr an dieser präferierten Seite des Monuments stehenbleiben, Bild und Inschrift wahrnehmen und dadurch des Verstorbenen gedenken. Dies formulieren auch die Texte der Grabinschriften bisweilen explizit, etwa das Grabmal des Thrason, dessen Epigramm Folgendes zum Inhalt hat: ${ }^{254}$

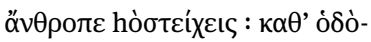

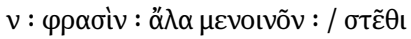

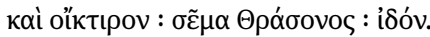

Mensch, der du des Weges ziehst, und dabei im Herzen an anderes denkst, bleib stehen und klage, wenn Du das Grabmal des Thrason erblickst.

(Übs. Klaus Hallof)

251 Zur Phrasikleia-Basis: Anm. 215. Vgl. Butz 2010, Taf. 46-49; Keesling 1999, 520.

252 Siehe die Beispiele bei Kissas 2000, 74-76 A 43, A 44, A 45 mit Abb. 52-55. Dagegen zeigt der oberste Block des Stelenunterbaus Athen, Kerameikos Museum Inv. P 1001, um 560 v. Chr. (Kissas 2000, 43f. A 10 Abb. 12) nur auf der Vorderseite ein Relief.

253 Vgl. Schmaltz 1983, bes. 157.

254 Athen, Epigraphisches Museum Inv. 10639, drittes Viertel des 6. Jhs. v. Chr.: Kissas 2000, 59 A 24 Abb. 37; IG I3 1204; CEG I 28. 


\section{Zusammenfassung - Inschrift und Monument}

Die Inschrift band sich an die marmornen und zugleich nicht-figürlichen Bereiche des Grabmals und lenkte durch ihre Gestaltung den Betrachterblick auf diesen Bereich des Monumentes, der ihm anzeigte, dass es aufwändig aus Marmor hergestellt und auf Dauer hin wie ein Gebäude errichtet wurde. Auf diesen Artefaktcharakter des Monumentes und seine unmittelbare Präsenz an einem konkreten Ort weisen aber nicht nur die ästhetischen Strategien der Inschrift hin, sondern auch der Textinhalt vieler archaischen Grabinschriften. Die bekannten Grabinschriften, die das Leben des Verstorbenen thematisieren (wie etwa die berühmten Inschriften der Phrasikleia ${ }^{255}$ und des Kroisos ${ }^{256}$ ), sind zahlenmäßig nicht besonders häufig. Viele nennen dagegen neben der auf das beschriebene Monument verweisende Angabe (,sêma / mnêma des N. N.“) denjenigen, der es errichtet und/oder gemacht habe. ${ }^{257}$ Variantenreich ver-

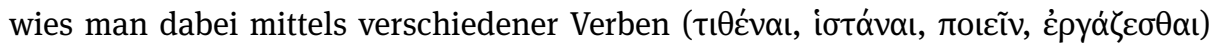
auf seine Fertigung und Aufstellung, was sich nicht allein mit einer wie bei den Vo-

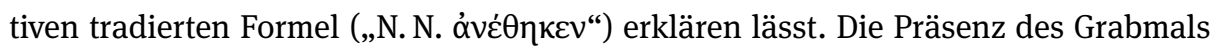
ist zudem in den Inschriften Ausgangspunkt für Handlungen des Betrachters ${ }^{258}$ - er wird aufgefordert, an diesem stehenzubleiben, ${ }^{259}$ es anzusehen ${ }^{260}$ und zu klagen beziehungsweise des Verstorbenen zu gedenken. ${ }^{261}$ In einzelnen Fällen wird sogar das Grabmal im Text selbst mit einer Charakterisierung versehen: Es sei schön (schön anzusehen) ${ }^{262}$ oder aus Stein gemacht. ${ }^{263}$

Auch die Bildhauerinschriften lassen sich in diesem Kontext verstehen, da sie den Leser dezidiert auf einen Aspekt der Herstellung des Grabmals hinwiesen. Das Phänomen der häufigen Bildhauerinschriften an archaischen Grabmonumenten (wie auch an den Votivmonumenten) findet damit auch eine Begründung im Fokus auf das

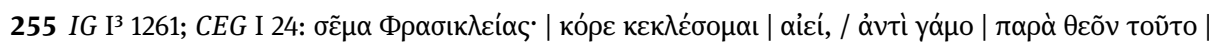
$\lambda \alpha \chi \tilde{o} \sigma$ ' övo $\mu \alpha$. (Grabmal der Phrasikleia. Jungfrau werde ich immer heißen: statt der Hochzeit habe ich von den Göttern diesen Namen erlost.).

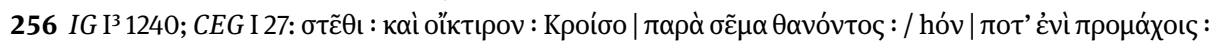

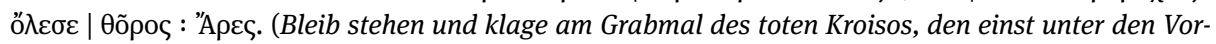
kämpfern vernichtete der stürmische Ares.).

257 Sourvinou-Inwood 1995, bes. 147-150 zu den verschiedenen Inschriftentypen.

258 Vgl. hierzu, auch zum Folgenden: Steiner 2001, $255 \mathrm{f}$.

259 IG I3 1240 (CEG I 27; Kissas 2000, 54f. A 20 Abb. 28-30), IG I3 1204 (CEG I 28; Kissas 2000, 59 A 24 Abb. 37).

260 Vgl. etwa IG I³ 1200 (CEG I 19; Kissas 2000, 39f. A 4 Abb. 7, 8), IG I³ 1219 (CEG I 51; Kissas 2000, 41f. A 7 Abb. 10), IG I 1277 (CEG I 68; Kissas 2000, 249 C 4); vgl. auch die Inschriften auf einer Stele IG I³ 1273bis und auf einer verschollenen Basis IG $\mathrm{I}^{3} 1215$ (CEG I 46).

261 Vgl. etwa IG I 1208 (= DNO I 347; CEG I 34; Kissas 2000, 51 A 18 Abb. 23-26).

262 IG I $\mathrm{I}^{3} 1251$ (CEG I 18; Kissas 2000, 46f. A 13 Abb. 16, 17), IG I 1214 (CEG I 42; Kissas 2000, 71-73 A 42 Abb.50, 51), Kat. 1.12. Zum Bezug des Attributes schön dezidiert auf das Monument und nicht auf die Person vgl. Robertson 2003, 60.

263 IG I³ 1357 (CEG I 58; Kissas 2000, 62f. A 29 Abb. 40). 
Grabmal als Artefakt und in der daraus resultierenden physischen Präsenz. ${ }^{264}$ Weitere Gründe für die Anbringung einer Bildhauerinschrift sind in den Interessen des Bildhauers und demjenigen, der das Grabmal in Auftrag gab, zu suchen. ${ }^{265}$ Diese unterschiedlichen Interessen, die letztlich auf ein Gesamtkonzept des Grabmals mit seinen Inschriften führen, erklären zudem, dass die Schreiberhand der jeweiligen Inschrift in fast allen Fällen keine Verbindung zur Bildhauernennung hat: Nicht der Bildhauer selbst markierte im Sinne des modernen Verständnisses einer Signatur das Werk mit seinem Namen. ${ }^{266}$

In vielen Grabinschriften nimmt die Herstellung und Errichtung des Grabmals sogar den größten Platz ein, noch bevor um den Toten geklagt wird und seine Eigenschaften hervorgehoben werden. Dies leistet ferner einen entscheidenden Anteil am Funktionieren des Monumentes als Grabmal: Indem man dezidiert einen Fokus auf die Fertigung und Errichtung legte, maß man dem Monument einerseits eine begründete Vergangenheit und andererseits eine Perspektive für die Zukunft zu. Als ,gebautes Monument' war es dauerhaft an einem Ort verankert. ${ }^{267}$ Nur dadurch war gewährleistet, dass auch die Erinnerung an den Verstorbenen fortbestand - erneuert durch jeden, der das Monument an diesem Ort passierte.

Visuell wurde eine solche Dauerhaftigkeit vor allem über Anleihen an architektonischen Elementen vermittelt. Die aufwändigen Unterbauten archaischer attischer Grabdenkmäler aus Pfeilern, Säulen oder aufgeschichteten Quadern (Abb.1.1), trugen ihren Anteil zur Wirkung des gesamten Monumentes bei. ${ }^{268}$ Der Unterbau hatte nicht allein die Funktion, die Aufstellung der aufwändig gefertigten und farbig gefassten Statue oder Stele zu ermöglichen und einen ästhetischen Ausgleich oder ihre Präsentation zu unterstützen. ${ }^{269}$ Vielmehr wurde mit der Architektur der Unterbauten eine

264 Siehe hierzu demnächst Reinhardt (im Druck).

$265 \mathrm{Zu}$ den unterschiedlichen Interessen bei der Anbringung von Bildhauerinschriften: vgl. etwa Ecker 1990, 136-138, 144; Viviers 2006, 149f.; Muller-Dufeu 2011, 117; DNO I, S. XXXI; Hurwit 2015, 147-152.

266 Vgl. etwa Jeffery 1962, 151; Hurwit 2015, 141; DNO I, S. XXXI. Einigen Bildhauern werden Inschriften als Autographen zugeschrieben, wobei hier die Argumentationsgrundlage schwierig ist. Zu Bildhauersignaturen vgl. den Sammelband Hegener 2013; zu antiken Bildhauersignaturen bes. Hurwit 2015. Die aktuelle Materialgrundlage ist detailliert in DNO aufbereitet. Obwohl das Schreiben der Bildhauerinschrift professionellen Schreibern zugeordnet wird, wird dahinter meist die bestimmende Hand des Bildhauers vermutet: etwa Hurwit 2015, 104. Zur problematischen Sichtweise der Bildhauerinschrift als Zeugnis eines menschlichen Bedürfnisses, das Produkt des eigenen Schaffens mit dem eigenen Namen zu versehen vgl. Hurwit 2015, 150.

267 Vgl. auch Steiner 2001, 256f.

268 Für attische Grabmonumente in der Zeit von ca. 560-480 v. Chr. scheint nach der Analyse von Kissas die Stufenbasis bemerkenswert häufig verwendet worden zu sein, auch wenn der Abgleich zu schlechter erhaltenen Materialgruppen andernorts nicht möglich ist (und sich damit nicht sicher ein Attika-Spezifikum erschließen lässt). Als Bestandteil von Votivmonumenten findet sie in Attika erst gegen Ende des 6. Jh. v. Chr. Verwendung, vgl. Kissas 2000, 15.

269 In diese Richtung zielen Erklärungsversuche zur Entstehung der Basis: Kissas sieht die zunehmende Anzahl der Stufenbasen in spätarchaischer Zeit und die Ablösung der noch in hocharchai- 
eigene Aussage getroffen. ${ }^{270}$ Eine solche Bedeutung teilen die Grabdenkmäler mit den archaischen Votivmonumenten aus Athen, ${ }^{271}$ die mit ihren Säulen- und Pfeilerunterbauten ebenfalls eindrücklich versuchten, dauerhaft im Heiligtum präsent zu bleiben und zudem die anderen zu übertreffen.

Die Inschriften unterstreichen demnach formal die steinerne Monumentalität des attischen Grabmals und stellen einen Bezug zum Bild nur insofern her, als dass sie an demselben Monument angebracht sind. ${ }^{272}$ Man könnte hier zudem noch die - jedoch aufgrund des Erhaltungszustandes nicht grundsätzlich nachzuweisende - These aufstellen, dass ein weiterer Bezug darin bestand, dass Inschrift und Figur dieselben Monumentseiten adressieren und darüber ein intensiveres Zusammenlesen/-Sehen der beiden Elemente möglich wurde, was bild-textlichen Verbindungen förderlich gewesen sein könnte. Darüber hinaus lassen sich jedoch in der Gestaltung der Inschriften keine Strategien wie etwa in der Vasenmalerei, an späteren Ehrenmonumenten (siehe S.51f. in diesem Kapitel) oder an späteren Grabreliefs (siehe Kapitel IV, S. 195-204) fassen, dass durch die Position des Namens eine auffällige formale Beziehung zwischen Figur und Name im Sinne einer Beischrift entsteht. Die formale Hervorhebung des Namens in wenigen Fällen - wie zuvor beschrieben - kann durchaus auch nur textinhärent begründet sein. Für den Rezipienten von Text und Bild mag dadurch aber auch eine zusätzliche Verbindung unterstützt worden sein.

Die großformatige Figur war im Rahmen der archaischen Grabmäler zwar ein etablierter, aber kein unabdingbarer Teil des Grabmonuments. ${ }^{273}$ Hierauf weisen auch

scher Zeit am häufigsten verwendeten Quaderbasis in einer Veränderung der Größe der aufgestellten Statuen. Die anfangs überlebensgroßen Statuen benötigten seiner Ansicht nach die Basis allein für die Aufstellung, während die späteren kleineren Statuen eine Erhöhung der Basis brauchen, um eine adäquate Wirkung zu entfalten; dies hätte die Stufenbasis geleistet: vgl. Kissas 2000, 11-15. WalterKarydi betonte bei der Frage nach der Entstehung der griechischen Statuenbasis den Zusammenhang zur Monumentalität, als deren charakteristische Merkmale sie „die aufeinander abgestimmten Proportionen und die achsiale Bindung an den Boden“ (Walter-Karydi 1980, 4) sah.

$270 \mathrm{Zu}$ „stability“ und dem ,unmoving character“ des Grabmals vgl. auch Steiner 2001, $256 \mathrm{f}$.

$271 \mathrm{Zu}$ diesen grundlegend $D A A$; Kissas 2000, 81-246, 258-284.

272 Eine auffällige Übereinstimmung scheint es dabei zwischen der Existenz von Stufenbasen in Athen und Attika und dem fehlenden Beschriften der Statuen zu geben. Während es außerhalb Attika üblich ist, direkt auf die Statuen zu schreiben, ist von dort kein vergleichbarer Fokus auf monumentale architektonische Unterbauten in Form von Stufenbasen und Pfeilerbasen wie in Attika überliefert (Kissas 2000, 15 zur Stufenbasis, 16, 20 zu den Pfeilerbasen); dagegen sind Säulenbasen auch außerhalb Attikas sehr verbreitet, stehen also vielleicht in einer anderen Tradition: vgl. zu den Basen Jacob-Felsch 1969, 23-48. Vgl. zu einem Zusammenhang zwischen der Beschriftung der Basis und der Bedeutung der Inschrift am Beispiel des Naxierkolosses: Giuliani 2006, bes. 107.

273 Vgl. zu archaischen Stelen ohne Figurendarstellungen: Schmaltz 1983, 160. Er wies zudem auf den Unterschied zwischen den Darstellungen von Figuren im Profil auf den Stelen und den frontalen Darstellungen der Statuen an Grabdenkmälern hin. Seiner Meinung nach wird der Kouros durch die „körperhafte Unmittelbarkeit“ und den Verzicht auf Attribute oder eine Handlung von der menschlichen Sphäre getrennt, während die Bilder auf den Reliefs das Gegenteil vermögen: Schmaltz 1983, 160. 
die Darstellungen auf den später entstandenen attischen, weißgrundigen Lekythen des 5. Jhs. v. Chr. hin, in denen das Stelenmonument als steinernes Mal im Vordergrund steht, ${ }^{274}$ es darauf jedoch kein Bild gibt. ${ }^{275}$ Inschriften wurden dagegen auf den Stelen in der Vasenmalerei in seltenen Fällen dargestellt (oder imitiert), wohl da sie wie die ornamentale Gestaltung zum Monument gehörten. ${ }^{276}$

Vergleichbare Inschriften, die das Grabmal dem Verstorbenen zuwiesen, gab es bei den „Figur-losen“ Grabmälern natürlich ebenso wie bei denjenigen mit Darstellung einer Figur, wovon etwa das Beispiel der Grabstele des Antiphanes zeugt (Kat. 1.3; Abb.1.5), bei dem der Name im Genetiv mitten horizontal auf dem Stelenschaft eingeschrieben ist. Darüber befand sich ehemals die Darstellung eines Hahns, wie bereits zuvor beschrieben. Auf eine Figur, die den Toten repräsentierte, scheint man hier verzichtet zu haben. Hier stellte nun der Name natürlich keinen - nicht einmal einen allgemeinen - Bezug zu einer Figur her, sondern kennzeichnete das Monument (so ist auch der Genetiv zu verstehen) als dem Toten zugehörig. Auch die in einzelnen Fällen erhaltenen dünneren Platten (Kat. 1.9, 1.10, 1.11, 1.19), von denen zwei aus Velanideza stammen, könnten eine Unabhängigkeit der Grabinschriften von der Figur nahelegen, wenn in den fehlenden Partien der Platten keine Figur dargestellt war und die Platten nicht in Zusammenhang zu einer Statuenaufstellung - etwa im Basisbereich - standen. Leider lässt sich über die ursprüngliche Verwendung der Platten und ihre Aufstellung/Anbringung nichts Konkretes mehr erschließen, so dass diese Frage nicht geklärt werden kann: Zwei Platten (Kat. 1.9 und 1.10) wurden ex situ im Bereich des großen Tumulus in Velanideza gefunden. ${ }^{277}$ Lilian Jeffery vermutete bei der Platte für Phil(ode)m(os) und (An)them(ion) (Kat. 1.10) einen Zusammenhang zum Hausgrab unter dem großen Tumulus, das zwei Gräber überdeckte. Da die Rückseiten nicht als Ansichtsseiten ausgearbeitet sind, schlug sie vor, dass solche Platten in die Außenwand der Grabhäuser eingelassen oder an die den Tumulus umgebende Mauer angebunden gewesen sein könnten. ${ }^{278}$ Bei der Platte mit Grabinschrift des Philos (Kat. 1.11) ist nach Jeffery nicht einmal klar, ob es sich bei der dünnen Zurichtung als Platte von $6 \mathrm{~cm}$ Dicke um den originalen Zustand handelt. Bei einer weiteren Platte (Kat. 1.19) ist die dünne Zurichtung von $10 \mathrm{~cm}$ Dicke als originale Fassung durch die auf beiden Seiten angebrachten Inschriften gesichert - der ursprüngliche Kontext bleibt jedoch fraglich.

274 Vgl. zu den Typen der Grabmonumente auf den Lekythen: Oakley 2007, 191-203.

275 Diesen Hinweis verdanke ich N. Dietrich.

276 Vgl. etwa: wgr. Lekythos, Genf, Musée d'Art et d'Histoire Inv. HR 299: Oakley 2007, Abb. 66; wgr. Lekythos, Athen, Nationalmuseum Inv. 17294: Oakley 2007, Abb. 88; wgr. Lekythos, Athen, Nationalmuseum Inv. 1958: Oakley 2007, Abb.111; wgr. Lekythos, Madrid, Museo Arqueológico Nacional Inv. 19497: Kurtz 1975, 202 Taf. 19,1. Inschriften auf den Grabmälern der weißgrundigen Lekythen sind selten, da sie das Bild in gewisser Weise personalisieren.

277 Jeffery 1962, $140 \mathrm{f}$.

278 Jeffery 1962, 140. 


\section{Bild und Inschrift - Bild und Text: Schlussbemerkungen}

Die Gestaltung und Position der Inschriften an Grabdenkmälern verraten folglich einen engen Zusammenhang zur gebauten, steinernen Qualität des Grabmals - mithin seiner Monumentalität, die sich durch die umfassenden Architekturanleihen (geschichtete Steinlagen, Verwendung von Basis - Säule/Pfeiler - Kapitell, Steinfarbigkeit) auszeichnet und damit auch durch eine besondere Größe, Form und Dauerhaftigkeit charakterisiert ist. Diese bedeutungsvolle Bezugnahme der Inschrift am archaischen Monument ergibt sich in erster Linie über die auf eine visuelle Wahrnehmung zielenden Strategien, findet sich jedoch auch zum Teil in den Textinhalten bestätigt, wenn diese etwa die Errichtung des Grabmals, seine physische Präsenz oder seine Qualitäten nennen.

Obwohl aber die Inschriften einen Fokus auf das Erscheinungsbild des gesamten Monumentes unterstützen und den Betrachter auf die spezifischen Qualitäten des Grabmals hinweisen, lassen sich vergleichbare - in erster Linie formale - Strategien nicht für einen Zusammenhang zwischen der Inschrift und dem figürlichen Bild des Grabmals feststellen. Gibt es aber tatsächlich keinerlei Bezüge zwischen den beiden Elementen Figur und Text? Kommt es nicht trotzdem zu einer wechselseitigen Abhängigkeit, da Figur und Inschrift gleichzeitig wahrnehmbar waren? Ergibt sich also durch das Lesen des Textes eine Auswirkung auf das Betrachten und Verständnis des Bildes oder bestimmt das Betrachten des Bildes den nachfolgenden Lesakt? Wäre eine solche Wechselwirkung überhaupt intendiert oder ist sie alleine als Option während des Rezeptionsvorganges denkbar? ${ }^{279}$

Peter Wagner prägte mit dem Begriff Ikonotext einen Begriff für „the use of (by way of reference or allusion, in an explicit or implicit way) an image in a text or vice versa“" ${ }^{280}$ was demnach solche Bild-Text-Kombinationen umfasst, bei denen sich durch die Verbindung beider Medien eine konkrete Bedeutung - auch eine weitere Bedeutungsebene - ergibt, nicht nur, dass das Verständnis eines der Teile von dem des anderen abhängt, ${ }^{281}$ wie dies etwa bei modernen Comics der

279 Zur komplementären Konzeption und zur komplementären Rezeption von Bild und Text als Prämissen bei der Analyse von Bild-Text-Verhältnissen am Grabmonument: Martini 2006, 1; Martini 2008, 269f.

280 Wagner 1996, 15. Dies als erweiterte Definition (vgl. Horstkotte/Leonhard 2006, 8), in der engeren Definition meine Ikonotext ein Artefakt ,in which the verbal and the visual signs mingle to produce rhetoric that depends on the co-presence of words and images.“ (Wagner 1996, 16), vgl. hierzu auch Horstkotte - Leonhard 2006, 8. Zum Problem der logozentrischen Herangehensweise an Ikonotexte vgl. Gerleigner 2015, 210.

281 Vgl. etwa in dem Vorlagepapier zur Tagung IkonoTexte - Duale Mediensituationen (Gießen 2006), die dies versuchte, vom Blickpunkt der Altertumswissenschaften in den Blick zu nehmen und in dem unter dem Begriff Ikonotext nach der Definition durch Peter Wagner Folgendes untersucht wird: „das wechselseitige unabdingbare Abhängigkeitsverhältnis, in dem die beiden Medien zueinander stehen: Das einzelne Medium kann nur vermittels seines Zusammenspiels mit dem anderen sinnvoll verstan- 
Fall ist. ${ }^{282}$ In letzteren Fällen ist vorauszusetzen, dass Bild und Text als konkret zusammengehörige Bestandteile konzipiert wurden und dadurch auf eine ebensolche Rezeption zielten.

In unseren Fällen sind Figur und Inschrift zwar Bestandteile desselben Grabmales und damit für den Rezipienten auch durchaus zusammen wahrnehmbar, aber eine komplementäre Konzeption wie im Falle der modernen Comics lässt sich nicht erschließen. Die formale Gestaltung kann hierfür ein Indikator sein. Wie zuvor dargelegt wurde, wird die Strategie der formalen Bezugnahme zwischen Inschrift und Bild nicht genutzt. Eine andere Möglichkeit - die Verwendung deiktischer Ausdrücke - lässt sich ebenfalls nicht eindeutig für ein komplementäres Konzeptionsverhältnis von Text-Figur auswerten. Es gibt zwar mit der häufigen Ansprache $\tau o ́ \delta \varepsilon ~ \sigma \tilde{\eta} \mu \alpha$ (dies [ist] das / dieses Grabmal) - Demonstrativpronomina, diese weisen aber auf das ganze Grabmal und nicht nur auf die dargestellte Figur hin. ${ }^{283}$

Durch die gemeinsame Anbringung am gleichen Grabmal sind Bild und Text natürlich zunächst einmal miteinander auch verbunden. Dies kann sich auf die einfache Feststellung beschränken, dass nun die gezeigte Figur mit der Person, deren Name in der Inschrift genannt wird, in Beziehung zu setzen ist, wie etwa bei dem Grabmal des Aristodikos. ${ }^{284}$ In einigen wenigen Fällen kann es weiterhin gelingen, die Text-BildVerbindung zu rekonstruieren, die nach dem Betrachten des Bildes und dem Lesen der Inschrift auftreten konnte. Hierfür liegt mit dem Xenokles-Grabmal ein Beispiel vor (Abb. 3.6): 285

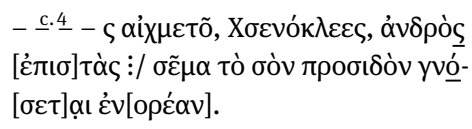

Wer an dein Grabmal, Xenokles, herantritt und es anschaut, wird die Mannhaftigkeit des Lanzenkämpfers erkennen.

(Übs. Ute Ecker)

Das Epigramm schildert in Ansprache an den Verstorbenen das aus dem Ansehen des Grabmals resultierende Wissen, das der Betrachter gewinnen wird: Der Text fordert

den und erschlossen werden." https://www.uni-giessen.de/fbz/fb04/institute/altertum/philologie/ dokumentationen/ikonotexte-duale-mediensituationen (Stand: 18.09.2019). Vgl. zu Text und Bild im Rahmen der griechischen Epigramme: Petrovic 2005.

282 Vgl. zum Problem der modernen Sichtweise (Stichwort Comic) auch kurz Gerleigner 2006, $10 \mathrm{f}$. zu Vasenbildern. Bei Comics, Graphic Novels oder Emblemen sind Bild und Text als ko-präsente Elemente in engem Zusammenhang miteinander konzipiert, sind aber klar voneinander abzugrenzen: vgl. hierzu u. a. Rippl 2014, 148.

283 Anders offenbar Petrovic 2005, 33.

284 Athen, Nationalmuseum Inv. 3938, um 500 v. Chr.: Kissas 2000, 68f. A 39 Abb. 46, 47; IG I³ 1244. 285 IG I3 1200; CEG I 19. Zum Epigramm und zur Übs.: Ecker 1990, 155-161; vgl. auch Robertson 2003. Zur Basis Athen, Kerameikos-Museum I 425: Kissas 2000, 39f. A 4 Abb. 7, 8. 


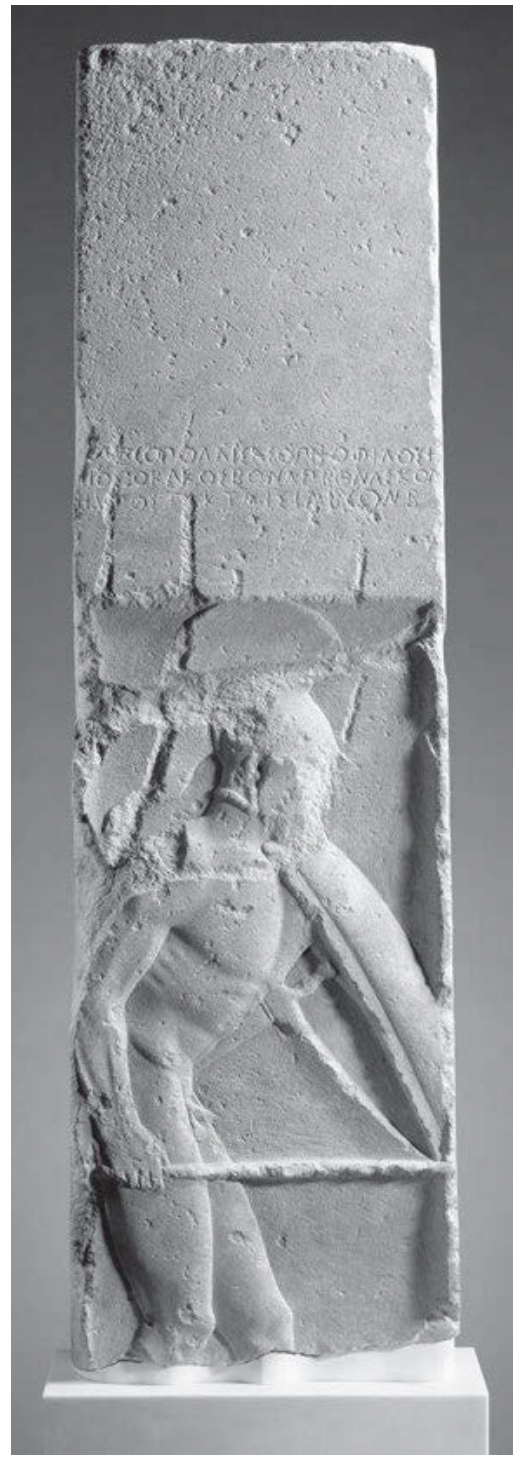

Abb.1.24: Grabstele des Pollis aus Megara, um $480 / 470$ v. Chr., The J. Paul Getty Museum, Los Angeles Inv. 90.AA.129.

den Leser explizit auf, die Mannhaftigkeit des Lanzenkämpfers zu sehen. ${ }^{286}$ Damit wird einerseits eine eigene Visualisierung erzeugt und andererseits diese aber auf das Grabmal bezogen. Mit Kenntnis der archaischen Grabmonumente könnte man etwa ein Bild vor Augen haben, wie auf einer Grabstele ein Krieger dargestellt ist - ähnlich wie auf der Grabstele des Pollis aus Megara (Abb.1.24). ${ }^{287}$

286 Vgl. zum Rezeptionsvorgang und zur Charakterisierung des Toten in diesem Epigramm: Ecker 1990, bes. 158-161.

287 Siehe Anm. 107. 
So vermeintlich schlüssig war dieses Grabmonument jedoch nicht, denn es handelte sich um die Basis eines Kouros, wie die Einlassung in der Oberseite nachweist. ${ }^{288}$ Hierauf ist vor dem Hintergrund anderer Grabstatuen ein Kouros ohne ikonographische Kennzeichnung als Krieger zu rekonstruieren. Der Text erzeugt demnach beim Betrachter einen Eindruck, den das Bild des Kouros zumindest ikonographisch nicht herstellt. ${ }^{289}$ Ikonographische Kennzeichnung mag aber nicht der einzige Weg einer Verbindung gewesen sein: Robertson hat darauf hingewiesen, dass das Epigramm Ähnlichkeiten zur poetischen Visualisierung von andreia zeige, die kleos mit der physischen Gestalt des Körpers verbindet. ${ }^{290}$ Die Präsenz eines derartigen Körpers am Grabmal kann daher als Referenzpunkt dauerhaftes kleos des Verstorbenen gewährleisten, wie er durch das Epigramm evoziert wird. Ein solcher Bezug zwischen dem dargestellten Körper und dem Totenlob, wie es hier explizit durch den Verweis im Text erscheint, ist jedoch die Ausnahme. ${ }^{291}$ Man kann hier aber auch etwas weiter gefasst an das Epigramm des Kroisos denken und dessen Inhalt mit Verweis auf die kriegerische Tapferkeit in dem kraftvoll dargestellten Körper des Kouros erkennen (Abb. 1.25). ${ }^{292}$ Hier wird jedoch auf einen Hinweis, dies zu vernetzen, (ob formal oder im Text der Inschrift) verzichtet - der Betrachter könnte aber natürlich beides in Verbindung bringen. ${ }^{293}$

Beide Medien haben zunächst unabhängig voneinander für die Person, der das Grabmal gewidmet ist, Bedeutung - nach ihren jeweiligen Eigenschaften und Möglichkeiten. Ein Bild am Grabmal kommuniziert so dem Betrachter nicht in erster Linie

288 Kissas 2000, 39f. A 4 Abb. 8.

289 Vgl. Robertson 2003, 64; Ecker ging am Kouros von passenden Attributen für einen Lanzenträger aus (Ecker 1990, 161); hierfür gibt es jedoch keine Hinweise. Zu Koren und Kouroi als Extremfälle fehlender ikonographischer Kennzeichnung der Identität des Dargestellten siehe Dietrich 2018a, 203-226.

290 Hierzu und zum Folgenden Robertson 2003.

291 Es wird im Rahmen der in den Inschriften genannten Tugenden der verstorbenen Person üblicherweise kein Bezug zwischen dem gezeigten Körper und den Tugenden hergestellt, vgl. Robertson 2003, 73.

292 Zur Statue Athen, Nationalmuseum Inv. 3851, um 530 v. Chr.: Pavlina Karanastasis, in: Despinis/ Kaltsas 2014, 202-207 I.1.185 Abb. 650-657 (mit Lit.). Zur Basis: Athen, Nationalmuseum Inv. 4754 und $3851 \alpha, \beta$, y: Pavlina Karanastasis, in: Despinis/ Kaltsas 2014, 207-211 I.1.185a Abb. 658-663 (mit Lit.);

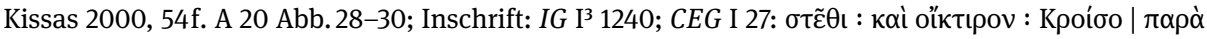

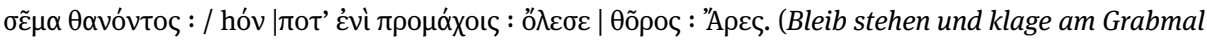
des toten Kroisos, den einst unter den Vorkämpfern vernichtete der stürmische Ares.). Basis und Statue werden in der Forschung eng verbunden, auch wenn letztlich keine absolute Sicherheit über die Zusammengehörigkeit besteht, da die Statue illegal ausgegraben wurde und ohne die Basis in den Kunsthandel kam; siehe hierzu Neer 2010, 24-27; Pavlina Karanastasis, in: Despinis/ Kaltsas 2014, $209 f$.

293 Lorenz legte dar, dass der Betrachter/Leser eine entscheidende Rolle für die mögliche komplementäre Rezeption und damit das Entstehen eines Ikonotextes am archaischen Denkmal spielte: Lorenz 2010, bes. 146. 


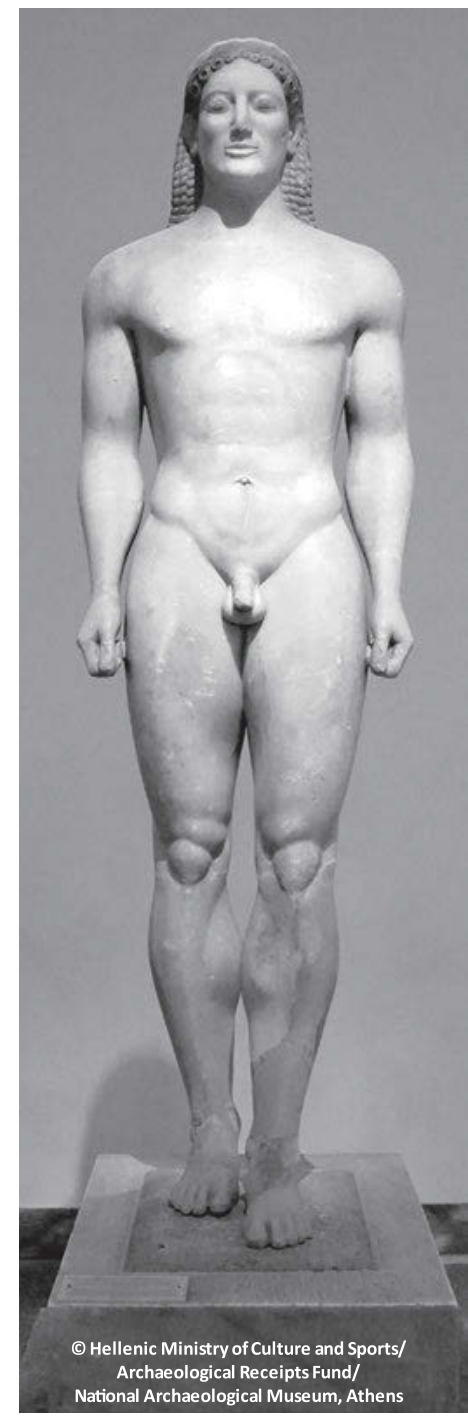

Abb.1.25: Kroisos von Anavyssos um 530 v. Chr. (Athen, Nationalmuseum 3851).

die spezifischen Eigenschaften des Verstorbenen, ${ }^{294}$ sondern es ermöglicht etwa die Präsenz des Verstorbenen in der Welt der Lebenden, ohne sein wirklichkeitsgetreues Abbild zu sein. ${ }^{295}$ Wenn für die Darstellung bestimmte ikonographische Marker oder Typen verwendet werden, die im Kontext aristokratischer Werte verständlich sind,

294 Vgl. zum Problem der Zeichentheorien im Kontext von Bild-Text-Zusammenhängen: Horstkotte/ Leonhard 2006, 7.

295 Zur Präsenz durch das Bild vgl. Vernant 1985, 349-351; Sourvinou-Inwood 1995, 141. Vgl. auch: Hölscher/von Möllendorf 2008, 328f. Zu möglichen Unterschieden zwischen Grabstelen und Statuen: Schmaltz 1983, 160. 
trifft dies also nicht zwingend eine Aussage über das Leben des Verstorbenen. ${ }^{296}$ Dagegen bezieht sich der Text bisweilen direkt auf dessen Leben, wenn etwa sein Tod im Kampf angesprochen wird. ${ }^{297}$

Da beide Elemente des archaischen Grabmals auch unabhängig voneinander verwendet werden, wie etwa die figurlose Stele des Antiphanes (Kat. 1.3) oder die Inschriften allein mit der Nennung „sêma des N. N.“ belegen, ist nicht für jedes Grabmal vorauszusetzen, dass der Text das Bild am Grabmal erklären, präzisieren oder bestätigen muss. ${ }^{298}$ Für die Frage danach, wie der Betrachter aus den beiden am Grabmal präsenten Elementen Bild und Text einen Ikonotext entstehen lassen kann, ist demnach jeder Einzelfall neu zu untersuchen, was jedoch durch die meist einzelne Erhaltung der Inschriften und der Statuen/Stelen nicht umfassend möglich ist.

Zurück zur eingangs gestellten Frage und zur Frage nach der Materialität der Inschriften und ihrer Bedeutung: Es stellte sich heraus, dass die formale Gestaltung und Präsentation der Inschriften am archaischen Grabmonument nicht dazu genutzt wurden, um eine weitere Bedeutungsebene im Zusammenspiel von Bild und Text zu erzeugen. Obwohl man im archaischen Attika das visuelle Potenzial des Geschriebenen an anderen Objekten und in anderen Bildmedien durchaus als Strategie in Bild-Text-Zusammenhängen einsetzte, verzichtete man im Bereich der Grabmäler weitgehend auf diese Option: Man konzentrierte sich vielmehr darauf, über die Position, Orientierung und Gestaltung der Inschriften den Betrachterblick auf die Monumentalität des Grabmales zu lenken. Einerseits sollte dies den vielfältigen Reichtum des Grabmals zeigen, andererseits aber auch die dauerhafte Präsenz des sêma und darüber die Erinnerung an den Verstorbenen gewährleisten.

$296 \mathrm{Zu}$ den überlieferten Typen: Sourvinou-Inwood 1995, 222f. Dietrich wies in einem Vortrag zum Thema „Das Bild des Verstorbenen in den antiken Kulturen des Mittelmeerraums“ (gehalten am 16.06.2016 an der Universität Heidelberg, Institut für Klassische Archäologie) auf den Bezug dieser Bilder auf die Gegenwart des Betrachters hin.

297 Etwa Grabmal des Tetichos, Athen, Epigraphisches Museum Inv. 10650, ca. Mitte 6. Jh. v. Chr.:

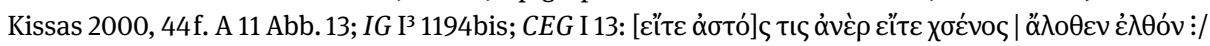

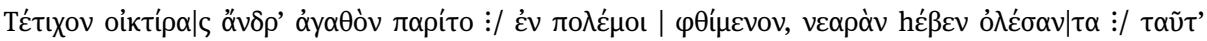

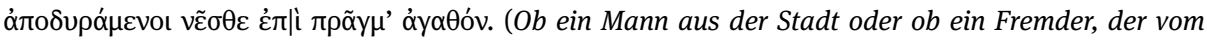
Meere kommet: er soll Tetichos, den guten Mann, beklagen und weiterziehen. Im Kriege gefallen, verlor er die strahlende Jugend. Dies beklagend, gehe weiter, zu guten Taten voran.).

298 Clairmont nahm einen solchen Zusammenhang zwischen Text und Bild bei dem Grabmal einer weiblichen Verstorbenen an, das Phaidimos fertigte (siehe Anm.160): Die Erwähnung, dass das sêma schön anzusehen sei, hätte beim Betrachter eine Verbindung zwischen der Schönheit der Statue und der Schönheit der Person im Leben hergestellt: Clairmont 1970, 16. 


\section{Anhang: \\ Archaische attische Grabstelen/Grabplatten mit Inschriften}

Anmerkung: Die hier im Beitrag zugrunde gelegten Basen attischer archaischer Grabmonumente sind durch Konstantinos Kissas (Kissas 2000, A1-A48; C1-C20) vorgelegt, der auch Verweise für weitere Literatur bietet. Die archaischen Grabstelen aus Attika sind vor Längerem zum Teil durch Gisela Richter (Richter 1961) und Lilian Jeffery (Jeffery 1962) vorgestellt worden. Seitdem sind jedoch einige Stücke hinzugekommen. Der folgende kurze Anhang stellt daher ergänzend zu den Basen mit knappen Angaben die mir bekannt gewordenen Grabstelen/Grabplatten mit Inschriften zusammen; auf sie wird im Text mit der Angabe „Kat.“ verwiesen. ${ }^{299}$

\section{Athen, Agora-Museum}

[1.1] Grabstele des -on (Abb.1.4, 1.18b)

Athen, Agora Museum Inv. I.2056. FO: Athen, Agora.

Inschrift auf dem Stelenschaft:

--]ovos

„[Grabmal] des -on.“

vor 520 v. Chr. (?)

Ed.: IG $I^{3} 1246$.

Lit.: Richter 1961, 44 Nr. 60B; 169 Nr. 60B (M. Guarducci) Abb. 150, 209; Jeffery 1962, 135 Nr. 38

Taf. 38 b; Harrison 1956, 27, $37 \mathrm{f}$.

\section{Athen, Nationalmuseum}

[1.2] Grabstele des Aristion (Abb.1.6a-b; 1.16)

Athen, Nationalmuseum Inv. 29. FO: Velanideza.

Inschrift auf der Basis:

Apıotíovos

„(Grabmal) des Aristion“

Inschrift auf der Leiste unter der Figur:

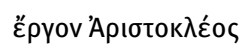

„Werk des Aristokles“

um 520/510 v. Chr.

Edd.: IG I3 1256; DNO I 374.

299 Bei der bei Jeffery genannten Platte aus Anavyssos (Jeffery 1962, 143 Nr. 55 Taf. 39d) handelt es sich wohl um eine Weihinschrift - vgl. hierzu die Rekonstruktion in: IG I3 972. Unklar ist der ursprüngliche Kontext einer Liste von Namen auf einer Stele (?) in Athen (Athen, Epigraphisches Museum Inv. 420: $I G \mathrm{I}^{3}$ 1033). Jeffery vermutete ein Grabmal einer Familie oder ein Polyandrion: Jeffery 1962, 128 Nr. 20 Taf. 36b. Ein früher Grabstein, vielleicht noch aus dem 7. Jh. v. Chr., ist zudem aus Vari erhalten

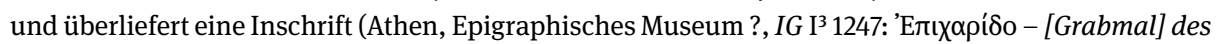
Epicharides; vgl. Jeffery 1962, 135f. Nr. 39 mit Abb.12). 
Lit.: Richter 1961, 47 Nr. 67; 170 Nr. 67 (M. Guarducci) Abb. 155-158, 180, 211, 212; Jeffery 1962, 141 f. Nr. 52; Kissas 2000, 256 C17 Abb. 342; Maria Salta, in: Despinēs/ Kaltsas 2014, 406-412 Kat. I.1.371 Abb. 1226 (mit ausführlicher Literaturliste).

[1.3] Grabstele des Antiphanes (Abb. 1.5)

Athen, Nationalmuseum Inv. 86. FO: Athen.

Inschrift horizontal auf der Stele in mittlerer Höhe:

'Avtıpávos

„(Grabmal) des Antiphanes“.

um 520 v. Chr.

Ed.: $I G I^{3} 1230$.

Literatur: Conze 1893, 10f. Nr. 22 Taf. XIII; Richter 1961, 40. Nr. 54; 168f. Nr. 54 (M. Guarducci) Abb.137, 208; Jeffery 1962, 131f. Nr. 29; Maria Salta, in: Despinēs/ Kaltsas 2014, 488-490 Kat. I.1.407 Abb. 1313 (mit ausführlicher Literaturliste).

\section{Athen, Kerameikos Museum}

[1.4] Grabstele des Semiades

Athen, Kerameikos Museum Inv. I 461. FO: Ostturm des Dipylon in Athen.

Inschrift auf dem Stelenschaft:

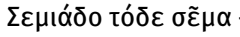

„Dies ist das Grabmal des Semiades.“

frühes bzw. früheres 6. Jh. v. Chr.

Ed.: IG I $\left.\right|^{3} 1203$ bis.

Lit.: Willemsen 1970, 27f. Abb.1 Taf. 10.

[1.5] Grabstele eines Unbekannten

Athen, Kerameikos Museum Inv. P 1046. FO: Athen.

Inschrift auf der Leiste unter der Figur:

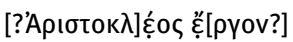

„Ein Werk des Aristokles“(?)

letztes Viertel 6. Jh. v. Chr.

Ed.: IG I $\left.\right|^{3} 1218$ bis.

Lit.: Willemsen 1970, 35f. Taf.16,1.

[1.6] Grabstele einer Unbekannten

Athen, Kerameikos Museum Inv. P 1265 + P 1656. FO: Ostturm des Dipylon in Athen.

Inschrift:

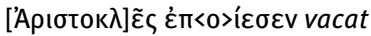

„Aristokles hat (das Grabmal) gefertigt.“

letztes Viertel 6. Jh. v. Chr.

Ed.: IG I $I^{3} 1229$ bis.

Lit.: Willemsen 1970, 36-38 Taf. 15,2; von Freytag gen. Löringhoff 1995, 644f. Abb. 28. 


\section{Athen, Epigraphisches Museum}

[1.7] Grabstele des (Eu)xenos

Athen, Epigraphisches Museum Inv. 416. FO: Athen.

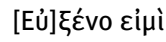

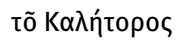

tõ Tnú́o.

„Ich bin [das Grabmal] des Euxenos, Sohn des Kaletor, aus Teos.“

spätes 6. Jh. v. Chr.

Ed.: IG I $^{3} 1372$.

Lit.: Richter 1961, 51 Nr. 78; 171 Nr. 78 (M. Guarducci) Abb. 214; Jeffery 1962, 128f. Nr. 21 Taf. 36 d.

\section{[1.8] (Attische?) Grabstele eines/einer Unbekannten}

Athen, Epigraphisches Museum Inv. 6237b, c, 6238. FO: unbekannt (aus der Sammlung der archäologischen Gesellschaft).

Nur wenige Buchstaben erhalten.

erste Hälfte 6. Jh. v. Chr.

Lit.: Richter 1961, 12 Nr. 6; 155 Nr. 6 (M. Guarducci) Abb. 21, 22, 196-198.

\section{[1.9] Grabstele/Platte des X-}

Athen, Epigraphisches Museum Inv. 6731. FO: Velanideza.

Inschrift auf der Stele/Platte (Ausrichtung unklar):

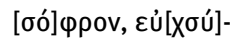

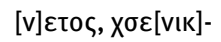

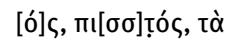

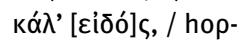

[á́o $\theta$ avó́t]o $\mu$ o-

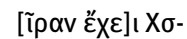

6vel minus vacat

„Verständig, leicht begreifend, gastfrei, zuverlässig, das Gute wissend, so hat das Los eines frühen Todes erhalten X-."

Ende 6.Jh. v. Chr. (?)

Edd.: IG I2 1026b; IG I 1258 ; CEG I 67.

Lit.: Peek 1942, 82 f. Taf. 6 unten; Jeffery 1962, 141 Nr. 51 Taf. 39c.

[1.10] Grabstele/Platte des Phil(ode)m(os) und (An)them(ion)

Athen, Epigraphisches Museum Inv. 6732. FO: Velanideza.

Inschrift auf der Stele/Platte (Ausrichtung unklar):

$\sigma \tilde{\varepsilon} \mu \alpha$ tód’ '́vүù-

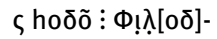

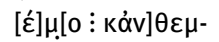

[íovos : ] / hòs $\theta \alpha$ -

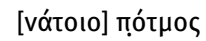

$[\ldots ? . .$.$] เКı$

-- c..7-- o५.

„Dieses Grabmal nahe am Weg ist für Philodemos und Anthemion, die des Todes Schicksal --...“ um 550 v. Chr.

Edd.: IG I2 1026a; IG I3 1255; CEG I 39.

Lit.: Peek 1942, 82 f. Taf. 6 oben; Jeffery 1962, 140 f. Nr. 50 Taf. 39b. 
[1.11] Grabstele/Platte des (Phil)os

Athen, Epigraphisches Museum Inv. 10253. FO: Athen - bei der Ausschachtung der Fundamente für die Metropolis-Kirche gefunden.

Inschrift:

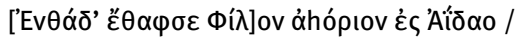

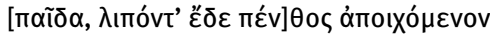

„Hier begrub er Philos, seinen Sohn, der bereits vorzeitig in den Hades ging und Trauer

hinterließ." (Übs. S. Wendl)

um 500 v. Chr.

Edd.: IG I² 980; IG I3 1235; SEG 10, 432a; SEG 15, 58; SEG 21, 186; CEG I 75.

Lit.: Jeffery 1962, 130 Nr. 25 Taf. 37a.

\section{Brauron, Archäologisches Museum}

[1.12] Grabstele des Archias und seiner Schwester (Abb.1.11)

Brauron, Archäologisches Museum Inv. BE 838; ehemals Liopesi Schulhaus. FO: Kalyvia. Inschrift horizontal im unteren Bereich der Stele:

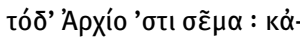

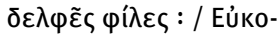

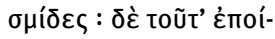

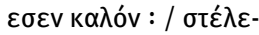

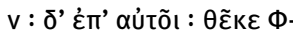

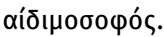

„Dies ist das Grab des Archias und seiner lieben Schwester. Eukosmides aber hat dieses

schöne (Grab) gemacht. Die Stele darauf jedoch hat Phaidimos gesetzt, der kunstfertige.“

um 540 v. Chr.

Edd.: IG I3 1265; CEG I 26; DNO I 360.

Lit.: Peek 1942, $85-87$ Nr. 140 Taf. 3, 2; Jeffery 1962, 139 f. Nr. 48 Taf. 38c; Richter 1961, 25 Nr. 35;

157f. Nr. 35 (M. Guarducci) Abb. 202; Ecker 1990, 144-149; Löschhorn 2007, 272-274 Anm. 16.

[1.13] Grabstele des -kleides

Brauron, Archäologisches Museum Inv. BE 126. FO: Attika, Demos Myrrhinus.

Inschrift vertikal auf dem Stelenschaft:

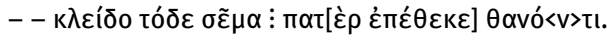

„Dies ist das Grabmal des -kleides; der Vater hat es dem Toten errichtet.“

um 500 v. Chr. (?)

Edd.: IG I 1263.

Lit. (ohne Abbildungen): Willemsen 1970, 28; Schmaltz 1979, 36 Anm. 96; Schmaltz 1983, 159. 


\section{New York, Metropolitan Museum of Art}

[1.14] Grabstele des -linos

New York, Metropolitan Museum of Art Inv. 24.97.87, Fletcher Fund, 1924. FO: angeblich Attika. Inschrift auf dem Kapitell:

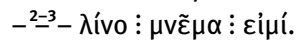

„Das Denkmal des -linos bin ich.“

um 580 v. Chr.

Edd.: IG $\left.\right|^{3} 1274$.

Lit.: Richter 1961, 10 Nr.1; 155 Nr.1 (M. Guarducci) Abb.1-7, 191; Lazzarini - Marconi 2014, 125 f.

Abb. 25.

[1.15] Grabstele des Kalliades (Abb.1.7)

New York, Metropolitan Museum of Art Inv. 55.11.4. FO: Spata.

Inschrift im Predellabereich:

K $\alpha \lambda \lambda \lambda_{\prime} \delta \varepsilon \varepsilon \varsigma$

Өoтıนі́סо

huiós.

„Kalliades, Thoutimides' Sohn.“

drittes Viertel 6.Jh. v. Chr.

Edd.: IG $I^{3} 1252$.

Lit.: Bothmer 1958, 187f. mit Abb.; Jeffery 1962, 136f. Nr. 43; Lazzarini - Marconi 2014, 119 Abb. 5; 138-139 (Appendix).

\section{[1.16] Grabstele eines Unbekannten}

New York, Metropolitan Museum of Art, Gift of Norbert Schimmel Trust Inv. 1989.281.83. FO:

unbekannt.

Inschrift auf der Leiste unter der Figur:

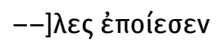

„-les hat es gemacht“

520-510 v. Chr.

Edd.: Thomas 1988 mit Abb.; SEG 42, 45.

Lit.: Thomas 1988 mit Abb.; Viviers 1992, 143f.; Lazzarini - Marconi 2014, 127f. Abb. 28.

\section{Aufbewahrungsort unbekannt:}

[1.17] Grabstele des Leokles

Verschollen. FO: Aus der Region Thorikos-Kypriano (?).

$\Lambda \varepsilon \circ \kappa \lambda \tilde{\varepsilon} \varsigma$

„Leokles“

Ende 6.Jh. v. Chr.(?)

Ed.: $I G I^{3} 1272$.

Lit.: Peek 1942, 87 f. Nr. 141 mit Abb.; Jeffery 1962, 146 Nr. 61. 
[1.18] Grabstele des Pediarchos

Ehemals Liopesi, Schule (?). FO: Paiania.

Unklare Ausrichtung der Inschrift:

$\varepsilon$ घứtov.

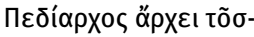

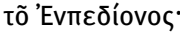

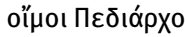

„Grabmalen. Pediarchos gebietet den Sohn des Enpedion. Weh über Pediarchos.“

um 530/520 v. Chr.

Ed.: IG I3 1267.

Lit.: Peek 1942, 88f. Nr.142 Taf. 2; Jeffery 1962, 136 Nr. 42 mit Abb. 13.

[1.19] Grabstele/Platte des Aristomachos

Aufbewahrungsort unbekannt. FO: Athen.

Inschrift auf einer Seite:

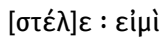

[Өavó]vтos

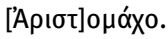

„Ich bin die Stele des toten Aristomachos.“

Inschrift auf der anderen Seite:

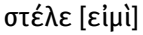

Ө̣avóṿ[toc]

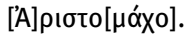

„Ich bin die Stele des toten Aristomachos.“

zweite Hälfte 6. Jh. v. Chr. (?)

Ed.: IG $\left.\right|^{3} 1221$.

Lit.: Wolters 1890 (mit Zeichnung); Jeffery 1962, 132 Nr. 32. 